Empregando técnicas de projeção multidimensional para transformação interativa de espaços de características

Gladys Marleny Hilasaca Mamani 

SERVIÇO DE PÓS-GRADUAÇÃO DO ICMC-USP

Data de Depósito:

Assinatura:

\title{
Empregando técnicas de projeção multidimensional para transformação interativa de espaços de características
}

\author{
Gladys Marleny Hilasaca Mamani
}

Orientador: Prof. Dr. Fernando Vieira Paulovich

Dissertação apresentada ao Instituto de Ciências Matemáticas e de Computação - ICMC-USP, como parte dos requisitos para obtenção do título de Mestre em Ciências - Ciências de Computação e Matemática Computacional. VERSÃO REVISADA 
Ficha catalográfica elaborada pela Biblioteca Prof. Achille Bassi e Seção Técnica de Informática, ICMC/USP, com os dados fornecidos pelo(a) autor(a)

\begin{tabular}{|c|c|}
\hline H641e & $\begin{array}{l}\text { Hilasaca-Mamani, Gladys } \\
\text { Empregando técnicas de projeção multidimensional } \\
\text { para transformação interativa de espaços de } \\
\text { características / Gladys Hilasaca-Mamani; orientador } \\
\text { Fernando Vieira Paulovich. -- São Carlos, } 2012 \text {. } \\
\quad 63 \text { p. }\end{array}$ \\
\hline & $\begin{array}{l}\text { Dissertação (Mestrado - Programa de Pós-Graduação en } \\
\text { Ciências de Computação e Matemática Computacional) -- } \\
\text { Instituto de Ciências Matemáticas e de Computação, } \\
\text { Universidade de São Paulo, 2012. }\end{array}$ \\
\hline & $\begin{array}{l}\text { 1. Projeções multidimensionais. 2. Transformação } \\
\text { interativa de espaços de caraterísticas. I. Vieira } \\
\text { Paulovich, Fernando, orient. II. Título. }\end{array}$ \\
\hline
\end{tabular}


Aos meus pais, Meliton e Rita. 

A Deus por guiar meus passos a cada etapa da minha vida.

Ao meu orientador, Prof. Dr. Fernando V. Paulovich, por me guiar durante o desenvolvimento deste trabalho e pela paciência com as minhas falhas e dúvidas. Nunca vou esquecer o que você fez por mim. Muito Obrigada!

Aos meus queridos pais, Meliton e Rita, pelas palavras de encorajamento, pelo apoio que me têm dado na vida e por aceitarem minha ausência. Obrigada Meliton pela inspiração e força que me transmitiu.

Aos meus irmãos, Jhon e Janeth, por serem meus amigos e pela alegria que me proporcionaram quando eu voltava para casa.

A todos os amigos que fiz aqui no ICMC. Especialmente a: Edwin, Nils, Pedro, Jorge C., Roni e Eliana pelo companheirismo, cooperação e apoio. Foi muito bom conhecer todos vocês.

A todos os colegas do laboratório do grupo de pesquisa em Visualização, Imagens e Computação Gráfica(VICG).

Ao Conselho Nacional de Desenvolvimento Científico e Tecnológico ( $\mathrm{CNPq}$ ) pelo apoio financeiro. 

A tecnologia atual permite armazenar grandes quantidades de dados, no entanto sua exploração e compreensão resultam em um enorme desafio devido não só ao tamanho dos conjuntos produzidos mas também sua complexidade. Nesse sentido a visualização de informação vem se mostrando um recurso extremamente poderoso para ajudar a interpretar e extrair informação útil desse universo de dados. Dentre as abordagens existentes, as técnicas de projeção multidimensional estão emergindo como um instrumento de visualização importante em aplicações que implicam a análise visual de dados de alta dimensão devido ao poder analítico que essas oferecem na exploração de relações de similaridade e correlação de dados abstratos. Contudo, os resultados obtidos por tais técnicas estão intimamente ligados à qualidade do espaço de características que descrevem os dados sendo processados. Se o espaço for bem formado e refletir as relações de similaridade esperadas por um usuário, os resultados finais serão satisfatórios. Caso contrário pouca utilidade terão as representações visuais geradas. Neste projeto de mestrado técnicas de projeção multidimensional são empregadas, para, não somente explorar conjuntos de dados multidimensionais, mas também para servir como um guia em um processo que visa "moldar" espaços de características. A abordagem proposta se baseia na combinação de projeções de amostras e mapeamentos locais, permitindo ao usuário de forma interativa transformar os atributos dos dados por meio da modificação dessas projeções. Mais especificamente, as novas relações de similaridade criadas pelo usuário na manipulação das projeções das amostras são propagadas para o espaço de característica que descreve os dados, transformando-o em um novo espaço que reflita essas relações, ou seja, o ponto de vista do usuário sobre as semelhanças e diferenças presentes nos dados. Resultados experimentais mostram que a abordagem desenvolvida nesse projeto pode com sucesso transformar espaços de características com base na manipulação da projeção de pequenas amostras, melhorando a coesão e separação de grupos. Com base no ferramental criado, um sistema de recuperação de imagens por conteúdo é sugerido, mostrando que a abordagem desenvolvida pode ser bastante útil nesse tipo de aplicação.

Palavras-chave: Projeções multidimensionais; Transformação interativa de espaços de caraterísticas. 

Although the current technology allows storing large volumes of data, their exploration and understanding remains as challenges not only due to the size of the produced datasets but also their complexity. In this sense, the information visualization has proven to be an extremely powerful instrument to help users to interpret and extract useful information from this universe of data. Among the existing approaches, multidimensional projection techniques are emerging as an important visualization tool in applications involving visual analysis of high dimensional data due to the analytical power that these techniques offer in the exploitation of similarity relations and abstract data correlation. However, the results obtained by these techniques are closely tied to the quality of the feature space which describes the data being processed. If the space is well formed and reflect the similarity relations expected by an user, the final results will be satisfactory. Otherwise, little utility will have the created visual representations. In this master's project, multidimensional projections techniques are employed not only to explore multidimensional data sets, but also to serve as a guide in a process that aims to "mold" features spaces. The proposed approach is based on the combination of projections of samples and local mappings, allowing the user to interactively transform the data attributes by modifying these projections. Specifically, the new similarity relations created by the user in manipulating the projections of the samples are propagated to the feature space that describes the data, transforming it into a new space that reflects these relationships, i.e., the point of view of the user about the similarities and differences in the data. Experimental results show that the approach developed in this project can successfully transform feature spaces based on the manipulation of projections of small samples, improving the cohesion and separation of groups. Based on the created framework, a content-based image retrieval system is suggested, showing that the developed approach can be very useful in this type of application.

Keywords: Multidimensional projection; Interactive transformation of features spaces. 

Abstract vii

Sumário $\quad$ ix

Lista de Figuras $\quad$ xii

Lista de Tabelas $\quad$ xiii

$\begin{array}{ll}\text { Lista de Siglas } & \text { Xv }\end{array}$

1 Introdução 1

1.1 Contextualização . . . . . . . . . . . . . . . . . . . . . . 1

1.2 Motivação e Objetivos . . . . . . . . . . . . . . . . . . . 3

1.3 Organização da Dissertação . . . . . . . . . . . . . . . . . . . . . . 3

2 Trabalhos Relacionados $\quad \mathbf{5}$

2.1 Considerações Iniciais . . . . . . . . . . . . . . . . . . . . . 5

2.2 Técnicas de Projeção de Dados Multidimensionais . . . . . . . . . . . 6

2.2.1 Decomposição Espectral . . . . . . . . . . . . . . . . . . . 7

2.2 .2 Minimização Não-linear . . . . . . . . . . . . . . . . . . . . 8

2.2.3 Modelo Baseado em Força . . . . . . . . . . . . . . . . . . . 8

2.2 .4 Operador Linear . . . . . . . . . . . . . . . . . . . . . 11

2.3 Abordagens para Transformação de Espaços Multidimensionais . . . . . . . . . . 12

2.3.1 Redução de Dimensionalidade Interativa . . . . . . . . . . . . . . . . . . . 12

2.3.2 Deformação do Espaço de Características . . . . . . . . . . . . . . . . . 15

2.4 Considerações Finais . . . . . . . . . . . . . . . . . . . . . 17

3 Empregando Projeções para Transformar Espaços de Características 19

3.1 Considerações Iniciais . . . . . . . . . . . . . . . . . . . . . . . . 19

3.2 Transformação do Espaço de Características . . . . . . . . . . . . . . . . . . 20

3.2.1 Seleção e Projeção das Amostras . . . . . . . . . . . . . . . . . . . . . . 21

3.2 .2 Manipulação do Layout . . . . . . . . . . . . . . . . . . . . . . . 22

3.2 .3 Force Scheme no Espaço de Características . . . . . . . . . . . . . . . . 22

3.2 .4 Transformação Final do Espaço . . . . . . . . . . . . . . . . . . . . . 24

3.3 Considerações Finais . . . . . . . . . . . . . . . . . . 26 
4 Resultados Experimentais $\quad \mathbf{2 7}$

4.1 Considerações Iniciais . . . . . . . . . . . . . . . . . . . 27

4.2 Conjuntos de Dados . . . . . . . . . . . . . . . . . . . 27

4.3 Análise dos Resultados . . . . . . . . . . . . . . . . . . . . . 28

4.3 .1 Análise da Projeção Inversa . . . . . . . . . . . . . . . . . . . . . . . 29

4.3.2 Análise da Transformação do Espaço de Características . . . . . . . . . . 30

4.3.3 Análise da Amostragem . . . . . . . . . . . . . . . . . . . . . . 32

4.4 Considerações Finais . . . . . . . . . . . . . . . . . . . . . 34

5 Aplicações $\quad 41$

5.1 Considerações Iniciais $\ldots \ldots \ldots \ldots \ldots$. . . . . . . . . . . . . . . 41

5.2 Aplicação em Coleções de Imagens . . . . . . . . . . . . . . . . . . . . . . . 42

5.3 Recuperação de Imagens baseada em Conteúdo . . . . . . . . . . . . . . . . . . 46

5.4 Considerações Finais . . . . . . . . . . . . . . . . . . . . . . . . 49

6 Conclusões 53

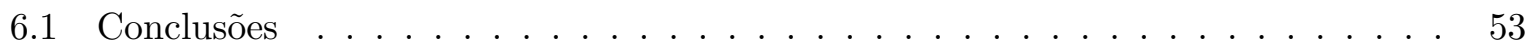

6.2 Limitações . . . . . . . . . . . . . . . . . . . . . . . . . . . . . 54

6.3 Trabalhos Futuros . . . . . . . . . . . . . . . . . . . 54

$\begin{array}{ll}\text { Referências Bibliográficas } & 57\end{array}$ 


\section{Lista de Figuras}

2.1 Exemplo de uma projeção de uma coleção de documentos contendo artigos cien-

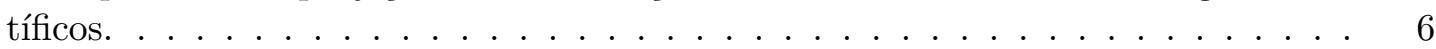

2.2 Interface do framework Rank-by-feature(retirado de (Seo e Shneiderman, 2005)). 13

2.3 Interface do sistema DimStiller (retirado de (Ingram et al., 2010)). . . . . . . . . 14

2.4 Exemplo de redução de dimensionalidade usando diferentes métricas de qualidade (retirado de (Johansson e Johansson, 2009)). . . . . . . . . . . . . . 15

2.5 Interface principal do sistema iPCA (retirado de (Jeong et al., 2009)). . . . . . . 16

2.6 Exemplo do workflow da abordagem proposta por Berger et al. (2011). . . . . . . 17

3.1 Um exemplo de projeção das imagens do conjunto Scene com a técnica Force Scheme. Em (a) os elementos visuais são representados por círculos e em (b) a própria imagem é utilizada como rótulo . . . . . . . . . . . . . .

3.2 O processo de transformação proposto tem quatro passos importantes: seleção e projeção das amostras, manipulação do layout, projeção inversa das amostras, transformação do espaço de características. . . . . . . . . . . . . . . . . 21

3.3 Projeção e manipulação da amostra do conjunto de dados segmentation. . . . . 23

4.1 Resultado da aplicação do IFS e NS-IFS sobre diferentes conjuntos de dados. Primeira coluna: Layout gerado usando-se a técnica Force Scheme para o conjunto de dados. Segunda coluna: manipulação feita pelo usuário no layout original. Terceira Coluna: layout gerado usando a técnica Force Scheme para o conjunto de dados transformado pelo IFS. Quarta Coluna: Layout gerado usando a técnica Force Scheme para o conjunto de dados transformado pelo NS-IFS . . . . . . . .

4.2 Resultado da aplicação do IFS e NS-IFS sobre diferentes conjuntos de dados. Primeira coluna: Layout gerado usando-se a técnica Force Scheme para o conjunto de dados. Segunda coluna: manipulação feita pelo usuário no layout original. Terceira Coluna: layout gerado usando a técnica Force Scheme para o conjunto de dados transformado pelo IFS. Quarta Coluna: Layout gerado usando a técnica Force Scheme para o conjunto de dados transformado pelo NS-IFS . . . . . . . .

4.3 Resultado da aplicação da nossa abordagem sobre diferentes conjunto de dados. Primeira linha: projeção das amostras escolhidas de cada conjunto de dados. Segunda linha: projeção usando $L A M P$ para o conjunto de dados original. Terceira linha: manipulação feita pelo usuário sobre a amostra. Quarta linha: projeção usando $L A M P$ do conjunto de dados transformado. Quinta linha: projeção usando a Classical Scaling para o conjunto de dados transformado. . . . . . . 
4.4 Resultado da aplicação da nossa abordagem sobre diferentes conjunto de dados. Primeira linha: projeção das amostras escolhidas de cada conjunto de dados. Segunda linha: projeção usando LAMP para o conjunto de dados original. Terceira linha: manipulação feita pelo usuário sobre a amostra. Quarta linha: projeção usando LAMP do conjunto de dados transformado. Quinta linha: projeção usando a Classical Scaling para o conjunto de dados transformado. . . . . . .

4.5 Aumentando o número de amostras é permitido ao usuário um melhor controle da transformação. Primeira linha: projeção empregando a LAMP sobre o conjunto de dados transformado. Segunda linha: projeção empregando a Classical Scaling sobre o conjunto de dados transformado. . . . . . . . . . . . . . .

4.6 Análises comparativas das amostragens. Usando-se essa análise é possível definir que a amostragem por agrupamento define melhores resultados, em termos de coeficiente de silhueta, e que conforme a amostra cresce, o resultado também melhora. . . . . . . . . . . . . . . . 40

5.1 Amostras da base de imagens Corel 1000. . . . . . . . . . . . . . . . . 42

5.2 Amostras da base de imagens Caltech. . . . . . . . . . . . . . . . . 42

5.3 Amostras da base de imagens ImageCLEF-2009. . . . . . . . . . . . . . . . 42

5.4 Visão geral do sistema de organização de coleções de imagens sobre a base Corel 100043

5.5 Projeções do conjunto de dados Corel 1000 considerando o espaço de características original e transformado. . . . . . . . . . . . . . . . 45

5.6 Visão geral do sistema de organização de coleções de imagens com a base Caltech 45

5.7 Projeções do conjunto de dados Caltech considerando o espaço de características original e transformado. . . . . . . . . . . . . . . . . . . 47

5.8 Projeções do conjunto de dados ImageCLEF2009 considerando o espaço de características original e transformado. . . . . . . . . . . . . . . . 47

5.9 Curvas de precisão e revocação obtidas para o conjunto de imagens Corel 1000. 49

5.10 Imagens recuperadas do conjunto de dados Corel 1000 . . . . . . . . . . . . 50

5.11 Curvas de precisão e revocação referentes ao conjunto de imagens Caltech. . . . 50

5.12 Imagens recuperadas do conjunto de dados Caltech. . . . . . . . . . . . . . . . . 51

6.1 Resultado da aplicação da abordagem proposta sobre o conjunto de dados Letter

Image Recognition. . . . . . . . . . . . . . . . . . . . . . 54 


\section{Lista de Tabelas}

2.1 Lista das técnicas de projeção multidimensional estudadas, com suas respectivas complexidades, onde $n$ e $k$ representam o número total de instâncias e o número de amostras respectivamente, $c$ é o número de iterações. . . . . . . . . . . . . 18

4.1 Informações sobre os conjunto de dados utilizados nos experimentos desse capítulo. 29

4.2 Dimensionalidade intrínseca, silhueta, stress para conjunto de dados original e transformado. . . . . . . . . . . . . . . . . 30

4.3 Análise quantitativa usando o coeficiente de silhueta dos resultados das transformações dos espaços de características. Foram usadas $\sqrt{n}$ amostras. É possível notar aumento significativo na coesão e separação nas classes dos dados no espaço transformado. . . . . . . . . . . . . . . . . .

4.4 Análise quantitativa usando o coeficiente de silhueta dos resultados das transformações dos espaços de características. Com o aumento do tamanho da amostra $(5 \times \sqrt{n})$, os resultados de coesão e separação também aumentam significativamente. 32

4.5 Acurácias do conjunto de dados original e transformado. . . . . . . . . . . 33

5.1 Matriz de confusão gerada a partir da classificação do conjunto Corel 1000. . . 46

5.2 Matrizes de confusão gerada com a classificação da base Caltech. . . . . . . . . . 48

5.3 Matrizes de confusão geradas com a classificação sobre o conjunto ImageCLEF2009. 49 



\section{Lista de Siglas}

$\begin{array}{ll}\text { FS } & \text { Force Scheme } \\ \text { ISOMAP } & \text { Isometric Feature Mapping } \\ \text { IFS } & \text { Inverse Force Scheme } \\ \text { KDD } & \text { Knowledge discovery in databases } \\ \text { LAMP } & \text { Local Affine Multidimensional Projection } \\ \text { L-ISOMAP } & \text { Landmark ISOMAP } \\ \text { L-MDS } & \text { Landmark Multidimensional Scaling } \\ \text { LSP } & \text { Least Square Projection } \\ \text { MDS } & \text { Multidimensional Scaling } \\ \text { NS-IFS } & \text { Neighbor-Sample Inverse Force Scheme } \\ \text { PCA } & \text { Principal Component Analysis } \\ \text { PLP } & \text { Piecewise Laplacian Projection } \\ \text { PLMP } & \text { Part Linear Multidimensional Projection } \\ \text { RP } & \text { Random Projection } \\ \text { SM } & \text { Sammon's Mapping } \\ \text { SMACOF } & \text { Scaling by Majorizing a Complicated Function }\end{array}$





\subsection{Contextualização}

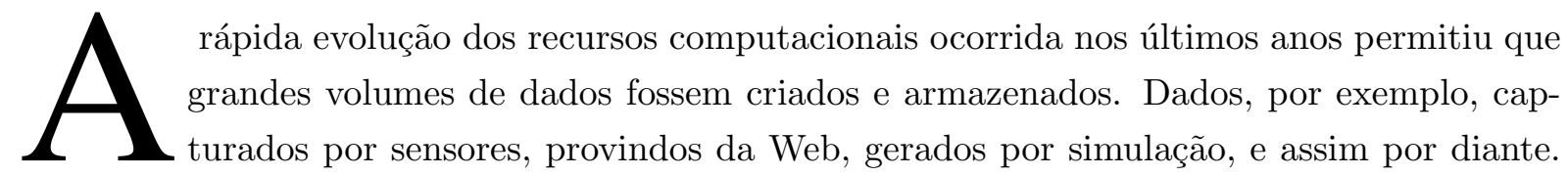
Embora os avanços tecnológicos tenham multiplicado a nossa capacidade de coletar e armazenar dados, extrair conhecimento, identificar informação útil, explorar e compreender grandes quantidades de dados se tornou um enorme desafio. Criar estratégias e ferramentas que apoiem os seres humanos em tarefas de análise e descoberta de informação em dados se tornou então uma grande frente de pesquisa científica.

Dentre as áreas de pesquisa que tentam tratar esse problema, duas são de interesse desse projeto: a Mineração de Dados e a Visualização. A mineração de dados é descrita como a atividade de extração de padrões ou modelos a partir de repositórios de dados, e está normalmente inserida em um processo mais amplo de extração de conhecimento denominado Knowledge Discovery in Databases (KDD) (Fayyad et al., 1996). KDD é um processo não trivial, cujo objetivo é obter informação potencialmente útil, válida e previamente desconhecida de conjuntos de dados.

Por outro lado a visualização refere-se ao processo de mapeamento de dados e informações em um formato gráfico, baseando-se em representações visuais e em mecanismos de interação, fazendo uso de suporte computacional e objetivando a ampliação da cognição (Card et al., 1999). O uso de uma representação visual, tal como um diagrama, facilita a criação de uma imagem mental de estruturas dentro de dados complexos com o propósito de explorar a sofisticada capacidade visual do ser humano para identificar padrões, interpretar e extrair informação útil dos dados. 
A visualização muitas vezes é dividida em Visualização Científica e Visualização de Informação. Nem sempre há uma fronteira clara entre elas uma vez que métodos de ambos os campos podem ser combinados e usados simultaneamente. Comumente os dois campos são separados com base nas propriedades dos dados que são analisados e sobre a forma como os dados são representados.

Visualização científica tende a tratar dados baseados na física e as representações gráficas utilizadas geralmente relacionam-se com as propriedades físicas dos dados (Spence, 2007). Uma aplicação típica de visualização científica, por exemplo, pode ser a utilização de uma representação visual de moléculas, incluindo átomos e ligações químicas, para análise de dados moleculares.

A visualização de informação, por outro lado, geralmente trata dados abstratos. A análise desses dados raramente requer ou se beneficia de uma representação visual do objeto físico real, e portanto, a visualização de informação está mais interessada em conceitos abstratos e representações (Card et al., 1999). A tarefa principal da visualização de informação é representar dados abstratos de uma maneira tal que a informação, quanto a estruturas úteis e interessantes, possa ser derivada a partir dela.

Um conjunto de dados abstratos pode ser definido como uma coleção de instâncias de dados descritas por múltiplos atributos, características ou dimensões. Uma instância pode representar, por exemplo, um paciente em um banco de dados médico, uma cidade em uma coleção de dados de censo, um teste em uma simulação ou uma amostra em um estudo de sequenciação de DNA, etc. Já os atributos descrevem propriedades ou características dessas instâncias. Por exemplo, em um conjunto de dados de censo as dimensões podem representar várias características das cidades, tais como tamanho da população, renda média, porcentagem desempregada e assim por diante. Um conjunto de dados abstrato quando apresenta mais de três dimensões é conhecido como multi-valorado ou multidimensional.

Visualização de informação fornece uma gama de abordagens de visualização para análise de dados multidimensionais. Dentre as existentes, a de interesse desse trabalho é conhecida como Projeção Multidimensional ou Técnica de Posicionamento de Pontos (Paulovich e Minghim, 2008). Essa gera uma representação gráfica das instâncias de dados multidimensionais onde a posição relativa dos elementos na representação criada reflete algum tipo de relacionamento entre as instâncias de dados, tal como similaridade ou vizinhança dada por uma função definida no espaço multidimensional. A visualização preserva as relações existentes entre os dados e deve ser compreensível o suficiente para permitir aos usuários empregar sua habilidade visual para extrair padrões presentes nos dados. As projeções têm como vantagem a possibilidade de representar grandes conjuntos de dados, não sendo dependente da dimensionalidade dos dados sendo processados. Várias abordagens vem sendo adotadas por diferentes técnicas, as quais têm em comum o fato que a representação dos dados no espaço projetado busca preservar relações definidas no espaço original. 


\subsection{Motivação e Objetivos}

Embora o conceito de projeção multidimensional venha recebendo grande atenção devido à sua capacidade intrínseca de construir representações visuais que permitem a usuários interpretar informação sobre relações de similaridade (Paulovich et al., 2010), nem sempre o layout gerado é de boa qualidade segundo o ponto de vista de um usuário, o que dificulta a interpretação dos dados, como a identificação satisfatória de grupos de elementos similares e suas fronteiras. Nesse ponto é que entra a necessidade de se transformar os dados de forma a refletir a opinião do usuário.

De fato, não somente projeções serão de baixa qualidade na presença de espaços de características que não reflitam o ponto de vista de um usuário, mas também tarefas de mineração, como classificação e agrupamento. De forma geral, podemos dizer que se os atributos ou características que representam os dados não refletirem o ponto de vista de um determinado usuário, tarefas de mineração e visualização serão propensas a falhar, ou seja, definir resultados que não são os esperados pelo usuário em termos de relação de similaridade.

O objetivo desse projeto de mestrado foi empregar técnicas de projeção multidimensional não somente para visualizar dados abstratos, mas também para servir como um guia em um processo iterativo e interativo de modificação de dados abstratos de forma a refletir percepções individuais de um usuário. Por meio da manipulação da projeção de uma amostra dos dados, agrupando os elementos similares e separando os diferentes, as relações de similaridade existentes no conjunto de dados original são transformadas, "moldando-o" para que as novas relações criadas pelo usuário na projeção da amostra sejam refletidas no conjunto completo, ou seja para que reflita o ponto de vista desse usuário.

O restante dessa dissertação apresenta detalhes sobre a abordagem definida para se atingir esse objetivo bem como os resultados alcançados e possíveis aplicações. A seguir é apresentado como ela está estruturada.

\subsection{Organização da Dissertação}

Esta dissertação esta organizada da seguinte maneira:

- No Capítulo 2 é apresentada uma revisão bibliográfica sobre técnicas de projeção multidimensional e técnicas de visualização para modificação de dados abstratos;

- No Capítulo 3 a abordagem definida nesse projeto de mestrado para transformação de espaços de características é detalhada;

- No Capítulo 4 uma avaliação qualitativa e quantitativa dos resultados alcançados é apresentada;

- No Capítulo 5 um exemplo de aplicação para recuperação de imagens por conteúdo que emprega a abordagem desenvolvida é apresentado; 
- Por fim, no Capítulo 6 apresenta-se as conclusões desse projeto de mestrado. 


\section{Trabalhos Relacionados}

\subsection{Considerações Iniciais}

esse capítulo as principais técnicas relacionadas a esse projeto de mestrado são apresentadas, com especial foco nas técnicas de visualização de informação para análise de relações de similaridade. Após isso, os principais métodos para transformação e exploração de espaços de características encontrados na literatura corrente são descritos, apontando suas principais características e limitações.

Atualmente existe uma grande quantidade de técnicas para a criação de representações visuais para dados multivariados, Coordenadas paralelas (Inselberg e Dimsdale, 1990; Inselberg, 2009), Matrizes de scatterplots (Andrews, 1972), Table lens (Rao e Card, 1994), RadViz (Hoffman et al., 1999), Técnicas Orientadas a Pixel (Keim et al., 1994, 1996), Técnicas Iconográficas (Chernoff, 1973; Pickett e Grinstein, 1988). Contudo, grande parte dessas apresenta limitações quando grandes conjuntos de dados são analisados devido à confusão visual, assim como dificuldade de navegação e interação. Com o intuito de superar esses problemas, algumas técnicas vem sendo sugeridas, como a Pixel displays (Keim, 2000) que consegue representar grandes conjuntos de dados mapeando cada valor de dados para um pixel colorido. Outro exemplo seria a abordagem apresentada por Yang et al. (2007a). Nessa, cada instância de dados é representada por um glyph em um espaço bidimensional. Os glyphs são posicionados de maneira a expressar relações entre as instâncias; os atributos (dimensões) das instâncias são representados dentro dos glyphs utilizando técnicas orientadas a pixel. As posições dos glyphs são definidas de forma que as instâncias mais similares fiquem próximas no layout final e as diferentes sejam posicionadas de forma afastada. A sua principal limitação é a sobreposição dos glyphs altamente correlacionados, o que torna difícil a identificação de padrões, tais como agrupamentos. 
Em geral, poucas técnicas de visualização são capazes de lidar com grandes conjuntos de dados multidimensionais e refletir relações de similaridade entre as instâncias de dados. Dentre essas, uma que tem despertado grande interesse da comunidade são as técnicas de projeção multidimensional. A seguir essas são detalhadas, apresentando as principais abordagens existentes que são de interesse desse projeto de mestrado.

\subsection{Técnicas de Projeção de Dados Multidimensionais}

Uma técnica de projeção multidimensional busca mapear dados definidos em um espaço $\mathbb{R}^{m}$, geralmente de alta dimensão, para um espaço $\mathbb{R}^{p}$ de menor dimensão com $p \in\{1,2,3\}$, na medida do possível preservando, no espaço projetado, as relações de similaridade ou vizinhança existentes entre as instâncias de dados no espaço original (Tejada et al., 2003a; Paulovich e Minghim, 2008). Assim, uma representação visual pode ser criada, geralmente um conjunto de elementos gráficos em um espaço visual, por exemplo, pontos em um plano. Essa representação gráfica é criada com o intuito de ajudar as pessoas a entender a estrutura do conjunto de dados em termos de agrupamentos ou outras relações de proximidade de interesse. A Figura 2.1 apresenta um exemplo de projeção multidimensional. Nesse exemplo, uma projeção de uma coleção de documentos contendo artigos científicos de 4 diferentes áreas é apresentada. Os círculos representam os artigos científicos e as cores identificam as áreas desses.

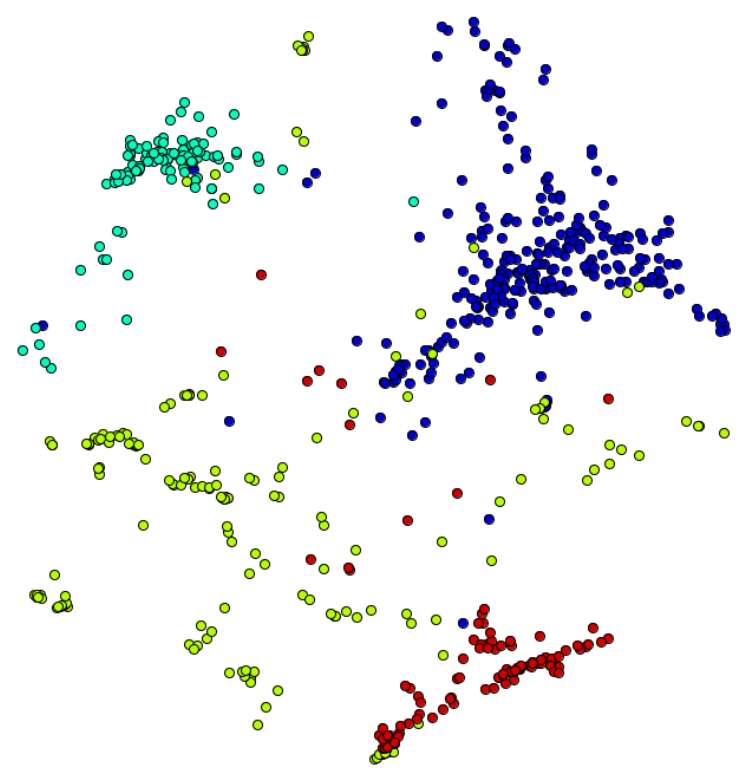

Figura 2.1: Exemplo de uma projeção de uma coleção de documentos contendo artigos científicos.

Projeção multidimensional é um caso especial de uma classe mais ampla de técnicas chamadas Multidimensional Scaling (MDS). Métodos de MDS realizam o mapeamento em um espaço p-dimensional das instâncias multidimensionais contando com a informação de distância entre pares dessas instâncias. Em outras palavras, o objetivo das técnicas MDS é encontrar coordenadas para $N$ pontos em um espaço $p$-dimensional, onde as distâncias $d_{i j}$ do espaço $p$-dimensional 
sejam o mais próximo possível as distâncias $\delta_{i j}$ do espaço $m$-dimensional. Normalmente, os algoritmos MDS trabalham minimizando uma função de perda baseada na diferença dessas distâncias, essa função geralmente é conhecida como stress, e uma de suas formulações mais conhecidas é (Kruskal, 1964):

$$
\frac{\sum_{i j}\left(\delta_{i j}-d_{i j}\right)^{2}}{\sum_{i j} \delta_{i j}^{2}}
$$

Quando o mapeamento é perfeitamente realizado, isto é, quando $d_{i j}=\delta_{i j}$, então o stress é 0 .

Os algoritmos MDS variam na forma como a função de stress é minimizada, ou mesmo na definição dessa função. Eles podem ser: aproximados ou exatos, iterativos ou analíticos. Essa diversidade de algoritmos gera resultados com diferentes precisões e tempos de execução. Com base na literatura corrente, as técnicas de projeção são divididas em quatro grandes grupos (Paulovich et al., 2010, 2011a):

(i) Decomposição espectral: Classical Scaling (MDS), Landmarks MDS (LMDS), Isometric Feature Mapping (ISOMAP), Landmarks ISOMAP (L-ISOMAP), FASTMAP.

(ii) Minimização não linear: Pekalska Approximation, Sammon's Mapping, SMACOF.

(iii) Modelo baseado em força: Spring Model, Chalmers, Modelo híbrido, Force Scheme, LSP, PLP, Glimmer.

(iv) Operador linear: Random Projection, PLMP, PCA, LAMP.

A seguir, discorremos sobre cada um desses grupos, iniciando pelas técnicas baseadas em decomposição espectral.

\subsubsection{Decomposição Espectral}

Dentre as técnicas de decomposição espectral, a mais conhecida é a Classical Scaling (Torgerson, 1965). A Classical Scaling calcula a incorporação de coordenadas cartesianas para cada instância de dados no espaço visual realizando uma decomposição espectral da matriz de dissimilaridade (construída em base na distância euclideana) entre todos os pares de instâncias de dados. Apesar da Classical Scaling atingir um alto grau de precisão na preservação de distâncias, sua complexidade, $\mathrm{O}\left(n^{3}\right)$, é proibitiva para grandes conjuntos de dados. Assim, uma aproximação foi desenvolvida denominada Landmarks MDS (LMDS) (de Silva e Tenenbaum, 2004). Nela a Classical Scaling é aplicada somente para um pequeno subconjunto de instâncias representativas (chamadas de landmarks) projetando as demais instâncias por interpolação.

Uma outra derivação da Classical Scaling, o algoritmo ISOMAP (Tenenbaum et al., 2000) pode ser visto como uma extensão não-linear dessa, substituindo a distância euclideana pela distância geodésica de forma a capturar as não-linearidades presentes no espaço original de alta dimensão. O ISOMAP exige a realização de um número de operações computacionalmente caras, 
isso pode resultar em um processo ineficiente e impraticável para grandes conjuntos de dados. Assim, de Silva e Tenenbaum (2003) propuseram o método Landmarks ISOMAP (L-ISOMAP). Na L-ISOMAP, assim como na LMDS, alguns pontos são inicialmente mapeados e o restante é interpolado na projeção final.

Por fim, a técnica FastMap (Faloutsos e Lin, 1995) visa reduzir a complexidade computacional da Classical Scaling substituindo o processo baseado em decomposição espectral por uma solução recursiva. No processo definido, dois pontos são inicialmente selecionados, denominados pivôs. Depois disso, os pontos restantes são interpolados entre esses dois pivôs por meio de mapeamentos em hiperplanos de dimensão menor. A complexidade dessa técnica é $O(n)$, porém apresenta uma grande perda de informação em termos da preservação das relações de similaridade para projeções de espaços de alta dimensão.

A seguir as técnicas baseadas em minimização não-linear são apresentadas.

\subsubsection{Minimização Não-linear}

Uma das primeiras técnicas baseadas em otimização não-linear, conhecida como Sammon's Mapping, foi proposta por Sammon (1969). Ela define uma função de perda com base na diferença entre as distâncias no espaço de características e as distâncias no espaço visual e minimiza tal função usando o método de gradientes descendentes para encontrar um mínimo para a função. A limitação da técnica de Sammon's Mapping é a complexidade $O\left(n^{2}\right)$, então o procedimento de minimização pode tornar-se proibitivo para grandes conjuntos de dados.

Um dos problemas da Sammon's Mapping é que essa minimiza a função de perda sem garantias de convergência. Uma abordagem que assegura convergência usando o método Iterative majorization no processo de otimização é conhecida como SMACOF de Leeuw (1977a). Embora a convergência possa ser garantida, mínimos locais ainda são um problema. Assim como a Sammon's Mapping, a complexidade do algoritmo SMACOF é $O\left(n^{2}\right)$.

Com o objetivo de reduzir o alto custo computacional desses métodos de otimização, Pekalska et al. (1999) introduziram uma nova abordagem. A ideia geral é usar um subconjunto de instâncias tomado do conjunto de dados e projetá-lo usando a Sammon's Mapping e interpolar os pontos restantes considerando essa projeção inicial. Os resultados dessa abordagem não só reduzem a complexidade computacional, como também atinge um alto grau de preservação das relações de similaridade e vizinhança.

A seguir os modelos baseados em força para projeção de dados multidimensionais são apresentados.

\subsubsection{Modelo Baseado em Força}

As técnicas MDS mais simples são as que utilizam um modelo baseado em força. O modelo baseado em força foi inicialmente concebida como uma heurística para o desenho de grafos (Eades, 1984). Nesse, cada instância é modelada como uma partícula sobre o efeito de forças de atração ou repulsão em relação às demais partículas. Como cada instância está sujeita às forças de todas 
as outras, o cálculo das forças é $O\left(n^{2}\right)$. Como para se gerar um layout estável são necessárias $n$ iterações, o algoritmo resultante tem complexidade $O\left(n^{3}\right)$.

Uma abordagem alternativa para tornar linear essa alta complexidade foi apresentada por Chalmers (1996.). Essa redução é conseguida por meio da redução do número de cálculos de força realizados em uma iteração. São feitos cálculos entre cada objeto $X_{i}$ e dois conjuntos distintos com tamanhos limitados. O primeiro conjunto $V_{i}$ armazena uma lista de "vizinhos" do objeto $X_{i}$. Tendo tamanho máximo $V \max$. Junto com $X_{i}$ é mantido um valor maxDist, que é a maior distância multidimensional entre $X_{i}$ e qualquer membro de $V_{i}$. O segundo conjunto, $S_{i}$, é reconstruído em cada iteração, e contém uma seleção aleatória de objetos que não pertençam a $V_{i}$. O tamanho do mesmo é definido por uma constante Smax. Para cada iteração, elementos são selecionados para serem inseridos em $S_{i}$, para cada elemento selecionado a dissimilaridade é calculada, se $\delta\left(X_{i}, X_{j}\right)<\operatorname{maxDist}$, então o novo objeto é inserido no conjunto $V_{i}$. Se não, o objeto é adicionado a $S_{i}$. Esse processo é repetido até que a lista $S_{i}$ tenha Smax elementos. Quando isso ocorrer, as forças em $X_{i}$ são calculadas usando um número limitado de partículas, reduzindo a complexidade de uma iteração para $\mathrm{O}(n)$.

Embora o algoritmo apresentado por (Chalmers, 1996.) torne linear a complexidade das iterações, como são necessárias no mínimo $n$ iterações, o processo como um todo ainda terá complexidade alta, $O\left(n^{2}\right)$. A fim de reduzir essa complexidade uma primeira abordagem Hibrida foi apresentada por (Morrison et al., 2002) e depois aperfeiçoada por (Morrison et al., 2003). Nesse modelo hibrido uma amostra é escolhida do conjunto de dados e projetada usando-se o método de Chalmers. As demais são posicionadas por meio de uma interpolação reduzindo a complexidade para $O(n \sqrt{n})$. Posteriormente (Jourdan e Melancon, 2004) otimizaram ainda mais esse processo, reduzindo essa complexidade para $O(n \log n)$. Apesar de realmente produzirem aumento de eficiência, essas abordagem mais rápidas perdem muito em precisão no que se refere ao posicionamento dos pontos, um objetivo importante no processo de projeção.

Outra abordagem, com o objetivo de reduzir a complexidade do modelo baseado em molas foi proposta por Tejada et al. (2003a), denominada Force Scheme. Ela se baseia no conceito de atração e repulsão de forças proporcionais a diferença entre as distâncias no espaço projetado e as distâncias no espaço original. Um posicionamento dos pontos é gerado inicialmente com uma técnica rápida e que busca preservar as distâncias, por exemplo a Fastmap. Em sequencia esse é iterativamente modificado movendo os pontos a fim de melhorar a preservação das relações de distância. Nesse processo, para cada ponto projetado $\mathbf{y}_{i} \in \mathbf{Y}$, calcula-se um vetor $\overrightarrow{\mathbf{v}}_{i j}=\left(\mathbf{y}_{j}^{\prime}-\mathbf{y}_{i}^{\prime}\right)$, $\mathbf{y}_{j}^{\prime} \neq \mathbf{y}_{i}^{\prime}$. Então, uma perturbação em $\mathbf{y}_{i}^{\prime}$ é aplicada na direção de $\overrightarrow{\mathbf{v}}_{i j}$ uma fração de $\Delta$, onde $\Delta$ é calculado pela Equação 2.2 e depende da diferença da distância no espaço projetado e no original. O Algoritmo 2.1 sumariza o processo empregado pela Force Scheme.

$$
\Delta=\frac{\left(d\left(\mathbf{y}_{i}, \mathbf{y}_{j}\right)-\delta\left(\mathbf{x}_{i}, \mathbf{x}_{j}\right)\right)-\delta_{\min }}{\delta_{\max }-\delta_{\min }}
$$

A complexidade final depende de $k$ e da complexidade de cada iteração, que é $O\left(n^{2}\right)$, portanto a Force Scheme é $O\left(k n^{2}\right)$. Embora essa seja uma técnica de alta precisão, seu custo ainda é elevado para grandes conjuntos de dados. 


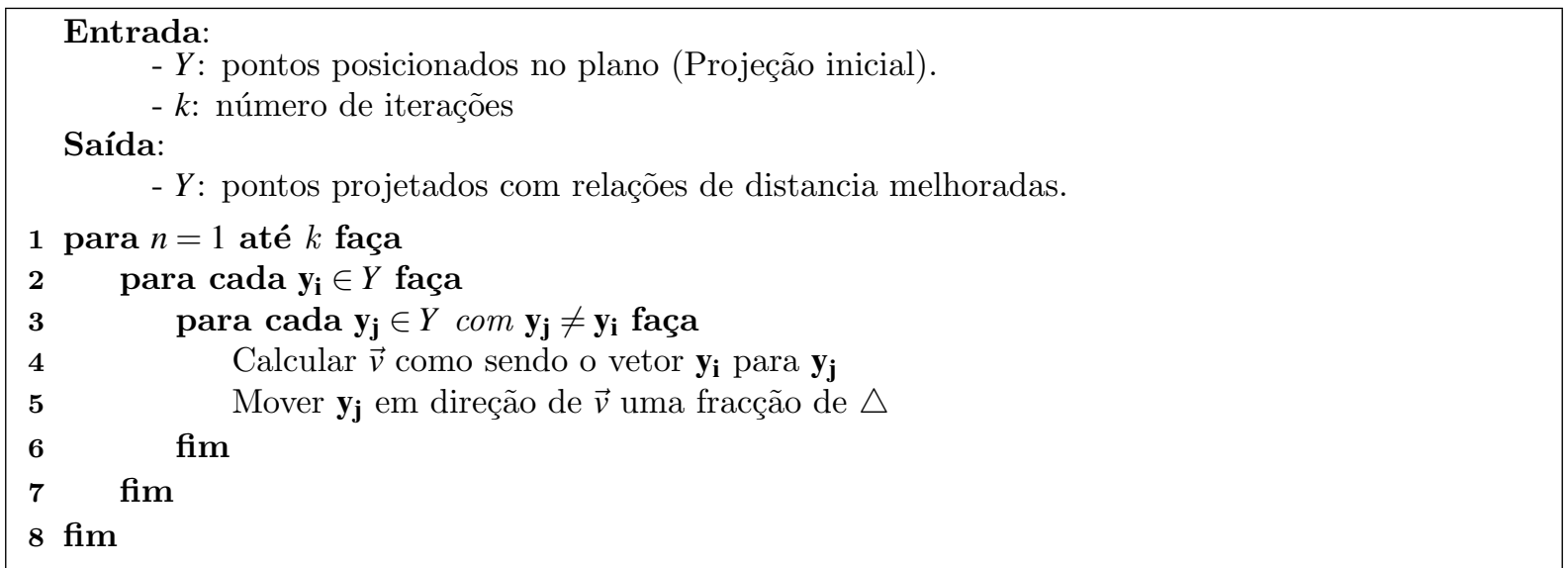

Algoritmo 2.1: Algoritmo - Force Sheme

Usando uma abordagem diferente das anteriores, a técnica Least Square Projection (LSP), proposta por (Paulovich et al., 2008b), emprega um processo baseado na solução de sistemas lineares buscando preservar relações de vizinhança entre os objetos $m$-dimensionais no espaço projetado $\mathbb{R}^{p}$, ao invés de tentar preservar relações de distância. Dois passos principais são executados nesse processo de projeção, primeiro um subconjunto de objetos multidimensionais, chamados de "pontos de controle" é escolhido e projetado no $\mathbb{R}^{p}$. Depois, fazendo uso das relações de vizinhança dos objetos no $\mathbb{R}^{m}$ e as coordenadas cartesianas dos pontos de controle são construídos sistemas lineares cuja solução define a projeção dos objetos restantes de forma que os mesmos residam no fecho convexo de seus $k$ vizinhos mais próximos. Os problemas da LSP envolvem o cálculo dos vizinhos mais próximos e o tempo de processamento para a resolução dos sistemas lineares, não conseguindo lidar com grandes conjuntos de dados.

De forma superar esse problema, uma nova técnica baseada na LSP foi desenvolvida, denominada Piecewise Laplacian-based Projection (PLP) (Paulovich et al., 2011a). Nessa o conjunto de dados é inicialmente dividido em agrupamentos. Após isso, a LSP é aplicada para cada um desses agrupamentos mantendo a coerência espacial por meio da seleção e projeção dos pontos de controle. Uma das principais características da PLP é que ela permite um grande controle da projeção final por meio do reposicionamento dos pontos de controle, possibilitando que aplicações interativas sejam derivadas de forma a adicionar no processo de projeção conhecimento do usuário.

Por fim, o Glimmer é um algoritmo multinível baseado em força para fazer projeções proposto por Ingram et al. (2009). Ao contrário de outros algoritmos, Glimmer foi projetado para explorar o paralelismo GPU em cada etapa do algoritmo, melhorando bastante a performance dos algoritmos convencionais baseados no modelo de molas. O problema nesse caso é a limitação do tamanho dos conjuntos de dados dada pela quantidade de memória disponível na placa gráfica utilizada.

A seguir o último grupo de técnicas de projeção é apresentado. 


\subsubsection{Operador Linear}

Dentre as técnicas de projeção que se baseiam em operadores lineares, a Random Projection (Bingham e Mannila, 2001) é uma das mais simples. Ela mapeia dados de um espaço de maior dimensão em outro de menor usando-se uma matriz gerada aleatoriamente cujas colunas têm tamanho unitário. Apesar de ser extremamente rápida por se tratar simplesmente de uma multiplicação de matriz por vetor, o erro produzido por ela na redução de dimensionalidade está diretamente relacionado ao número de dados a serem processados (Achlioptas, 2003), quanto mais dados, menor a preservação das relações de similaridade.

A fim de melhorar esse resultado a técnica Part Linear Multidimensional Projection (PLMP) (Paulovich et al., 2010) substitui a matriz aleatória empregada na Random Projection por uma construída levando-se em consideração relações de distância. A ideia nessa abordagem é primeiro projetar uma amostra dos dados. Então com base nessa projeção inicial um mapeamento linear é criado que é empregado para mapear as instâncias restantes. PLMP foi desenvolvida para tratar dados multidimensionais representados em um espaço cartesiano necessitando só informação sobre as distâncias entre amostras. Esta característica faz com que a PLMP seja mais rápida do que outras técnicas para processar grandes conjuntos de dados, preservando com sucesso as relações de distância do espaço multidimensional original no espaço projetado.

Outra técnica linear, a Principal Component Analysis (PCA) (Jolliffe, 1986), transforma um conjunto de variáveis correlacionadas em um conjunto menor de variáveis (componentes principais) com o objetivo de reter tanto quanto possível a variação no conjunto de dados. Quando a métrica de distância no espaço de multidimensional é Euclideana, é possível provar que o resultado alcançado pelo PCA é o mesmo da Classical Scaling. Assim, a PCA também pode ser usada como técnica de projeção multidimensional. A desvantagem da PCA é seu alto custo computacional para grandes conjuntos de dados.

Por fim, a técnica Local Affine Multidimensional Projection (LAMP) (Joia et al., 2011), assim como as técnicas PLMP, PLP, faz uso de um subconjunto de amostras chamados de pontos de controle e sua projeção no espaço visual. Para cada ponto a ser projetado é construído um mapeamento ortogonal afim que projeta os dados do espaço multidimensional para o espaço visual, sendo que o mapeamento segue o layout definido pelos pontos de controle. Em outros termos, a LAMP projeta cada ponto para o espaço visual encontrando a melhor transformação afim $f_{x}(p)=p M+t$ que minimiza a expressão 2.3

$$
\sum_{i} \alpha_{i}\left\|f_{x}\left(x_{i}\right)-y_{i}\right\|^{2}
$$

restringindo $M^{T} M=I$, sendo $I$ a matriz identidade, $t$ o vetor de translação, $M$ matriz de transformação linear e $\alpha_{i}$ os pesos escalares definidos na equação 2.4

$$
\alpha_{i}=\frac{1}{\left\|x_{i}-x\right\|^{2}}
$$


Diferente da PLMP e PLP, a LAMP requer um número pequeno de pontos de controle, portanto ela é bastante indicada para cenários onde projeções são realizadas levando em consideração intervenção do usuário (Silva et al., 2012).

Embora as técnicas de projeção aqui apresentadas representem o estado da arte em termos de precisão e custo computacional, a qualidade da projeção final gerada está diretamente ligada à qualidade do espaço multidimensional de entrada. Se esse apresentar estruturas, essas possivelmente serão reveladas na projeção. Caso contrário alguma técnica que vise modificar tal espaço a fim de revelar essas estruturas deve ser usada antes do processo de projeção. A seguir algumas técnicas interativas são apresentadas.

\subsection{Abordagens para Transformação de Espaços Multidimensionais}

Pode ser notado pela própria definição de uma projeção multidimensional que a qualidade visual de uma projeção está intimamente ligada ao espaço no qual os dados sendo projetados estão definidos. Se nesse espaço estruturas forem bem definidas, essas poderão ser representadas no layout final. Caso contrário alguma transformação nos dados deve ser realizada de forma a ser possível evidenciar essas estruturas. A seguir apresentamos algumas técnicas com esse objetivo, divididas em técnicas de redução de dimensionalidade e técnicas para deformação do espaço de características, com especial atenção para as técnicas que embutem o usuário no processo de transformação.

A seguir apresentamos algumas técnicas para redução interativa de dimensionalidade.

\subsubsection{Redução de Dimensionalidade Interativa}

Dentro do campo de visualização de informação uma série de sistemas de redução de dimensionalidade interativos foram desenvolvidos com foco na preservação de estruturas dentro dos conjunto de dados.

Na abordagem de Guo (2003) um sistema focado em estruturas de agrupamentos é apresentado, onde cada subespaço bidimensional do conjunto de dados é analisado com base a uma medida de qualidade do agrupamento gerado. Esta medida é baseada em três critérios, o percentual de itens dentro dos agrupamentos, a densidade dos agrupamentos e a dependência das duas variáveis sendo analisadas. Quando a qualidade do agrupamento é calculada para todos os subconjuntos bidimensionais, um agrupamento hierárquico é usado para classificar as variáveis de forma que variáveis altamente correlacionadas são posicionadas próximas. As variáveis ordenadas são visualizadas em uma matriz onde cada célula corresponde a um subespaço bidimensional. A cor da célula representa uma medida. Utilizando a visualização da matriz um usuário pode encontrar subespaços possivelmente interessantes com bons agrupamentos. Subespaços podem ser formados de forma interativa, selecionando um número de subespaços bidimensionais. Os subespaços bidimensionais finais selecionados compõem o novo conjunto de dimensões.

Na abordagem de Seo e Shneiderman (2005) um arcabouço de ranqueamento das dimensões é apresentado com intuito de detecção interativa de variáveis. O arcabouço fornece um con- 
junto de critérios para o ranqueamento, tais como correlação, regressão linear, uniformidade, número de agrupamentos, dos quais o usuário pode selecionar uma para a análise. Todos os possíveis subconjuntos de variáveis são analisados de acordo com os critérios selecionados e são apresentados em displays tabulares onde a cor da célula representa a pontuação de ranking do subconjunto correspondente. Assim como na abordagem apresentada por Guo (2003), o usuário pode selecionar interativamente subespaços interessantes na tabela para futuras análises, guiado pela pontuação do ranking escolhido. A Figura 2.2 mostra a interface interativa dessa abordagem.

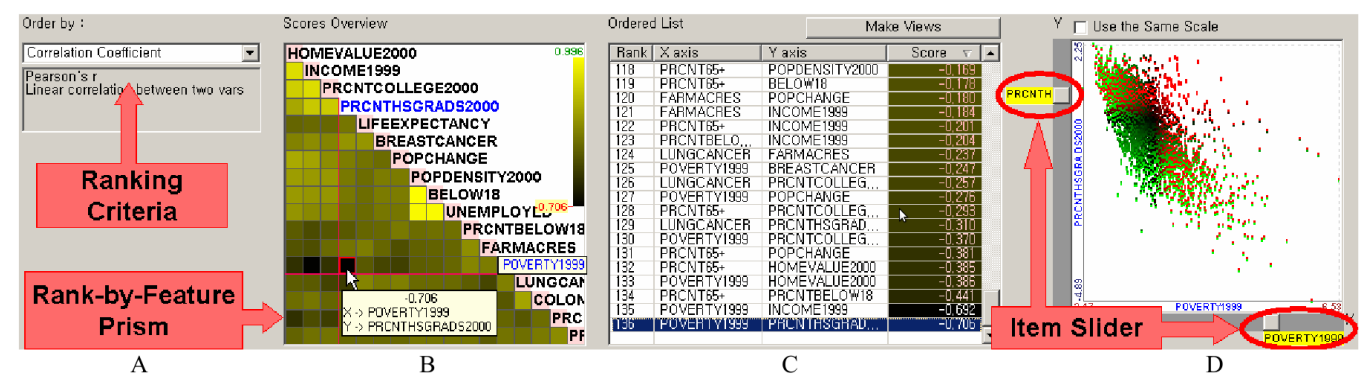

Figura 2.2: Interface do framework Rank-by-feature(retirado de (Seo e Shneiderman, 2005)).

Na abordagem Visual Hierarchical Dimension Reduction (VHDR), Yang et al. (2003b) apresentaram um método onde agrupamento das variáveis e interação do usuário são combinados a fim de encontrar espaços de menores dimensão que tenham sentido para o usuário. Uma estrutura hierárquica das variáveis é gerada usando um algoritmo de agrupamento baseada em similaridades entre pares de variáveis. O usuário tem a possibilidade de navegar através da estrutura hierárquica, modificando e selecionando os agrupamentos de interessante na estrutura hierárquica. A redução de dimensionalidade é então realizada através da seleção das variáveis que representam os agrupamentos selecionados, gerando assim um novo conjunto de dados em menor dimensão que pode ser analisado por qualquer reapresentação visual padrão.

A abordagem Dimension Ordering, Spacing and Filtering Approach (DOSFA) (Yang et al., 2003a), assim como a VHDR, está baseada em uma estrutura hierárquica derivada das similaridades entre as dimensões. Porém, ela não somente reduz o número de variáveis de um conjunto de dados de alta dimensão, mas também encontra uma representação visual de variáveis que facilita a detecção de padrões dentro dos dados. Esse processo se inicia com a ordenação das variáveis. Para essa ordenação duas abordagens são apresentadas: Ordenação baseada em similaridade, onde as variáveis similares estão posicionadas umas perto das outras. E a ordenação baseada em importância, onde a ordenação é baseada em alguma medida de importância para as variáveis, como, por exemplo, a variância. Depois da ordenação uma abordagem de espaçamento de variáveis é empregada, onde o espaço entre as variáveis adjacentes reflete como elas são semelhantes umas as outras. Variáveis altamente semelhantes são posicionadas próximas, e as variáveis não semelhantes são posicionados mais afastadas. Para o espaçamento das variáveis se calcula a correlação entre eixos adjacentes, sendo a distância entre eixos proporcional aos valores obtidos. O passo final é a filtragem das dimensões removendo variáveis com base em uma 
combinação de similaridade e medida da importância. O usuário pode modificar interativamente a ordenação, espaçamento, e filtragem, obtendo diferentes conjuntos de dados finais reduzidos.

O sistema de redução de dimensionalidade DimStiller apresentado por Ingram et al. (2010) se baseia na aplicação de transformações por meio de operadores a tabelas de dados (onde as linhas são pontos e as colunas são dimensões). Os operadores são funções que mapeiam uma tabela $n \times m$ para uma tabela $n^{\prime} \times m^{\prime}$, onde pontos ou dimensões podem ser adicionados, excluídos ou alterados. Cada operador pode ter um controle associado e/ou uma representação gráfica. Os controles de um operador são elementos de uma interface gráfica que permitem aos usuários analisar os operadores individuais, ajustar seus parâmetros, e observar os efeitos sobre as transformações resultantes nas representações visuais. O objetivo é fornecer tanto orientação global e local ao longo do processo de redução, auxiliando o usuário na escolha de uma cadeia útil de transformações, bem como fornecer feedback visual facilitando os ajustes de parâmetros.A Figura 2.3 apresenta a interface principal dessa abordagem.

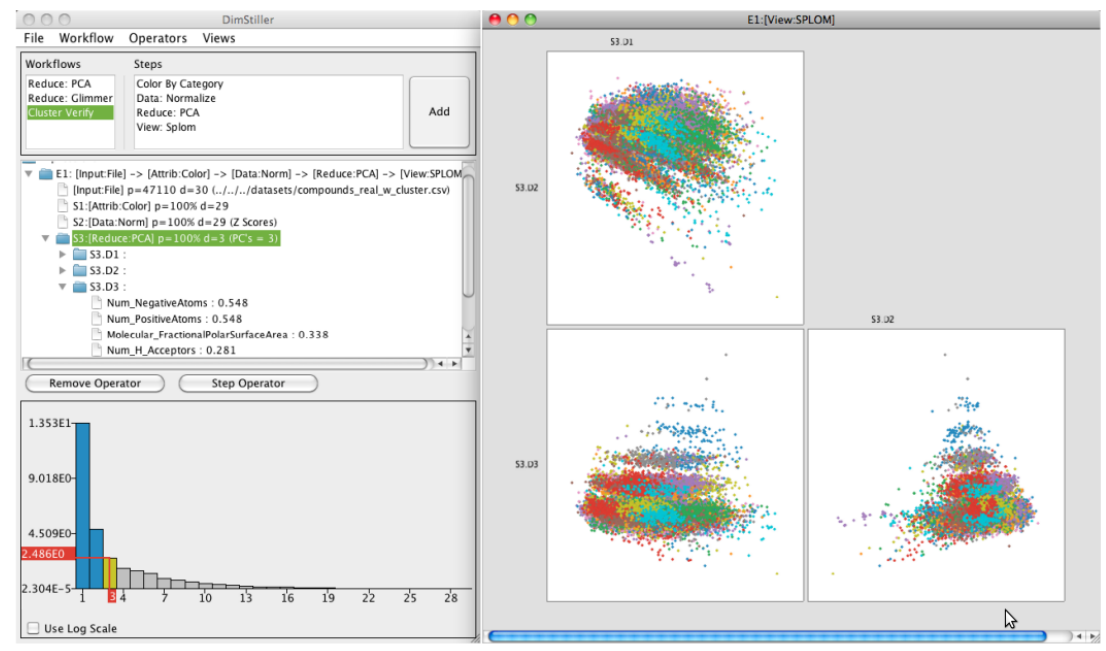

Figura 2.3: Interface do sistema DimStiller (retirado de (Ingram et al., 2010)).

Na abordagem desenvolvida por Johansson e Johansson (2009) um sistema é apresentado para reduzir a dimensionalidade e explorar conjuntos de dados multidimensionais com grande número de variáveis (atributos) preservando o máximo possível as estruturas importantes com base em métricas de qualidade. A importância de cada métrica é controlada pelo usuário mediante a atribuição de funções peso (Figura 2.4). Com o intuito de determinar as variáveis mais importantes do conjunto de dados é definido uma métrica de qualidade para cada um das variáveis. O sistema permite a investigação da relação entre o número de variáveis e perda de informação, o usuário decide sobre o número de variáveis para manter no conjunto de dados reduzido e o sistema seleciona as variáveis mais importantes com base nos valores de peso e a importância da métrica, proporcionando ao usuário uma representação visual (coordenadas paralelas) do conjunto de dados reduzido. 


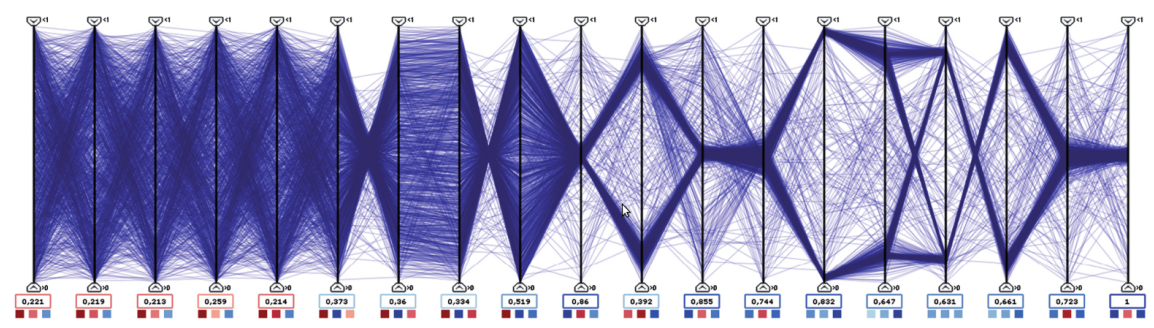

Figura 2.4: Exemplo de redução de dimensionalidade usando diferentes métricas de qualidade (retirado de (Johansson e Johansson, 2009)).

\subsubsection{Deformação do Espaço de Características}

Nas abordagens apresentadas na seção anterior os dados são transformados mediante a redução de dimensionalidade guiadas por um usuário. Porém, nenhuma de essas abordagens modifica os atributos dos dados. Algumas poucas tentativas vem sendo feitas no sentido de permitir que um usuário possa manipular o espaço de características, entre elas, destacamos a Interactive System for PCA-based Visual Analytics (iPCA) (Jeong et al., 2009) e a técnica para visualização de espaço de parâmetros desenvolvida por Berger et al. (2011).

A iPCA define um sistema interativo com múltiplas visões coordenadas dos dados que permite alterar os valores das instâncias de dados no espaço multidimensional e observar em uma projeção produzida pela técnica Principal Component Analysis (PCA) (Jolliffe, 1986) o resultado dessa manipulação. A Figura 2.5 apresenta a vista geral desse sistema. A Projection View(Figura 2.5A) mostra instâncias de dados projetados em duas dimensões. A Eigenvector View(Figura 2.5B) apresenta os autovetores e seus autovalores calculados usando-se coordenadas paralelas. A Data View(Figura 2.5C) mostra as instâncias de dados em coordenadas paralelas, e a Correlation View(Figura 2.5D) mostra a matriz de correlação entre todas as dimensões dos dados. Os valores das instâncias de dados podem ser modificados na Projection View, Data View ou Eigenvector View. O sistema iPCA também permite manipulação direta das covariâncias (parâmetros do PCA) pelo uso de sliders (Figura 2.5E), permitindo aumentar ou diminuir a contribuição de cada uma das dimensões do conjunto de dados a fim de descobrir as dimensões contribuem na formação ou dispersão de agrupamentos. Essas interações permitem ao usuário testar cenários hipotéticos. Assim, se o usuário suspeitar que uma instância de dados deve aparecer em um determinado agrupamento, é possível mover manualmente essa instância e observar como os valores da instância são alterados. O problema desse sistema é que conforme o número de dimensões das instâncias de dados aumenta, as possibilidades de modificação crescem exponencialmente de forma que o trabalho de se definir as modificações corretas passa a ser um trabalho exaustivo e caro.

A Abordagem interativa proposta por Berger et al. (2011) permite análise do espaço de parâmetros fornecendo resultados de objetivos múltiplos. Essa abordagem emprega métodos de aprendizado de máquina para predizer resultados em tempo real em qualquer ponto definido pelo usuário e a sua vizinhança. Em particular, fornece uma orientação visual ao usuário permitindo uma navegação eficiente para regiões de parâmetros potencialmente interessantes, visualizando 


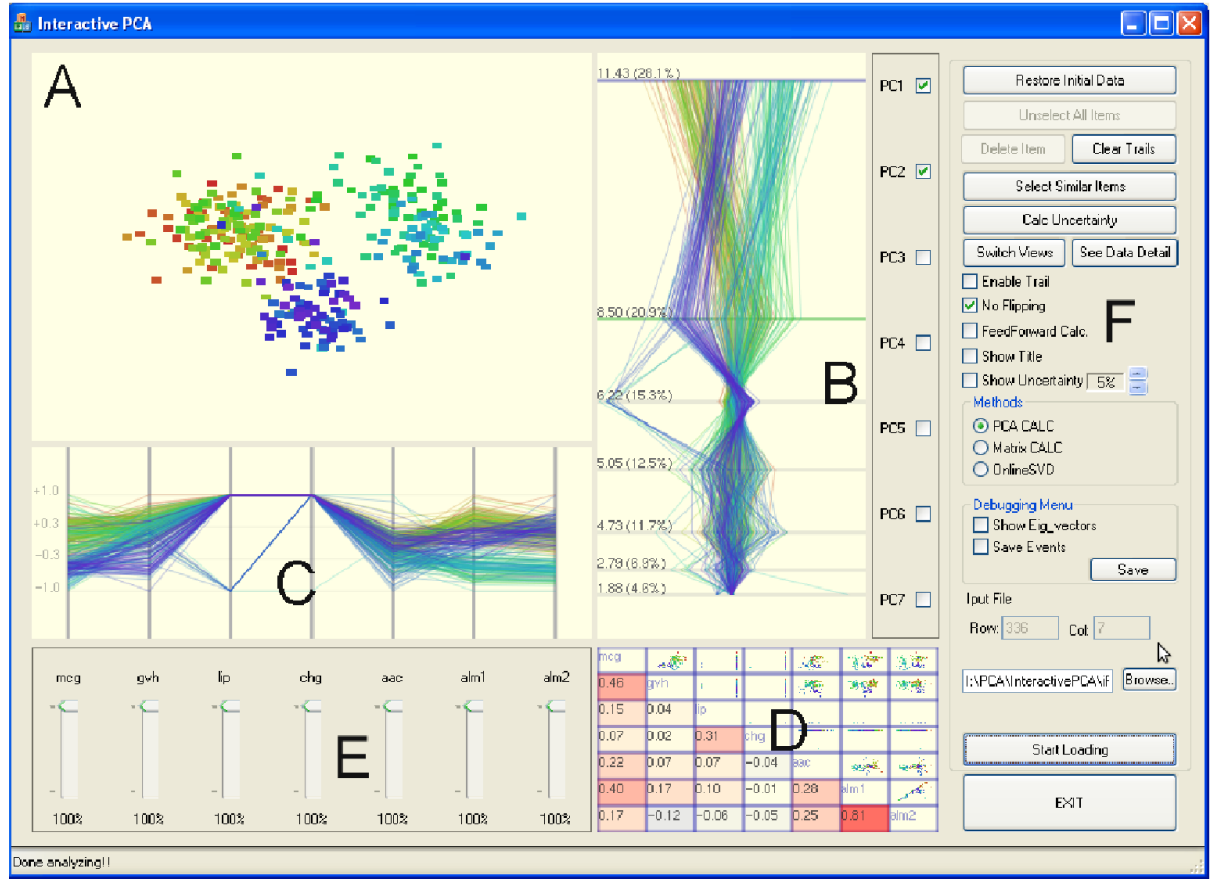

Figura 2.5: Interface principal do sistema iPCA (retirado de (Jeong et al., 2009)).

a incerteza inerente das previsões usando scatterplots e Coordenadas paralelas. Inicialmente se identifica um ponto focal $F$ para permitir uma navegação e previsão. Um ponto focal é uma tupla do espaço de parâmetro estabelecida pelo usuário. Permitem uma interação com $F$ e por consequência atualizações locais e globais de $F$. Atualizações locais afetam um subconjunto de dimensões de cada vez, enquanto as atualizações globais definem valores para todas as dimensões simultaneamente.

A Figura 2.6 apresenta um exemplo do workflow dessa abordagem. Primeiro um ponto focal $F$ inicial é estabelecido pelo usuário para à analise (Figura 2.6(a) e (b)). Em um scatterplot é amostrado o impacto dos parâmetros sobre os dois maiores objetivos (Figura 2.6(c)). O usuário restabelece $F$ com respeito ao parâmetro que consegue melhorar ambos objetivos, imediatamente atualizações são executadas (Figura 2.6(d)). Um scatterplot mostra guias de área entre os objetivos em relação a esses parâmetros (Figura 2.6(e)). Essa visualização revela quais parâmetros poderiam ser aumentados o diminuídos em função dos objetivos. As atualizações são mostradas em coordenadas paralelas (Figura 2.6(f)). Boxplots são usados a fim de garantir que os valores previstos são confiáveis (Figura 2.6(g)). No passo final o usuário pode investigar a sensibilidade do gráfico quanto à modificação dos parâmetros (Figura 2.6(h)).

Esta abordagem fornece poderosos recursos interativos para que o usuário possa realizar modificações locais e globais dos atributos. Embora a manipulação e modificação seja viável com esta abordagem, os layouts de visualização gerados não são intuitivos o suficiente ou são tão sofisticados que é preciso algum treinamento para serem usados corretamente. 


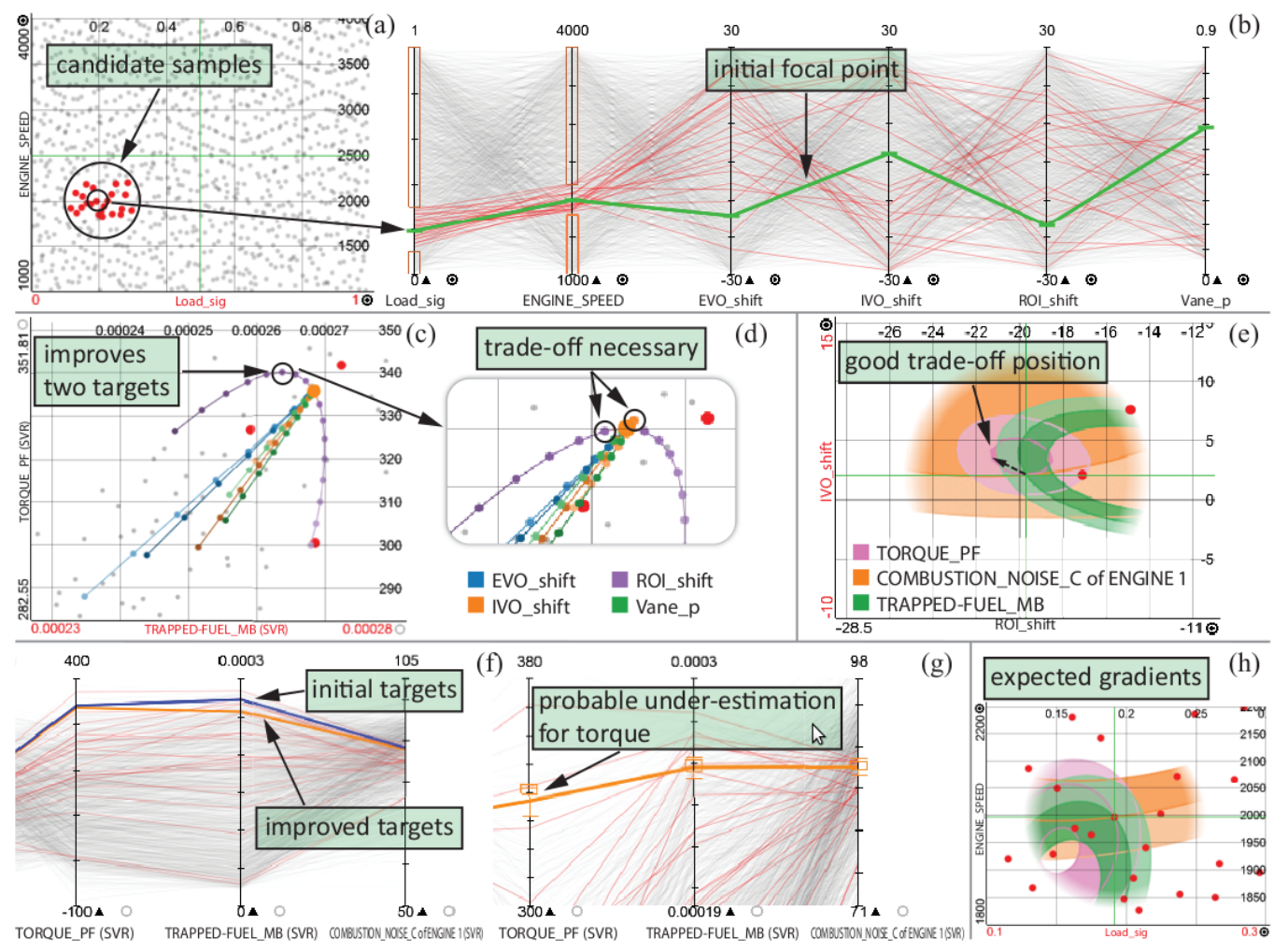

Figura 2.6: Exemplo do workflow da abordagem proposta por Berger et al. (2011).

\subsection{Considerações Finais}

Neste capítulo, foi apresentada uma revisão das técnicas de projeção multidimensional. Tais técnicas visam mapear injetivamente objetos em espaço de alta dimensão para um espaço visual, preservando, na medida do possível, as relações de distância existentes entre os objetos multidimensionais. Dessa maneira a habilidade visual humana pode ser usada para a interpretação dos dados. As técnicas apresentadas aqui foram agrupadas em quatro categorias principais: (1) decomposição espectral; (2) minimização não linear; (3) modelo baseado em força; e (4) operador linear. A Tabela 2.1 apresenta a complexidade computacional das técnicas estudadas neste capítulo.

Além das técnicas de projeção, foi abordada uma visão geral de arcabouços interativos para a redução de dimensionalidade e transformação de espaços de características, assuntos bastante relacionados à proposta desse trabalho de mestrado. No próximo capítulo apresentamos nossa abordagem para distorção de espaços de características usando-se projeções multidimensionais, onde um usuário pode transformar o espaço multidimensional de forma a alterar as relações de similaridade e vizinhanças presentes nos dados. 
Tabela 2.1: Lista das técnicas de projeção multidimensional estudadas, com suas respectivas complexidades, onde $n$ e $k$ representam o número total de instâncias e o número de amostras respectivamente, $c$ é o número de iterações.

\begin{tabular}{|c|c|c|}
\hline Nome & Fonte & Complexidade \\
\hline \hline Classical Scaling (MDS) & Torgeson (1965) & $O\left(n^{3}\right)$ \\
\hline Landmarks MDS & de Silva e Tenenbaum (2004) & $O\left(k^{3}+k n\right)$ \\
\hline LLE & Roweis e Saul (2000) & $O\left(n^{2}\right)$ \\
\hline ISOMAP & Tenenbaum et al. (2000) & $O\left(n^{2}\right)$ \\
\hline Landmarks ISOMAP & Silva e Tenenbaum (2002) & $O\left(k^{2} n\right)$ \\
\hline FASTMAP & Faloutsos e Lin (1995) & $O(n)$ \\
\hline Pekalska approximation & Pekalska et al. (1999) & $O\left(2 k^{3}+k n\right)$ \\
\hline Sammon's Mapping & Sammon (1969) & $O\left(c n^{2}\right)$ \\
\hline SMACOF & de Leeuw (1977b) & $O\left(c n^{2}\right)$ \\
\hline Spring model & Eades (1984) & $O\left(n^{3}\right)$ \\
\hline Chalmers & Chalmers (1996.) & $O\left(n^{2}\right)$ \\
\hline Modelo híbrido & Jourdan e Melancon (2004) & $O(n l o g n)$ \\
\hline Force Scheme & Tejada et al. (2003b) & $O\left(c n^{2}\right)$ \\
\hline LSP & Paulovich et al. (2008b) & $O\left(k^{2}+n^{2}\right)$ \\
\hline PLP & Paulovich et al. (2011a) & $O(n \sqrt{n})$ \\
\hline Glimmer & Ingram et al. (2009) & $O(c n l o g(m))$ \\
\hline Random Projection & Bingham e Mannila (2001) & $O(m k n)$ \\
\hline PLMP & Paulovich et al. (2010) & $O(n)$ \\
\hline PCA & Jolliffe (1986) & $O\left(n^{3}\right)$ \\
\hline LAMP & Joia et al. (2011) & $O(k n)$ \\
\hline
\end{tabular}




\section{Empregando Projeções para Transformar Espaços de Características}

\subsection{Considerações Iniciais}

os últimos anos, o interesse pelas técnicas de projeção multidimensional tem crescido na comunidade científica devido o poder analítico que essas oferecem na exploração de relações de similaridade de dados abstratos. Essas vem sendo aplicadas com sucesso em diversas áreas, como, por exemplo, na análise de coleções de documentos (Paulovich et al., 2008b), para a verificação de resultados da Web (Paulovich et al., 2008a), passando pela exploração de fibras neuronais (Chen et al., 2009) e mais recentemente servindo para a análise de dados de biossensores (Paulovich et al., 2011b).

Apesar desse sucesso, resultados satisfatórios, do ponto de vista de um usuário, só serão alcançados se as características (dimensões) que descrevem o conjunto de dados sendo analisado conseguirem refletir bem o que o mesmo entende como sendo similar e não similar. Esse fato deriva direto da própria natureza das técnicas de projeção multidimensional que buscam preservar no espaço projetado (visual) as mesmas relações de similaridade encontradas no espaço original. Assim, se no espaço original os elementos similares formarem grupos bem definidos, o resultado visual normalmente será satisfatório. Caso contrário, se os valores dos atributos dos dados junto com a função de dissimilaridade empregada não forem capazes de indicar grupos de elementos similares, as projeções invariavelmente irão falhar. A Figura 3.1 apresenta uma projeção usando a técnica Force Scheme de uma parte do conjunto Scene (Oliva e Torralba, 2001) contendo 1.678 imagens em preto e branco. Para essa projeção foram extraídas características usando histogramas (Swain e Ballard, 1991), resultando em 256 dimensões. A cor dos círculos e nas 
bordas das imagens indica a classe que a imagem pertence. É possível notar que a similaridade empregada em conjunto com as características extraídas das imagens não foram capazes de criar grupos coerentes.

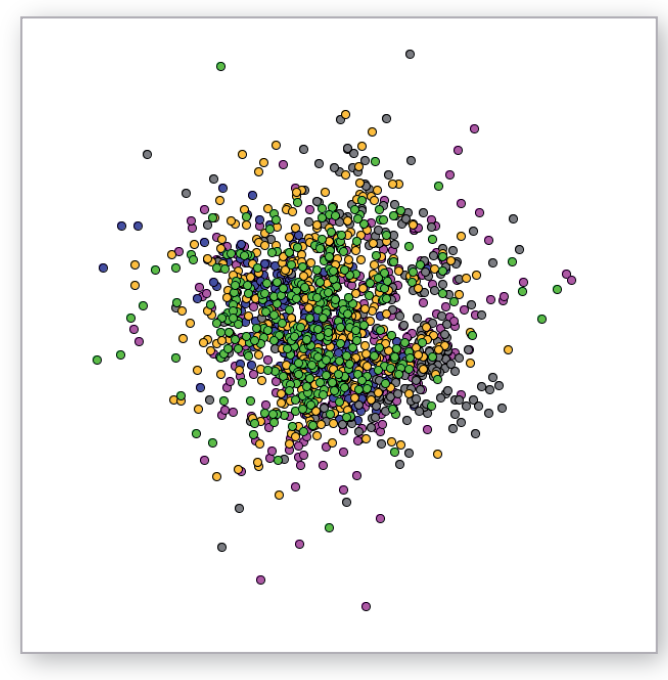

(a)

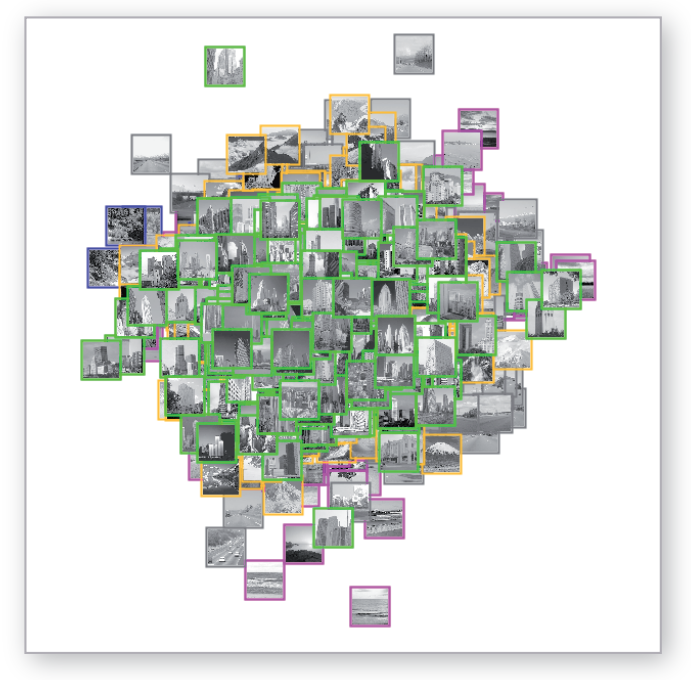

(b)

Figura 3.1: Um exemplo de projeção das imagens do conjunto Scene com a técnica Force Scheme. Em (a) os elementos visuais são representados por círculos e em (b) a própria imagem é utilizada como rótulo

Esse projeto de mestrado busca apresentar uma metodologia para superar esse gap semântico que pode ocorrer entre a representação de objetos usando espaços vetoriais multidimensionais e a expectativa de um determinado usuário sobre as relações de similaridade entre os objetos. A metodologia proposta baseia-se em uma combinação de projeção multidimensional e mapeamentos locais que permite ao usuário modificar atributos de dados a partir de uma manipulação interativa de projeções.

A seguir essa proposta para transformar o espaço de características segundo as necessidades de um usuário é detalhada.

\subsection{Transformação do Espaço de Características}

A abordagem para a transformação de espaços de características aqui definida emprega conceitos de projeção multidimensional em um processo iterativo e interativo de modificação de dados abstratos de forma a refletir percepções individuais. A ideia é estabelecer um processo onde um usuário possa manipular a projeção de uma amostra dos dados e a informação dessa manipulação possa ser usada para transformar o conjunto de dados original, "moldando-o"de forma a refletir nesse seu ponto de vista em termos das relações de similaridade entre os objetos ou instâncias de dados. 


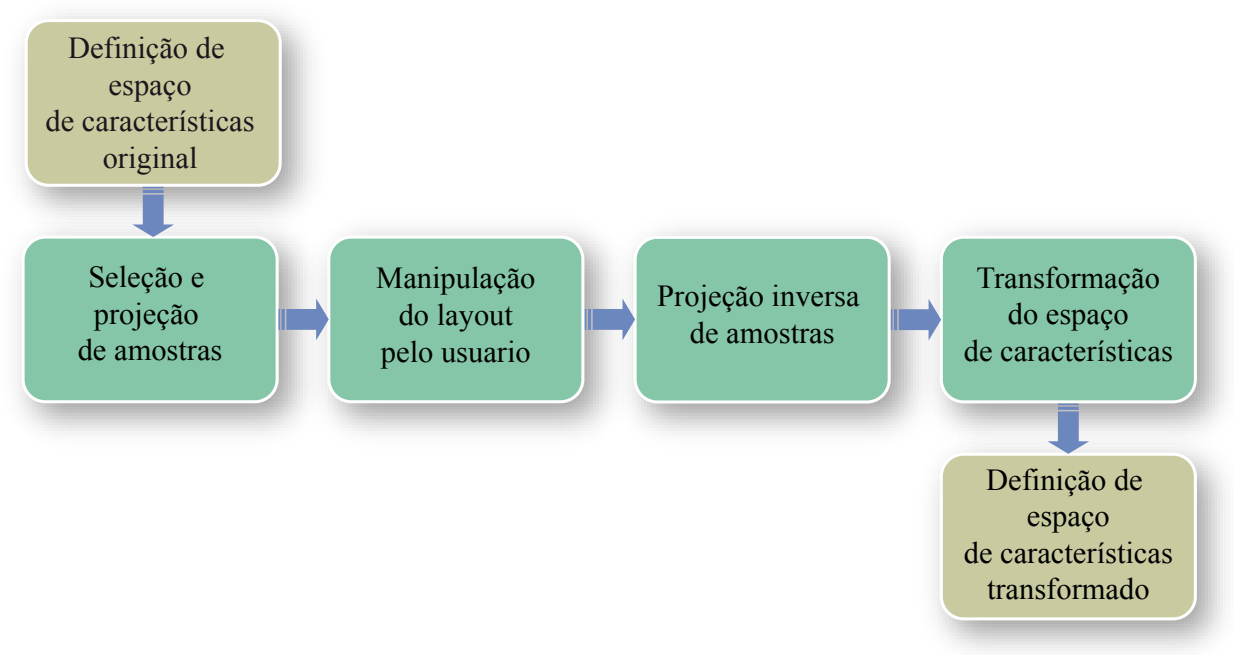

Figura 3.2: O processo de transformação proposto tem quatro passos importantes: seleção e projeção das amostras, manipulação do layout, projeção inversa das amostras, transformação do espaço de características.

A Figura 3.2 apresenta um resumo da sequência de passos a serem realizados para a transformação dos dados. Inicialmente uma amostra é escolhida e projetada no espaço visual; se o layout gerado pela projeção não condizer com o esperado pelo usuário, ele pode manipular a projeção a fim de definir um layout que agrupe melhor os elementos semelhantes e separe os elementos diferentes. Aqui, semelhança e diferença dadas pelo ponto de vista do usuário. Após a interação do usuário, as estruturas de vizinhança no espaço visual e no espaço multidimensional não serão as mesmas. Com o intuito de tornar essas novamente semelhantes, as posições das amostras representativas no espaço multidimensional são alteradas de tal forma que as distâncias no espaço multidimensional sejam as mais próximas o possível das distâncias do espaço visual. Com base nessa informação a transformação final do espaço de características é realizada por uma família de mapeamentos locais afins definidos a partir da nova posição das amostras representativas.

Detalhes sobre esses passos são dados a seguir.

\subsubsection{Seleção e Projeção das Amostras}

No primeiro passo, seja $\mathscr{X}=\left\{x_{1}, \ldots, x_{n}\right\}$ vetores de características no espaço multidimensional, uma amostra $\mathscr{X}_{s} \subset \mathscr{X}, \mathscr{X}_{s}=\left\{x_{s_{1}}, \ldots, x_{s_{n}}\right\}$ é escolhida do conjunto de dados. Idealmente essa amostra deve ser selecionada de forma a refletir o melhor possível a distribuição dos dados no espaço multidimensional e possíveis grupos existentes. A seleção da amostra pode ser feita por vários métodos. A seguir são apresentados alguns dos métodos usados nesse projeto.

- Amostragem aleatória: neste método, um sub-conjunto de instâncias é escolhida dentro do conjunto de dados sendo que todas as instâncias têm a mesma probabilidade de serem escolhidas para fazer parte da amostra. Ou seja, qualquer combinação das instâncias do conjunto de dados tem a mesma probabilidade de ocorrência. Este método é rápido mas tem baixa precisão, não existindo garantias de representatividade; 
- Amostragem por agrupamento: nesse método o conjunto de dados é inicialmente particionado usando algum algoritmo de agrupamento (clustering). Então, a partir dos grupos formados, representativos são escolhidos de cada grupo. Nesse projeto, as amostras são os medóides dos agrupamentos, ou seja, as instâncias mais próximas dos centroides. Qualquer método de agrupamento pode ser utilizado nesse processo. Aqui foi empregado o algoritmo bisecting k-means (Steinbach et al., 2000) por sua baixa complexidade computacional e por conseguir definir grupos de tamanho balanceado. Esta processo de amostragem tende a ser mais caro que uma amostragem aleatória mas de forma geral assegura uma melhor representatividade;

- Amostragem MaxMin: nesse método as amostras são escolhidas uma de cada vez, sendo que cada nova amostra deve maximizar, sobre todas as instâncias de dados não utilizadas, a distância mínima às amostras existentes. A primeira amostra é escolhida aleatoriamente (de Silva e Tenenbaum, 2004).

Após selecionada, a amostra $\mathscr{X}_{s}$ é projetada no espaço visual utilizando alguma técnica de projeção multidimensional que preserva as relações de distância precisamente, obtendo as amostras mapeadas $y_{s_{i}} \in \mathscr{Y}_{S}$ ( $\mathscr{Y}_{s}$ é a imagem de $\mathscr{X}_{s}$ no espaço visual). Qualquer técnica de projeção pode ser empregada nesse processo. Na Seção 2.2 apresentamos uma breve revisão sobre o assunto, apresentando possíveis candidatas.

\subsubsection{Manipulação do Layout}

Considerando que a técnica de projeção empregada preserva com precisão as relações de similaridade do espaço multidimensional, se a projeção obtida não condizer com o esperado pelo usuário, isso significa que o espaço de característica e a similaridade empregada não representam bem os dados. Nesse caso, o usuário pode manipular diretamente os dados projetados modificando o posicionamento das amostras movendo as amostras $y_{s_{i}}$ a novas posições $\tilde{y}_{s_{i}} \in \tilde{\mathscr{Y}}_{s}$ no espaço visual. O usuário pode modificar livremente as estruturas de vizinhança durante a interação, agrupando e separando as instâncias de acordo com seu conhecimento de domínio.

A Figura 5.12(a) apresenta a projeção de uma amostra por agrupamento do conjunto de dados segmentation. As cores indicam a classificação das instâncias. É possível notar que as instâncias de mesma classe não formam grupos compactos, o que seria o desejável nesse exemplo. Com base nessa observação um usuário poderia manipular os dados até obter um novo layout formando esses agrupamentos, como o apresentado na Figura 5.12(b).

Essa informação de manipulação é então usada para transformar o espaço de características das amostras buscando refletir as novas relações de similaridade definidas pela interação do usuário com a projeção. A seguir a técnica para realizar essa transformação é detalhada.

\subsubsection{Force Scheme no Espaço de Características}

Após modificações no "layout" terem sido feitas pelo usuário, as relações de similaridade do espaço de característica das amostras não mais correspondem com as relações de similaridade 


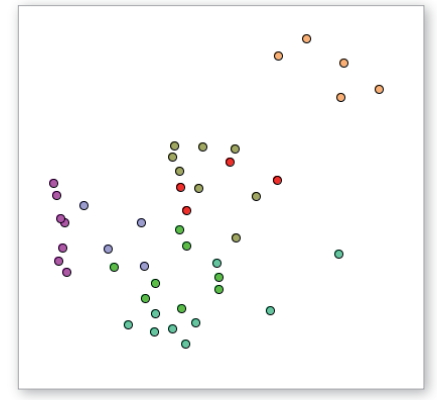

(a) Layout gerado usando-se a técnica Force Scheme.

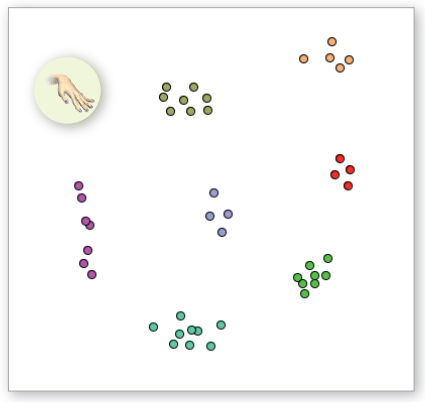

(b) Interação com o layout.

Figura 3.3: Projeção e manipulação da amostra do conjunto de dados segmentation.

da representação visual. De forma a restaurar essa correspondência, necessária para o passo final do nosso processo de transformação dos dados, o espaço de características é iterativamente modificado. Nesse processo buscamos assegurar que os vizinhos no espaço visual sejam também vizinhos no espaço multidimensional e vice-versa. Portanto, a relação de vizinhança criada pelo usuário no espaço visual, deve ser mapeada de volta para o espaço de características, deslocando as amostras $x_{s_{i}}$ para novas posições $\tilde{x}_{s_{i}}$.

Para obter uma nova configuração de $\tilde{x}_{s_{i}}$, inicialmente foi desenvolvido um algoritmo baseado no método de projeção Force Scheme (Tejada et al., 2003a), mas em uma forma inversa, ou seja, operando no espaço multidimensional em vez do espaço visual, razão pela qual denominamos esse como Inverse Force Scheme (IFS). Nessa abordagem para cada instância $x_{S_{i}}$ vetores $\vec{v}$ são criados de $x_{s_{i}}$ para $x_{s_{j}}, i \neq j$, e uma pertubação é aplicada sobre $x_{s_{j}}$ na direção de $\vec{v}$. Essa perturbação é expressada pela equação 3.1 , onde $d_{2}(\cdot, \cdot)$ representa a distância entre pares de elementos gráficos na projeção e $d_{m}(\cdot, \cdot)$ a distância entre pares de instâncias no espaço multidimensional. É possível notar que pares de instâncias multidimensionais cujo $d_{m}(\cdot, \cdot)>d_{2}(\cdot, \cdot)$ serão aproximadas. Caso contrário serão afastadas. A abordagem completa é apresentada o Algoritmo 3.1.

$$
\tilde{x}_{s_{j}}=\tilde{x}_{s_{j}}+\frac{\vec{v}}{\|\vec{v}\|}\left(d_{2}\left(\tilde{y}_{s_{i}}, \tilde{y}_{s_{j}}\right)-d_{m}\left(\tilde{x}_{s_{i}}, \tilde{x}_{s_{j}}\right)\right)
$$

Com essa abordagem os resultados são bem precisos, obedecendo à manipulação feita pelo usuário, isto é, as relações de vizinhança entre instâncias no espaço multidimensional e no espaço visual ao final do processo são praticamente as mesmas (nos testes executados). Porém, apresenta problema de perda de dimensionalidade no conjunto de dados transformado devido às transformações de cada instância levarem em consideração a informação global, já que cada instância é afetada por todas as outras instâncias.

Com intuito de manter as alterações nos dados o mais localmente possível, o algoritmo IFS foi expandido de forma a empregar conceitos originalmente propostos na abordagem de projeção de Chalmers (Chalmers, 1996). Nessa versão expandida, quando uma instância $\tilde{x}_{s_{i}}$ está sendo processada, as pertubações não são aplicadas a todas as amostras em $\tilde{\mathscr{X}}_{s}$, mas só para instâncias 


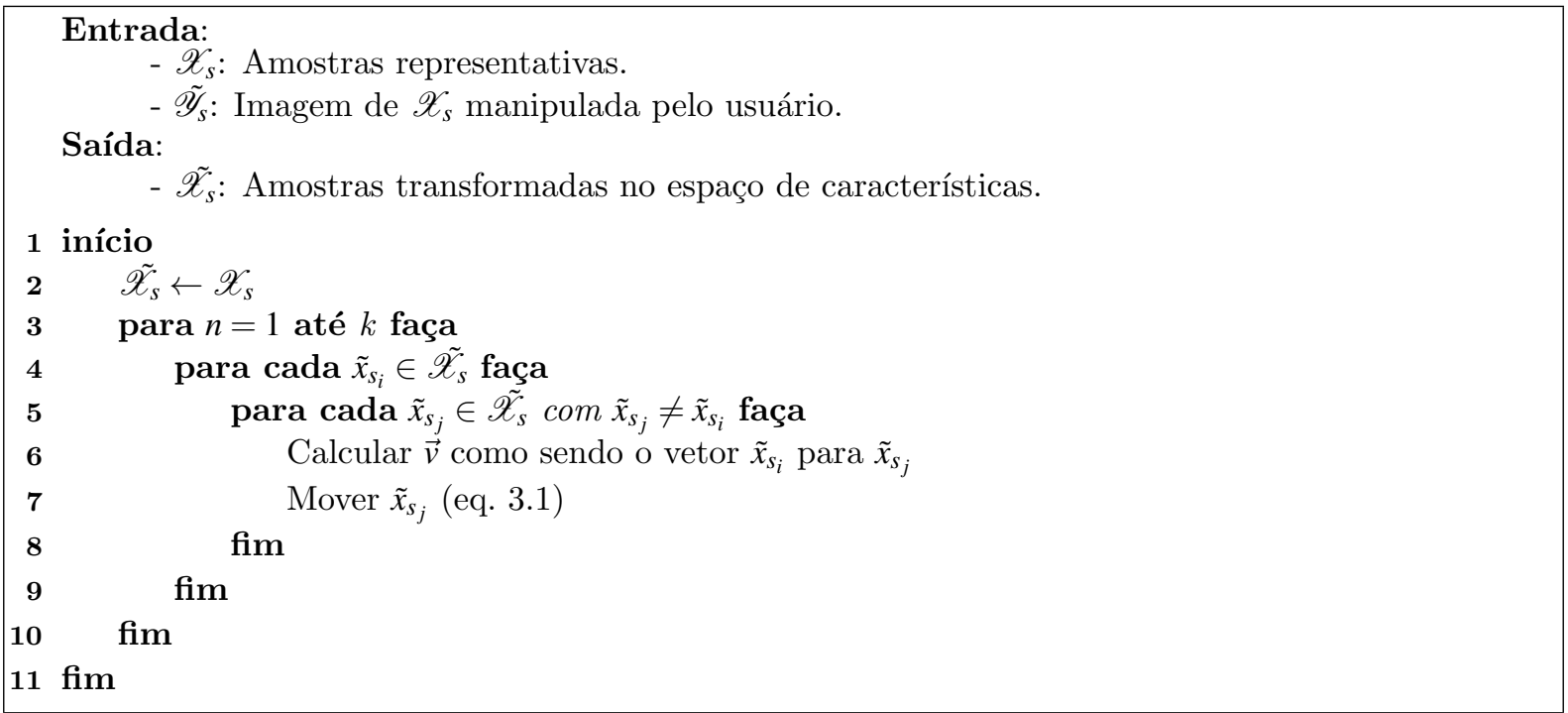

Algoritmo 3.1: Inverse Force Scheme (IFS)

do subconjunto $N_{\tilde{x}_{s_{i}}} \cup R_{\tilde{x}_{s_{i}}}$, onde $N_{\tilde{x}_{s_{i}}}$ contém os $k$-vizinhos mais próximos de $\tilde{x}_{s_{i}}$ e $R_{\tilde{x}_{s_{i}}}$ contém instâncias escolhidas aleatoriamente de $\tilde{X}_{s}$. Tanto $N_{\tilde{x}_{s_{i}}}$ como $R_{\tilde{x}_{s_{i}}}$ têm tamanhos limitados. Nesse trabalho os testes foram executados com $N_{\tilde{x}_{s_{i}}}$ contendo $5 \%$, e $R_{\tilde{x}_{s_{i}}} 20 \%$ de $\tilde{X}_{s}$ (esses parâmetros podem ser mudados se for necessário). Assim, além de tornar o processo mais local, a quantidade de cálculos necessários ao final do processo diminui consideravelmente.

Nessa abordagem as instâncias são movidas iterativamente até o processo convergir. O critério de convergência adotado é expresso pela Equação 3.2, que mede, a grosso modo, a diferença das relações de similaridade no espaço visual e no espaço multidimensional de características. Se a média das diferenças for menor do que um limiar o processo termina.

$$
S\left(\tilde{\mathscr{X}}_{s}, \tilde{\mathscr{Y}}_{s}\right)=\frac{1}{n^{2}} \sum_{i} \sum_{j}\left(d_{2}\left(\tilde{y}_{s_{i}}, \tilde{y}_{s_{j}}\right)-d_{m}\left(\tilde{x}_{s_{i}}, \tilde{x}_{s_{j}}\right)\right)^{2}<\varepsilon
$$

onde $n$ representa o número de instâncias do conjunto de dados e $\varepsilon=10^{-4}$.

Essa abordagem, que denominamos Neighbor-Sample Inverse Force Scheme (NS-IFS), é sumarizada no Algoritmo 3.2.

Com essa abordagem baseada em vizinhanças, a precisão final alcançada foi bem próxima da obtida usando-se o IFS. Contudo, como as modificações são locais, a dimensionalidade intrínseca do espaço transformado é mantida igual ou muito próxima da dimensionalidade intrínseca do espaço original (comparações e análises nesse sentido serão apresentadas no Capítulo 4). Além disso, o processo como um todo converge mais rapidamente, empregando apenas uma fração do tempo necessário para a convergência da IFS.

\subsubsection{Transformação Final do Espaço}

De posse das amostras transformadas $\tilde{\mathscr{X}}_{s}$, ou seja, de uma nova conformação para o espaço de características que as representa, um mapeamento afim $T_{x_{i}}$ é calculado para cada instância $x_{i}$ 


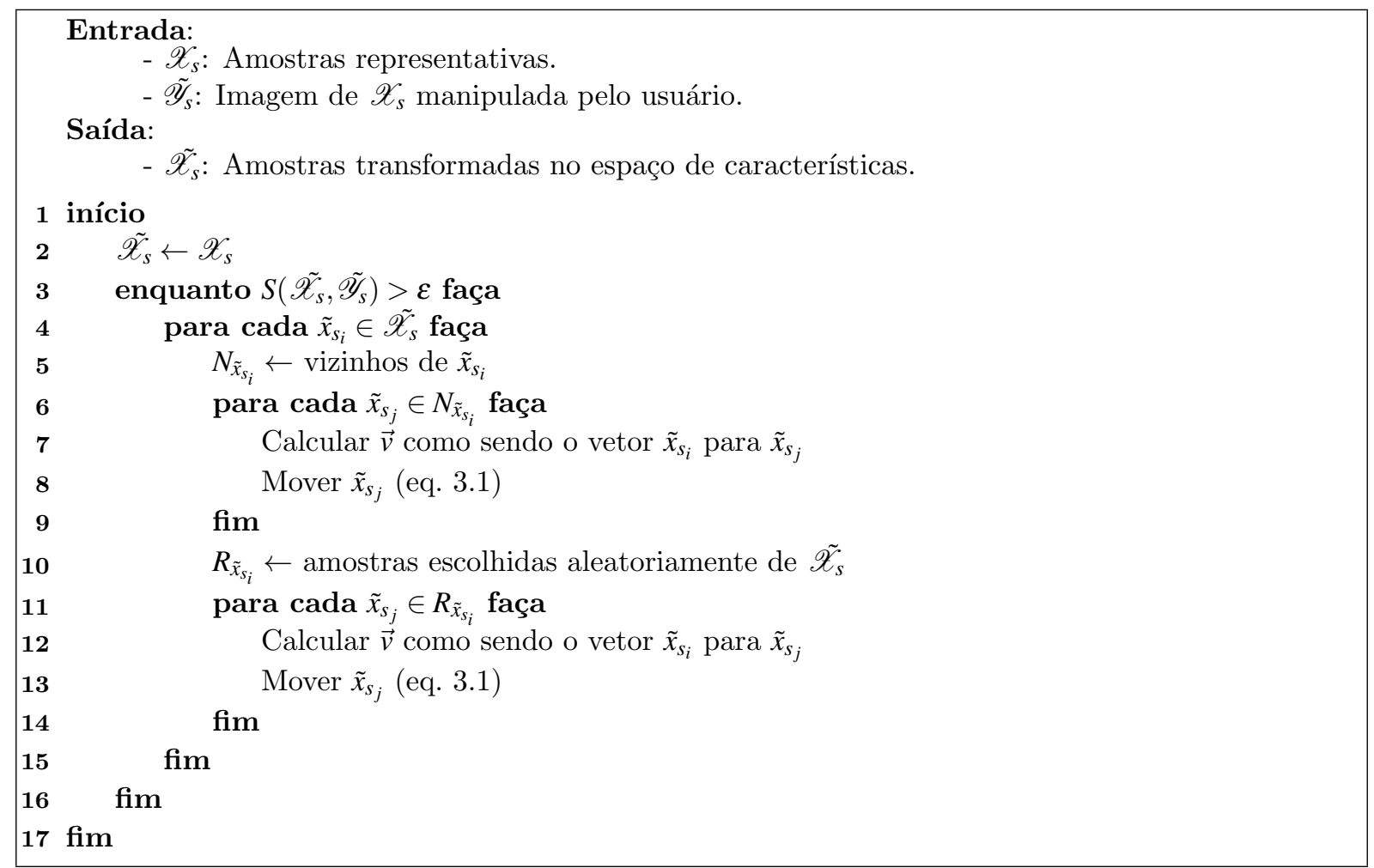

Algoritmo 3.2: Neighbor-Sample Inverse Force Scheme (NS-IFS)

no conjunto de dados para transformar as dimensões de $x_{i}$ de forma a encontrar $\tilde{x}_{i}$ que leve em consideração essa nova conformação. Considerando que essa é calculada usando a IFS ou a NS-IFS, o mapeamento $T_{x_{i}}$ transformará $x_{i}$ levando em consideração as relações de similaridade impostas pelo usuário na manipulação da projeção da amostra, ou seja, seu ponto de vista com relação ao que é semelhante ou diferente.

A transformação afim $T_{x_{i}}(x)=x M+t$ associada a $x_{i}$ é definida para minimizar:

$$
\sum_{x_{s_{j}} \in \tilde{\mathscr{X}}_{s}} \alpha_{j}\left\|T_{x_{i}}\left(x_{s_{j}}\right)-\tilde{x}_{s_{j}}\right\|^{2}, \quad \alpha_{j}=\frac{1}{\left\|x_{s_{j}}-x_{i}\right\|^{2}}
$$

onde a matriz $M m \times m$ e o vetor $t$ são as incógnitas. Assim, $T_{x_{i}}$ deve transformar $x_{i}$ modificando sua posição no espaço multidimensional de forma a refletir o espaço transformado $\tilde{\mathscr{X}}_{s}$.

Após manipulação matemática, a equação 3.3 pode ser expressada em uma forma matricial:

$$
\|D(A M-B)\|_{F}
$$

Onde $\|\cdot\|_{F}$ denota a norma de Frobenius, $D$ é uma matriz diagonal $D_{i i}=\sqrt{\alpha_{i}}, A$ e $B$ são matrizes de $s_{n} \times n$ onde cada $i$-ésima linha é dada pelos vetores $x_{s_{i}}-\frac{\sum_{j} \alpha_{j} x_{s_{j}}}{\sum_{j} \alpha_{j}}$ e $\tilde{x}_{s_{i}}-\frac{\sum_{j} \alpha_{j} \tilde{x}_{s_{j}}}{\sum_{j} \alpha_{j}}$, respectivamente.

A minimização da equação (3.4) pode ser obtida fazendo:

$$
M=\left(A^{\top} D^{2} A\right)^{-1} A^{\top} D^{2} B
$$


Uma vez calculada $M$, a transformação $\tilde{x}_{i}$ de $x_{i}$ é realizada por:

$$
\tilde{x}_{i}=\left(x_{i}-\frac{\sum_{j} \alpha_{j} x_{s_{j}}}{\sum_{j} \alpha_{j}}\right) M+\frac{\sum_{j} \alpha_{j} \tilde{x}_{s_{j}}}{\sum_{j} \alpha_{j}}
$$

O Algoritmo 3.3 resume os principais passos envolvidos para transformar o espaço de características das instâncias.

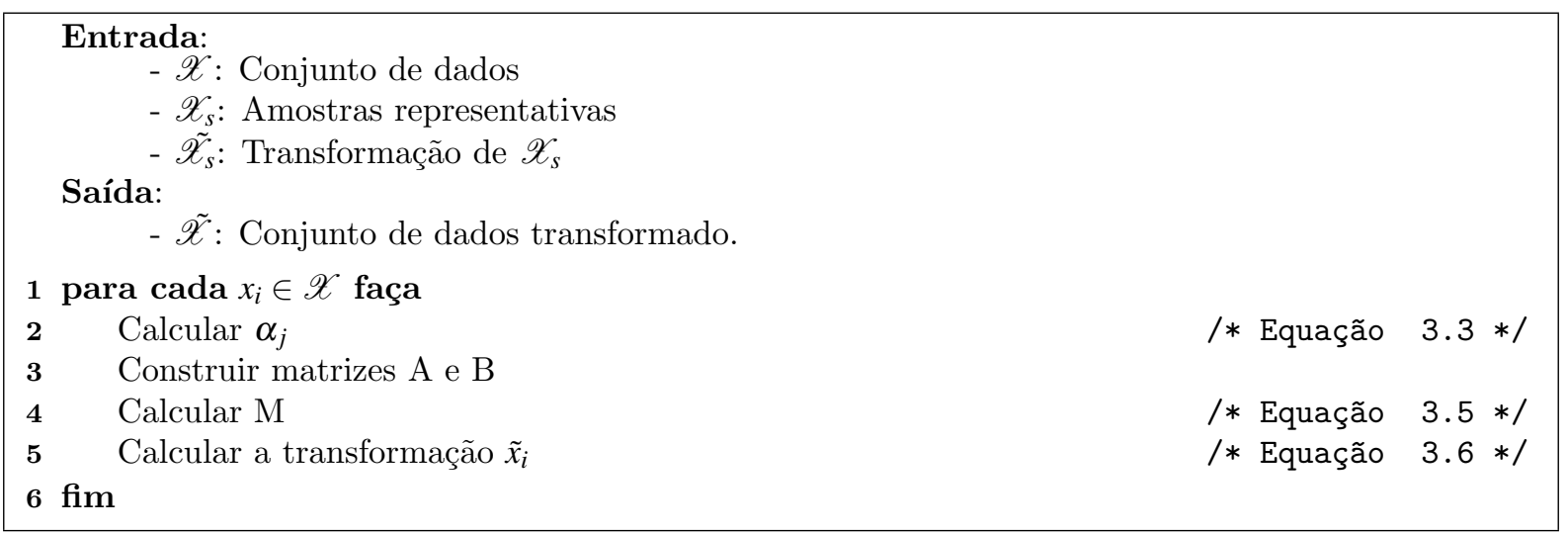

Algoritmo 3.3: Transformação do espaço de características.

\subsection{Considerações Finais}

Neste capítulo foi apresentado uma nova abordagem para a transformação de espaços de características que combina o conceito de projeções multidimensionais com mapeamentos locais a fim de refletir no espaço transformado percepções individuais de usuários em termos das relações de similaridade entre objetos ou instâncias de dados. No próximo capítulo uma avaliação detalhada dessa abordagem é apresentada junto com experimentos que visam mostrar sua capacidade nesse processo. 


\section{Resultados Experimentais}

\subsection{Considerações Iniciais}

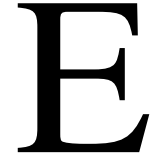

ste capítulo apresenta resultados experimentais a fim de validar o método proposto e definido no Capítulo 3. O método proposto é avaliado por meio de índices de silhueta e acurácias com intuito de verificar como as modificações realizados pelo usuário sobre uma projeção são propagadas para o espaço de características que define um conjunto de dados. A seção a seguir descreve os conjuntos de dados utilizados nesses experimentos.

\subsection{Conjuntos de Dados}

Os experimentos foram realizados utilizando oito conjuntos de dados com diferentes características: Iris, WDBC, diabetes, segmentation, shuttle obtidos do repositório UCI (Asuncion e Newman, 2007), us-counties $^{1}$ e finalmente fibers que foi obtido do 2009 Pittsburgh Brain Competition $(P B C)$ - Brain Connectivity Challenge ${ }^{2}$. Para efeito de medição de tempo, os testes foram executados em um computador Intel ${ }^{\circledR}$ Core $^{\mathrm{TM}} 2$ Quad Processor Q9650 9.0 GHz.

As principais características desses conjuntos são listadas a seguir.

- Iris: Contém dados sobre o comprimento da sépala, largura da sépala, comprimento da pétala e largura da pétala de 150 flores de iris de três diferentes espécies;

\footnotetext{
${ }^{1}$ http://www.cs.umd.edu/hcil/hce/examples/application_examples.html

${ }^{2}$ http://pbc.lrdc.pitt.edu/
} 
- WDBC: Wisconsin Diagnostic Breast Cancer é um conjunto de dados relacionados ao câncer de mama. O conjunto de dados foi obtido a partir de imagens digitalizadas de nódulos mamários. Diferenciando-se em dois grupos distintos, o câncer maligno e benigno;

- Diabetes: Composto por instâncias representativas de mulheres portadoras de diabetes positivo ou negativo;

- Segmentation: As instâncias foram obtidas aleatoriamente a partir de pixels de 7 diferentes imagens de exteriores. As imagens foram segmentadas para criar uma classificação manusl de cada pixel;

- US-counties: Contém informação de censo da população de municípios americanos a cada dez anos entre 1900 e 1990;

- Spam: Compreende dados extraídos de e-mails classificados como spam e non-spam;

- Fibers: Contém informações de fibras cerebrais, classificadas em 8 classes diferentes;

- Shuttle: Compreende registros da posição de radiadores no interior de uma nave espacial.

A Tabela 4.1 resume as informações dos conjuntos contendo o número de instâncias, número de dimensões originais, número de classes, dimensionalidade intrínseca e o índice de silhueta de cada conjunto de dados. A dimensionalidade intrínseca é calculada usando-se o método Maximun Likelihood Estimation (Levina e Bickel, 2005), porque é uma técnica precisa quando grandes conjuntos dados são usados (Xia et al., 2006). Outros métodos foram testados, mas esse se mostrou o mais adequado aos propósitos desse trabalho. O índice da silhueta (Kaufman e Rousseeuw, 1990) mede a qualidade de um agrupamento, ou seja, o grau de coesão dos dados pertencentes ao mesmo grupo e o grau de separação entre os diferentes grupos. A coesão $a_{x}$ de uma instância $x$ é calculada pela média das distâncias entre $x$ e todas as outras instâncias pertencentes ao mesmo grupo. A separação $b_{x}$ é a distância mínima entre $x$ e todas outras instâncias de outros grupos. O índice da silhueta de um conjunto de dado é definido por:

$$
\frac{1}{n} \sum_{x \in \mathscr{X}} \frac{\left(b_{x}-a_{x}\right)}{\max \left(a_{x}, b_{x}\right)}
$$

O índice de silhueta pode variar entre $[-1,1]$, quanto maior é o valor obtido pela silhueta, melhor é a coesão e separação entre os grupos (Tan et al., 2005). Será usado o índice da silhueta para quantificar a eficácia da nossa abordagem, com o intuito de melhorar a coesão e separação entre os grupos, após da transformação do espaço multidimensional.

A seguir são apresentados os resultados obtidos da abordagem proposta.

\subsection{Análise dos Resultados}

Nesta seção, são descritos os resultados obtidos na avaliação experimental, com o objetivo de demostrar a eficacia da abordagem proposta. Começamos pela análise da projeção inversa. 
Tabela 4.1: Informações sobre os conjunto de dados utilizados nos experimentos desse capítulo.

\begin{tabular}{l|l|l|l|l|l}
$\begin{array}{l}\text { Conjunto } \\
\text { de dados }\end{array}$ & Instâncias & Dimensões & Classes & $\begin{array}{l}\text { Dimen. } \\
\text { Intrínseca }\end{array}$ & Silhueta \\
\hline \hline iris & 150 & 4 & 3 & 2.6229 & 0.5130 \\
wdbc & 569 & 30 & 2 & 8.2564 & 0.2965 \\
diabetes & 768 & 8 & 2 & 5.8312 & 0.0963 \\
segmentation & 2,100 & 18 & 7 & 4.3591 & 0.2409 \\
us-counties & 3,028 & 14 & 3 & 7.1655 & 0.0260 \\
spam & 4,601 & 57 & 2 & 11.4473 & 0.0445 \\
fibers & 19,029 & 40 & 8 & 3.5347 & 0.3953 \\
shuttle & 43,500 & 9 & 7 & 3.1246 & 0.2878
\end{tabular}

\subsubsection{Análise da Projeção Inversa}

A fim de verificar a eficácia do método de projeção inversa definido no Capítulo 3, os dados são inicialmente projetados usando-se a Force Scheme (Tejada et al., 2003b). Depois o layout gerado é manipulado pelo usuário e essa informação é usada para alterar os espaços de características a fim de modificá-los para que as relações de similaridade no espaço multidimensional sejam as mesmas das projeções manipuladas. As Figuras 4.1 e 4.2 apresentam os resultados obtidos com os conjuntos de dados analisados. A primeira coluna apresenta a projeção inicial produzida pela Force Scheme. É possível perceber que as instâncias não são separáveis de acordo com as classes definidas. A segunda coluna apresenta as projeções manipuladas manualmente a fim de separar essas classes. Com base nessa projeção o algoritmo IFS (ver Seção 3.2.3) (com $k=6$ ) é aplicado, assim um novo conjunto de dados é produzido. A terceira coluna apresenta a projeção desse novo conjunto de dados. A quarta coluna apresenta a projeção do conjunto de dados transformado com o algoritmo NS-IFS (ver Seção 3.2.3).

É possível notar que nas novas projeções, usando-se os conjuntos transformados, os grupos são separáveis conforme o estabelecido pelo usuário, tanto usando-se a IFS e a N-IFS. No entanto, o novo conjunto de dados apresentou perda de dimensionalidade mais acentuada para a IFS. Na N-IFS essa perda é bastante reduzida. A Tabela 4.2 contém a comparação dos cálculos da dimensionalidade intrínseca, silhueta, stress dos conjuntos de dados analisados. A segunda coluna mostra a dimensionalidade do conjunto de dados original. A terceira e quarta coluna apresentam a dimensionalidade dos conjuntos de dados transformados com o algoritmo IFS e NS-IFS, respetivamente. A quinta, sexta e sétima apresentam a silhueta do conjunto original, e os transformados com o algoritmo IFS e NS-IFS respetivamente. As duas últimas colunas apresentam o stress comparando com a projeção modificada e os resultados da IFS e da N-IFS respetivamente.

Os resultados obtidos são bastante animadores, mostrando que a N-IFS consegue transformar o espaço de características de forma a seguir o que foi definido manualmente pelo usuário na projeção, com perda mínima da dimensionalidade intrínseca dos dados. Isto é, os dados não são "achatados" em um plano bi-dimensional quando a N-IFS é aplicada. Cabe ressaltar que essa 
Tabela 4.2: Dimensionalidade intrínseca, silhueta, stress para conjunto de dados original e transformado.

\begin{tabular}{l|l|l|l|l|l|l|l|l}
$\begin{array}{l}\text { Conjunto } \\
\text { de dados }\end{array}$ & $\begin{array}{l}\text { Dim. } \\
\text { original }\end{array}$ & $\begin{array}{l}\text { Dim. } \\
\text { IFS }\end{array}$ & $\begin{array}{l}\text { Dim. } \\
\text { NS-IFS }\end{array}$ & $\begin{array}{l}\text { Silhueta } \\
\text { original }\end{array}$ & $\begin{array}{l}\text { Silhueta } \\
\text { IFS }\end{array}$ & $\begin{array}{l}\text { Silhueta } \\
\text { NS-IFS }\end{array}$ & $\begin{array}{l}\text { Stress } \\
\text { IFS }\end{array}$ & $\begin{array}{l}\text { Stress } \\
\text { NS-IFS }\end{array}$ \\
\hline \hline iris & 2.6229 & 1.867 & 2.0075 & 0.5130 & 0.8563 & 0.8516 & $1.111 \times 10^{-6}$ & $3.395 \times 10^{-4}$ \\
wdbc & 8.2564 & 2.2986 & 7.2524 & 0.2965 & 0.4920 & 0.4901 & $2.032 \times 10^{-4}$ & 0.002300876 \\
diabetes & 5.8312 & 1.7234 & 4.0573 & 0.0963 & 0.8879 & 0.8843 & $2.831 \times 10^{-6}$ & 0.0012506256 \\
segmentation & 4.3591 & 2.6193 & 4.3484 & 0.2409 & 0.9100 & 0.9081 & $3.841 \times 10^{-7}$ & $1.628 \times 10^{-4}$ \\
us-counties & 7.1655 & 2.7678 & 6.0745 & 0.0260 & 0.9427 & 0.9406 & $9.349 \times 10^{-8}$ & $2.904 \times 10^{-4}$ \\
spam & 11.4473 & 2.9077 & 9.573 & 0.0445 & 0.3553 & 0.3544 & $4.676 \times 10^{-5}$ & 0.00463954 \\
fibers & 3.5347 & 4.0972 & 4.1316 & 0.3953 & 0.9753 & 0.9751 & $2.438 \times 10^{-8}$ & $5.186 \times 10^{-5}$ \\
shuttle & 3.1246 & 1.3896 & 4.5937 & 0.2878 & 0.9745 & 0.9704 & $4.624 \times 10^{-9}$ & $2.186 \times 10^{-5}$
\end{tabular}

dimensionalidade pode cair se mais iterações da N-IFS forem realizadas. Aqui todos os testes foram feitos considerando o critério de parada da Equação 3.2.

Apesar da qualidade desses resultados, alterar todos os dados manualmente para se transformar o espaço de características não faz muito sentido, além de ser um processo muito caro e exaustivo para o usuário. Assim, nossa abordagem de transformação do espaço multidimensional se baseia em amostras para essa transformação de forma que a intervenção do usuário ocorra apenas sobre um montante limitado de instâncias. A seguir resultados quantitativos e qualitativos dessa abordagem para transformação baseada em amostras são apresentados, bem como uma análise de como o processo de amostragem influencia nesses resultados.

\subsubsection{Análise da Transformação do Espaço de Características}

Iniciamos o estudo da abordagem proposta analisando o resultado da sua aplicação sobre os diferentes conjuntos de dados anteriormente listados. Nesses resultados, o usuário manipula a projeção da amostra a fim de agrupar instâncias de dados que pertençam a mesma classe. As Figuras 4.3 e 4.4 ilustram os resultados obtidos. A primeira linha de imagens apresenta a projeção da amostra. O número de amostras escolhidas foi de $\sqrt{n}$ ( $n$ é o total de instâncias no conjunto de dados), elas são selecionadas empregando-se o esquema de agrupamento, e são mapeadas ao espaço visual usando-se a técnica de projeção multidimensional Force Scheme. A segunda linha mostra a projeção de todo o conjunto de dados empregando a técnica de projeção LAMP (Joia et al., 2011). A terceira linha mostra o layout das amostras após a interação do usuário, percebe-se que as amostras que pertencem à mesma classe são agrupadas pelo usuário, resultando em uma melhor definição dos agrupamentos no espaço visual. Por fim, a quarta linha mostra o resultado da projeção usando-se LAMP para o conjunto de dados transformado usando a abordagem proposta. Observe que nessa projeção é possível distinguir os grupos depois da transformação.

A fim de mostrar que o bom resultado da transformação, agrupando e separando as instâncias de acordo com a manipulação do usuário, não é uma consequência das propriedades do LAMP, o conjunto de dados transformado também é projetado utilizando a técnica Classical Scaling. As projeções obtidas são apresentadas na última linha das Figuras 4.3 e 4.4. Pode-se observar que os grupos formados manualmente pelo usuário na projeção da amostra são distinguíveis na 
projeção final, mostrando assim que as instâncias são realmente agrupadas de acordo com a intervenção do usuário no espaço de características após a transformação.

A Tabela 4.3 fornece dados quantitativos sobre a eficácia da abordagem proposta. Os resultados obtidos anteriormente são analisados usando-se o coeficiente de silhueta a fim de verificar se o grau de coesão e separação do grupos aumentou e de quanto foi esse aumento. Na tabela, a segunda coluna mostra o número de amostras escolhidas de cada conjunto de dados. As próximas colunas apresentam a dimensionalidade intrínseca e os índices de silhueta dos dados transformados. Validando os resultados visuais, é possível observar aumento significativo nos valores silhueta dos conjuntos de dados transformados. Valores de silhueta usando outros processos de amostragem também são listados para efeito de comparação.

Tabela 4.3: Análise quantitativa usando o coeficiente de silhueta dos resultados das transformações dos espaços de características. Foram usadas $\sqrt{n}$ amostras. É possível notar aumento significativo na coesão e separação nas classes dos dados no espaço transformado.

\begin{tabular}{l|l|l|l|l|l|l}
$\begin{array}{l}\text { Conjunto } \\
\text { de dados }\end{array}$ & $\begin{array}{l}\text { Núm. } \\
\text { amostra }\end{array}$ & $\begin{array}{l}\text { Dim. } \\
\text { intrínseca }\end{array}$ & $\begin{array}{l}\text { Silhueta } \\
\text { original }\end{array}$ & $\begin{array}{l}\text { Silhueta } \\
\text { clustering }\end{array}$ & $\begin{array}{l}\text { Silhueta } \\
\text { random }\end{array}$ & $\begin{array}{l}\text { Silhueta } \\
\text { maxMin }\end{array}$ \\
\hline \hline iris & 12 & 3.4539 & 0.5130 & 0.7562 & 0.6380 & 0.6231 \\
wdbc & 30 & 8.2421 & 0.2965 & 0.6899 & 0.6267 & 0.4410 \\
diabetes & 25 & 5.7956 & 0.0963 & 0.1503 & 0.1506 & 0.1461 \\
segmentation & 45 & 6.3015 & 0.2409 & 0.4755 & 0.3768 & 0.2472 \\
us-counties & 55 & 10.5118 & 0.0260 & 0.1175 & 0.0463 & 0.0555 \\
spam & 67 & 8.6807 & 0.0445 & 0.4118 & 0.3665 & 0.0626 \\
fibers & 137 & 13.7368 & 0.3953 & 0.7813 & 0.7537 & 0.6369 \\
shuttle & 208 & 2.7970 & 0.2878 & 0.8208 & 0.7074 & 0.8752
\end{tabular}

Pela Tabela 4.3 é possível observar que a dimensionalidade intrínseca dos dados também mudou devido à transformação do espaço de características. Esta mudança é esperada, já que, algum espaço é necessário para separar as classes fortemente ligadas (tendendo a aumentar a dimensionalidade), também um efeito snugging(aproximação) é propenso a acontecer quando instâncias da mesma classe são aproximadas pela transformação do espaço de características (tendendo a reduzir a dimensionalidade). Porém, essa não variou consideravelmente, o que indica que características multidimensionais foram preservadas.

Embora a maioria dos resultados sejam animadores, apresentando melhoria significativa na separação e coesão, nos conjuntos diabetes, us-counties, spam a separação dos grupos ainda não é evidente. Isto é, instâncias de diferentes classes permanecem próximas umas das outras, mesmo que as amostras sejam bem separadas pelo usuário. Esse efeito precisa ser melhor entendido, mas uma das razões é a pouca representatividade das amostras o que leva a um baixo controle do usuário no processo de manipulação dos dados.

Uma solução simples para esse problema é aumentar o número de amostras com a esperança de selecionar melhor as amostras, que representem melhor a distribuição ou os grupos presentes. Embora esta estratégia exija uma maior interação do usuário, os resultados obtidos melhoram consideravelmente. A Tabela 4.4 apresenta o resultado da dimensionalidade intrínseca e os índices da silhueta dos conjuntos de dados transformados quando o número de amostras é 
incrementada em 5 vezes $(5 \times \sqrt{n})$. Observe que os índices da silhueta aumentam consideravelmente, melhorando a separação visual de classes. A Figura 4.5 apresenta as projeções resultantes usando a LAMP e a Classical Scaling dos conjuntos de dados transformados. É também possível notar visualmente a melhoria na separação dos grupos.

Tabela 4.4: Análise quantitativa usando o coeficiente de silhueta dos resultados das transformações dos espaços de características. Com o aumento do tamanho da amostra $(5 \times \sqrt{n})$, os resultados de coesão e separação também aumentam significativamente.

\begin{tabular}{l|l|l|l|l|l}
$\begin{array}{l}\text { Conjunto } \\
\text { de dados }\end{array}$ & $\begin{array}{l}\text { Núm. } \\
\text { amostra }\end{array}$ & $\begin{array}{l}\text { Dim. } \\
\text { intrínseca }\end{array}$ & $\begin{array}{l}\text { Silhueta } \\
\text { clustering }\end{array}$ & $\begin{array}{l}\text { Silhueta } \\
\text { random }\end{array}$ & $\begin{array}{l}\text { Silhueta } \\
\text { maxMin }\end{array}$ \\
\hline \hline iris & 60 & 3.7538 & 0.8368 & 0.8272 & 0.8418 \\
wdbc & 115 & 8.7836 & 0.7276 & 0.7139 & 0.6936 \\
diabetes & 135 & 5.9152 & 0.2851 & 0.2560 & 0.2911 \\
segmentation & 225 & 4.9536 & 0.6101 & 0.5489 & 0.4868 \\
us-counties & 275 & 9.5382 & 0.1979 & 0.1591 & 0.1053 \\
spam & 335 & 9.7489 & 0.5063 & 0.4481 & 0.4222 \\
fibers & 685 & 10.4649 & 0.8336 & 0.8066 & 0.7486 \\
shuttle & 1040 & 3.0522 & 0.9476 & 0.9132 & 0.9433
\end{tabular}

Com esses resultados é possível notar que a amostragem inicial tem papel central na qualidade das transformações produzidas. A seguir apresentamos um estudo a fim de definir as diferenças quantitativas entre métodos de amostragem e como o tamanho da amostra influencia no resultado final.

\subsubsection{Análise da Amostragem}

Idealmente a amostra deve ser selecionada de forma a representar o melhor possível a distribuição dos dados no espaço multidimensional. Como esse é um processo complexo de ser realizado, empregamos três diferentes heurísticas (veja Seção 3.2.1), amostragem aleatória, por agrupamento ou MaxMin. Neste trabalho optamos por empregar um tamanho de amostra de $\sqrt{n}$, com $n$ sendo o número de instâncias no conjunto de dados, porque é uma heurística frequentemente empregada em algoritmos de agrupamento para definir o limite superior de agrupamentos que podem existir em um conjunto de dados (Pal e Bezdek, 1995). Nas abordagens de Chalmers (1996.), Paulovich et al. (2010), Paulovich et al. (2011a) foram usados esse tamanho de amostragem apresentando bons resultados. Embora estejamos usando $\sqrt{n}$ como padrão para definir o tamanho de amostras representativas, os experimentos mostraram que esse tamanho pode ser bem menor se poucos grupos estão presentes nos dados.

Assim, começamos a análise da abordagem para transformação do espaço de características verificando o efeito do método de amostragem e tamanho das amostras no processo como um todo.

A Figura 4.6 apresenta a análise das silhuetas para os conjuntos de dados transformados pelo processo completo. Para cada conjunto são apresentados os valores de silhueta para as amostras transformadas usando-se a N-IFS (amostragem aleatória, por agrupamento e maxMin), e para 
as transformações completas usando-se essas amostras. Foram usadas amostras variando-se o tamanho de $\sqrt{n}$ até $\sqrt{n} \times 7$. A manipulação das projeções foi feita de forma a compor grupos com base nas classes existentes nos dados. É possível notar que os melhores resultados em termos de separação e coesão dos grupos formados pelo usuário (maior silhueta) foram alcançados quando a amostra foi produzida empregando métodos de agrupamento. Em alguns casos o segundo melhor tipo de amostragem foi a amostragem aleatória e em outros MaxMin. Portanto não sendo possível definir qual dos dois métodos é superior.

Também é possível notar pela Figura 4.6 que conforme o tamanho da amostra cresce, a transformação final melhora em termos do coeficiente de silhueta. Porém, a variação não é muito significativa para na maioria dos resultados. Isso indica que com amostras pequenas $(\sqrt{n})$ é possível controlar bem as modificações no espaço multidimensional de forma a conseguir definir espaços de características que se moldem bem as relações definidas pelo usuário na projeção modificada.

Adicionalmente às análises baseadas no coeficiente de silhueta, técnicas de classificação foram empregadas para verificar se melhores resultados podem ser obtidos nesse tipo de tarefa também. Foram calculadas as acurácias dos conjuntos de dados originais e transformados, usando-se o classificador Support Vector Machines (SVM) com o algoritmo Sequential Minimun Optimization (SMO) (Platt, 1999) e o classificador Naive Bayes (John e Langley, 1995). A Tabela 4.5 mostra os resultados das acurácias dos conjuntos de dados processados com esses dois classificadores. As acurácias do conjunto de dados transformado é maior do que o original usando o classificador Naive Bayes com uma amostra de $\sqrt{n}$ instâncias. Aumentado o número de amostras para $5 \times \sqrt{n}$ e $7 \times \sqrt{n}$ as acurácias dos conjuntos transformados é maior, comparado com os conjuntos de dados originais com ambos classificadores.

O mesmo efeito observado com o coeficiente de silhueta em se obter melhor resultados aumentando-se as amostras usadas pode ser observado aqui. Porém, isso implica uma maior interação do usuário na definição dos grupos. Além disso, caso o resultado visual da projeção da amostra seja ruim, quer dizer, que os grupos não se percebem bem, o usuário terá que realizar varias manipulações. O que não é desejável para aplicações interativas.

Tabela 4.5: Acurácias do conjunto de dados original e transformado.

\begin{tabular}{|c|c|c|c|c|c|c|c|c|}
\cline { 2 - 9 } \multicolumn{1}{c|}{} & \multicolumn{4}{c|}{ SVM } & \multicolumn{3}{c|}{ Naive Bayes } \\
\hline $\begin{array}{c}\text { Conjunto } \\
\text { de dados }\end{array}$ & original & $\begin{array}{c}\text { Transf. } \\
\sqrt{n}\end{array}$ & $\begin{array}{c}\text { Transf. } \\
5 \times \sqrt{n}\end{array}$ & $\begin{array}{c}\text { Transf. } \\
7 \times \sqrt{n}\end{array}$ & original & $\begin{array}{c}\text { Transf. } \\
\sqrt{n}\end{array}$ & $\begin{array}{c}\text { Transf. } \\
5 \times \sqrt{n}\end{array}$ & $\begin{array}{c}\text { Transf. } \\
7 \times \sqrt{n}\end{array}$ \\
\hline iris & 96 & 95.3333 & 99.3333 & 100 & 96 & 96.2589 & 99.3333 & 100 \\
\hline wdbc & 97.3638 & 95.4306 & 96.6608 & 97.5395 & 92.9701 & 95.4306 & 96.3093 & 97.3638 \\
\hline diabetes & 76.8229 & 69.2708 & 79.8177 & 84.1146 & 75 & 75.9219 & 79.8177 & 84.1146 \\
\hline segmentation & 92.8095 & 88.7619 & 94.5238 & 97.3333 & 79.9524 & 85.5714 & 93.0952 & 96.3333 \\
\hline us-counties & 69.716 & 62.7477 & 69.1546 & 73.8771 & 60.3369 & 62.7477 & 68.0978 & 73.8771 \\
\hline spam & 90.4151 & 82.2647 & 88.8068 & 92.2408 & 79.2871 & 82.243 & 88.7633 & 91.0237 \\
\hline fibers & 99.9159 & 99.9947 & 100 & 100 & 99.1224 & 99.7583 & 100 & 100 \\
\hline shuttle & 96.8253 & 98.9218 & 99.5218 & 99.7402 & 90.6276 & 97.9425 & 99.331 & 99.5655 \\
\hline
\end{tabular}




\subsection{Considerações Finais}

Este capítulo apresentou os experimentos realizados para avaliar os diferentes aspectos da abordagem proposta para transformação de espaços de características. Os experimentos mostraram que projeções de amostras podem ser usadas como um guia na melhoria de conjunto de dados multidimensionais. O ponto principal é que esta abordagem permite que o usuário interfira nas relações de similaridade existentes por meio da manipulação dessas projeções, embutindo no conjunto de dados como um todo seu ponto de vista do que é semelhante e do que é diferente.

Um aspecto que deve ser considerado é o tamanho da amostra, pois apesar de amostras maiores definirem melhores resultados em termos da coesão e separação dos grupos criados pelo usuário, quanto maior uma amostra mais interações serão necessárias por parte do usuário. Portanto, um balanço entre qualidade e tamanho de amostra deve ser levado em consideração na aplicação da abordagem proposta. 


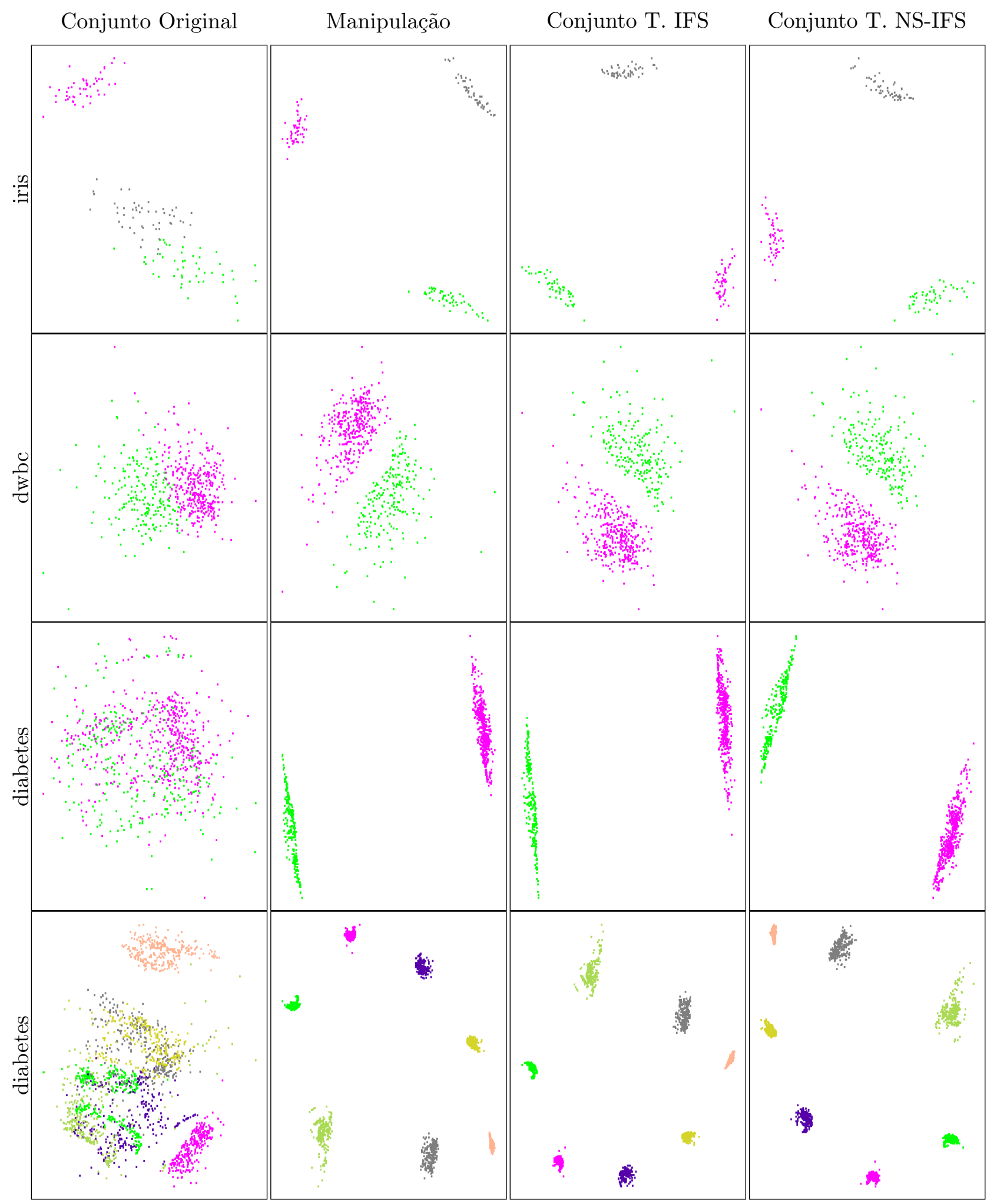

Figura 4.1: Resultado da aplicação do IFS e NS-IFS sobre diferentes conjuntos de dados. Primeira coluna: Layout gerado usando-se a técnica Force Scheme para o conjunto de dados. Segunda coluna: manipulação feita pelo usuário no layout original. Terceira Coluna: layout gerado usando a técnica Force Scheme para o conjunto de dados transformado pelo IFS. Quarta Coluna: Layout gerado usando a técnica Force Scheme para o conjunto de dados transformado pelo NS-IFS 


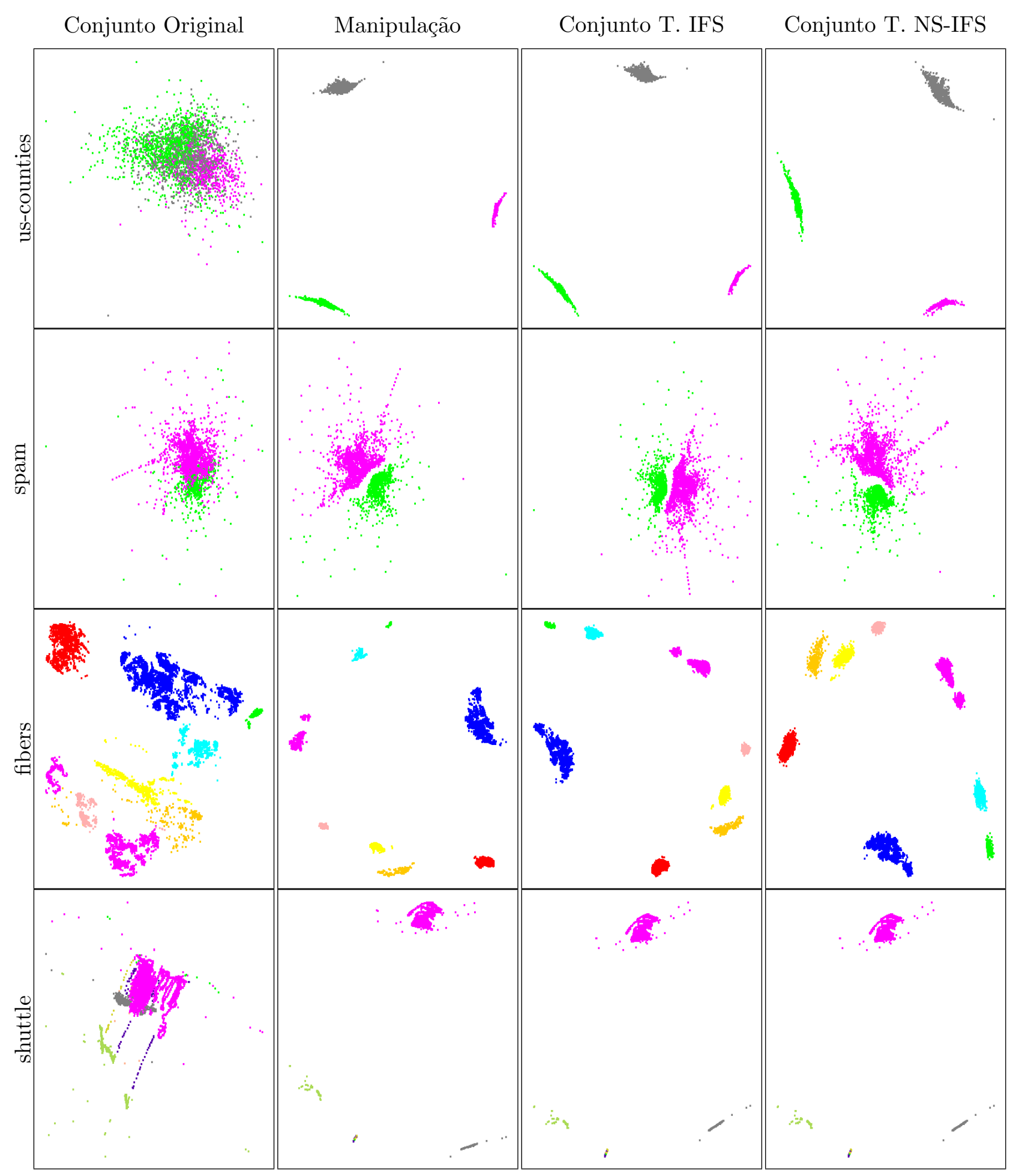

Figura 4.2: Resultado da aplicação do IFS e NS-IFS sobre diferentes conjuntos de dados. Primeira coluna: Layout gerado usando-se a técnica Force Scheme para o conjunto de dados. Segunda coluna: manipulação feita pelo usuário no layout original. Terceira Coluna: layout gerado usando a técnica Force Scheme para o conjunto de dados transformado pelo IFS. Quarta Coluna: Layout gerado usando a técnica Force Scheme para o conjunto de dados transformado pelo NS-IFS 


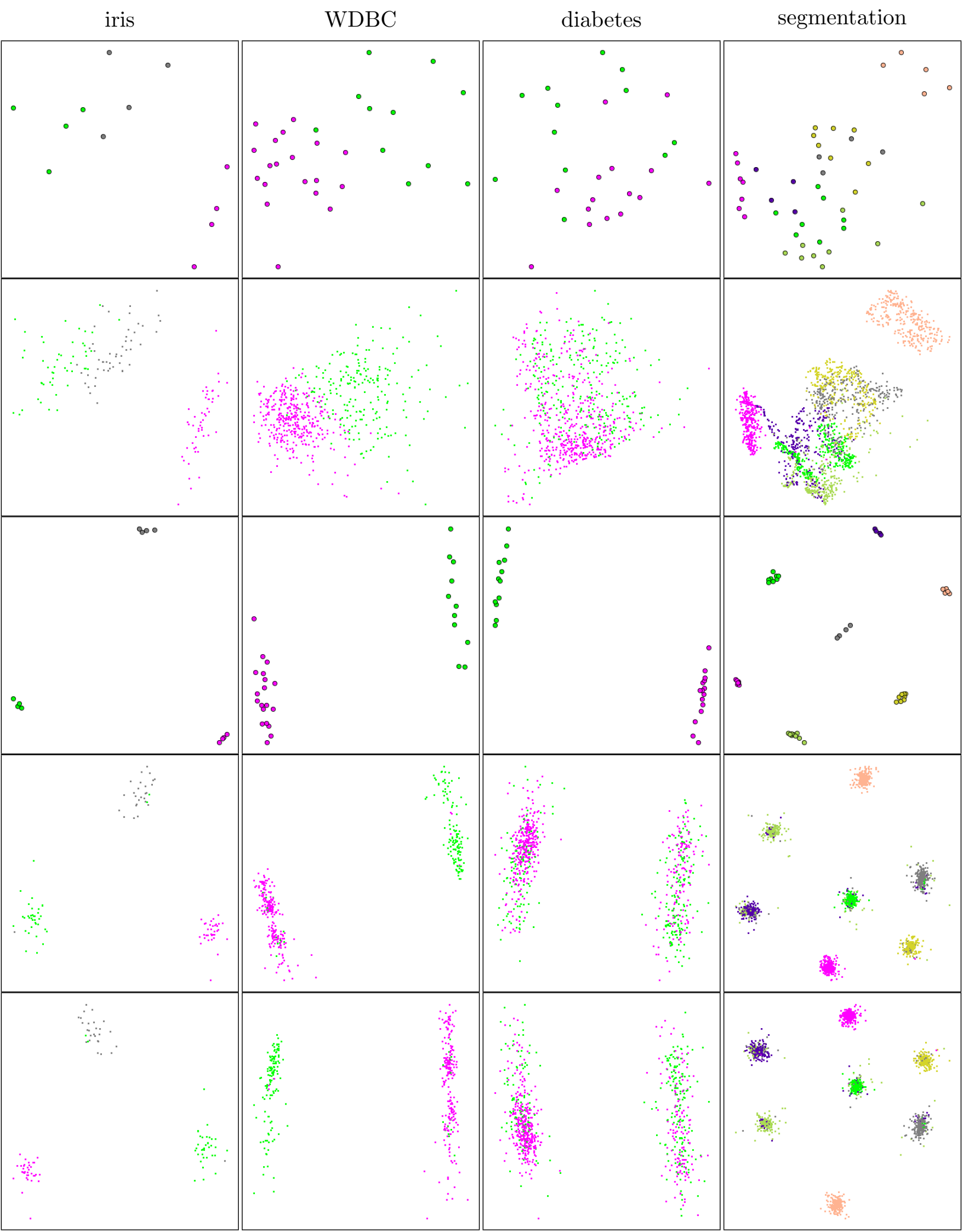

Figura 4.3: Resultado da aplicação da nossa abordagem sobre diferentes conjunto de dados. Primeira linha: projeção das amostras escolhidas de cada conjunto de dados. Segunda linha: projeção usando $L A M P$ para o conjunto de dados original. Terceira linha: manipulação feita pelo usuário sobre a amostra. Quarta linha: projeção usando LAMP do conjunto de dados transformado. Quinta linha: projeção usando a Classical Scaling para o conjunto de dados transformado. 
us-counties

spam

fibers

shuttle

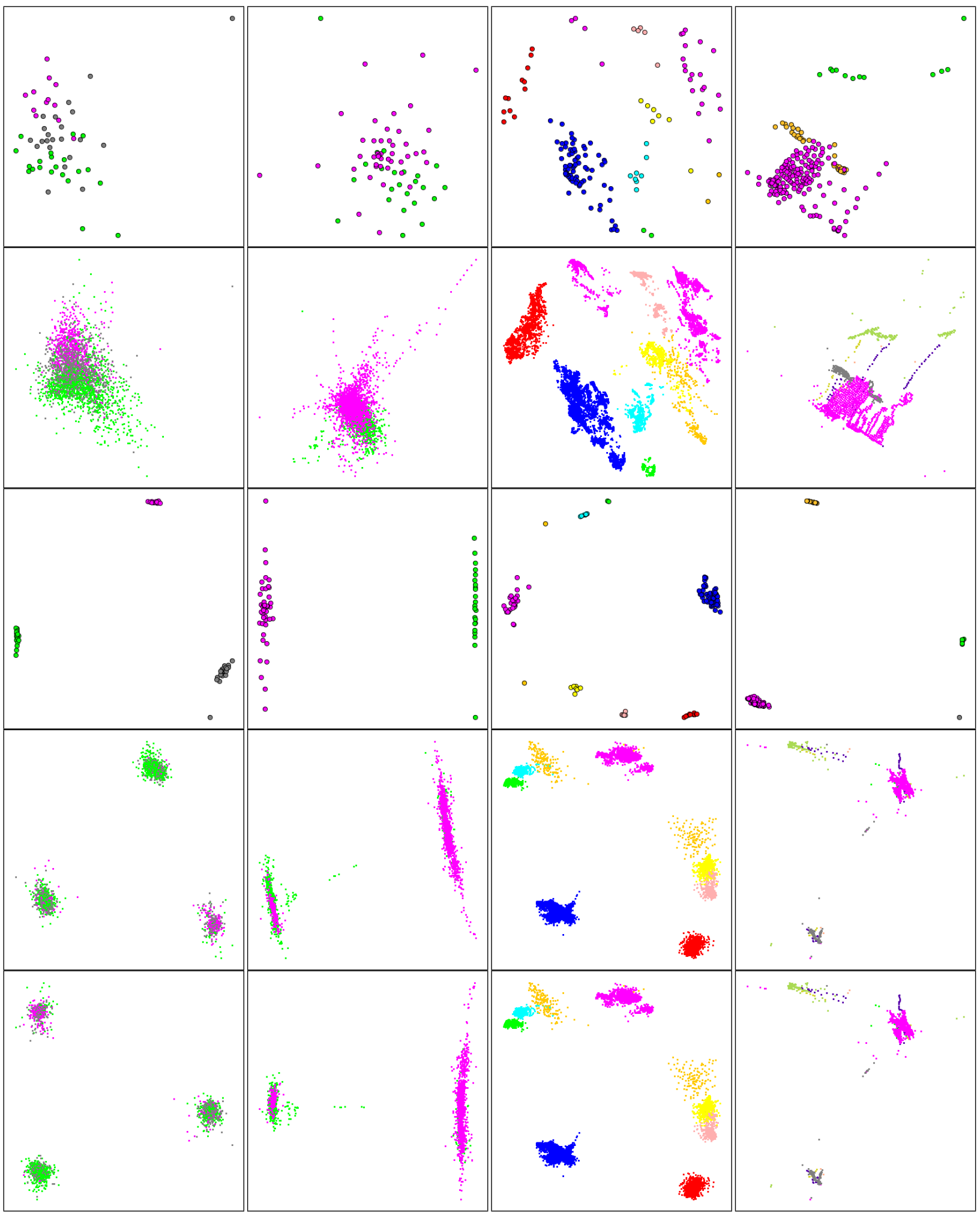

Figura 4.4: Resultado da aplicação da nossa abordagem sobre diferentes conjunto de dados. Primeira linha: projeção das amostras escolhidas de cada conjunto de dados. Segunda linha: projeção usando LAMP para o conjunto de dados original. Terceira linha: manipulação feita pelo usuário sobre a amostra. Quarta linha: projeção usando LAMP do conjunto de dados transformado. Quinta linha: projeção usando a Classical Scaling para o conjunto de dados transformado. 


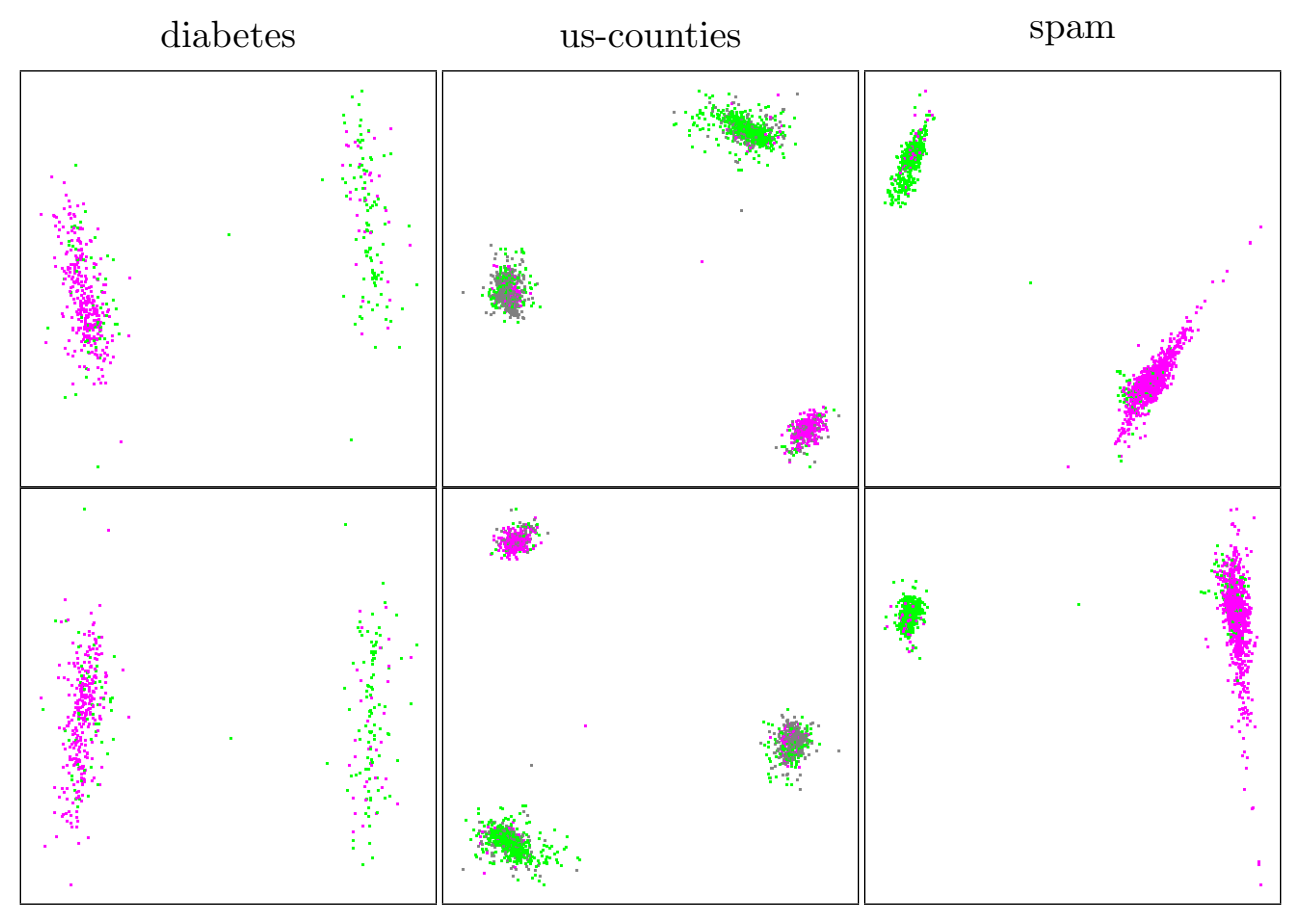

Figura 4.5: Aumentando o número de amostras é permitido ao usuário um melhor controle da transformação. Primeira linha: projeção empregando a LAMP sobre o conjunto de dados transformado. Segunda linha: projeção empregando a Classical Scaling sobre o conjunto de dados transformado. 


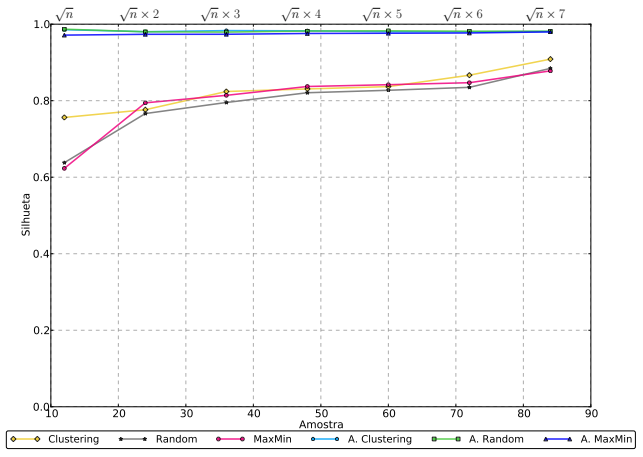

(a) iris

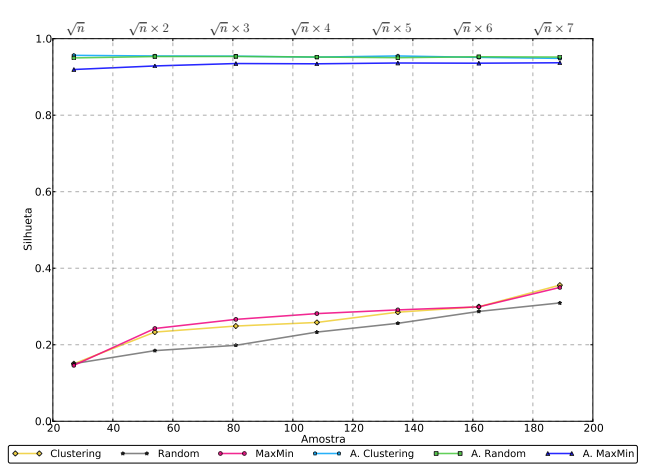

(c) diabetes

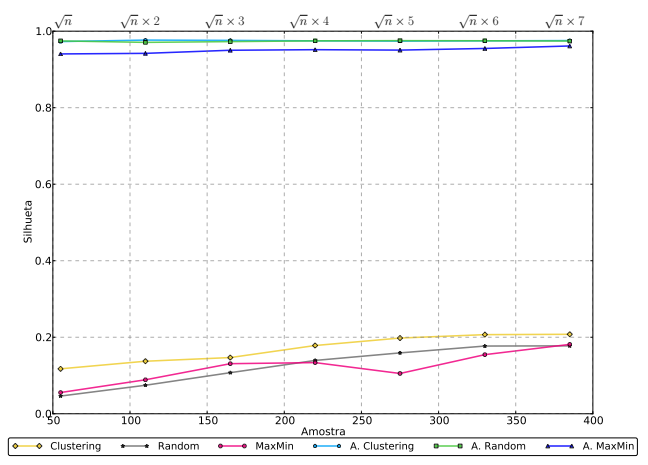

(e) us-counties

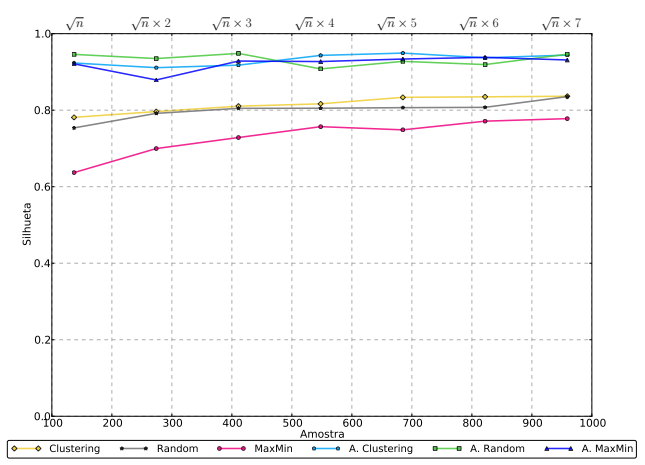

(g) fibers

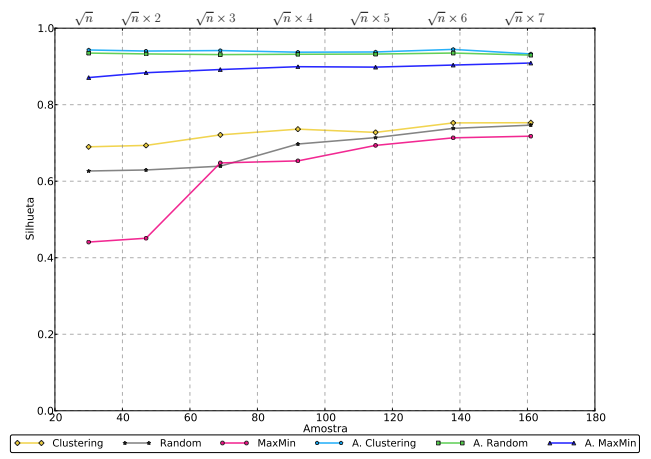

(b) wdbc

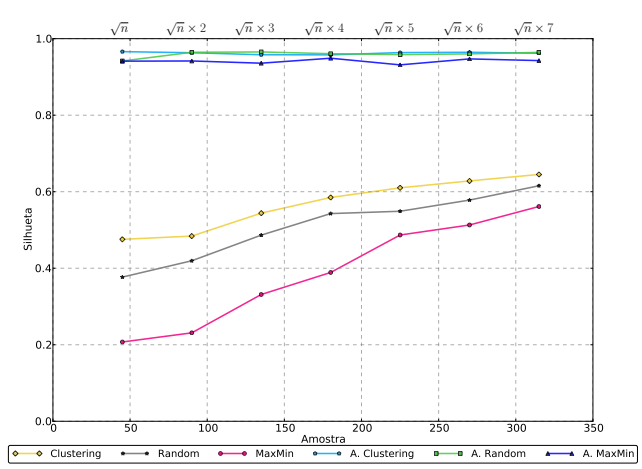

(d) segmentation

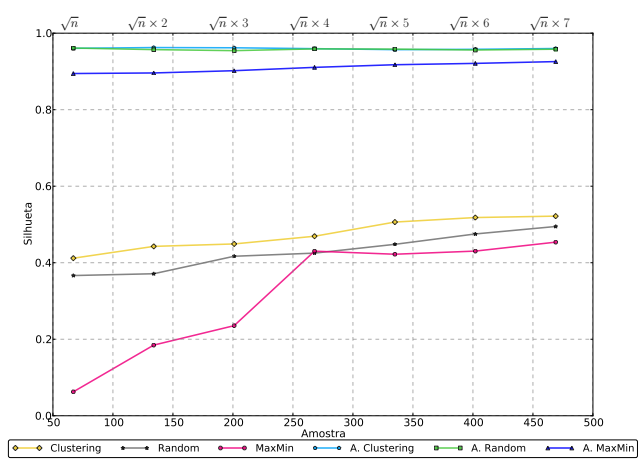

(f) spam

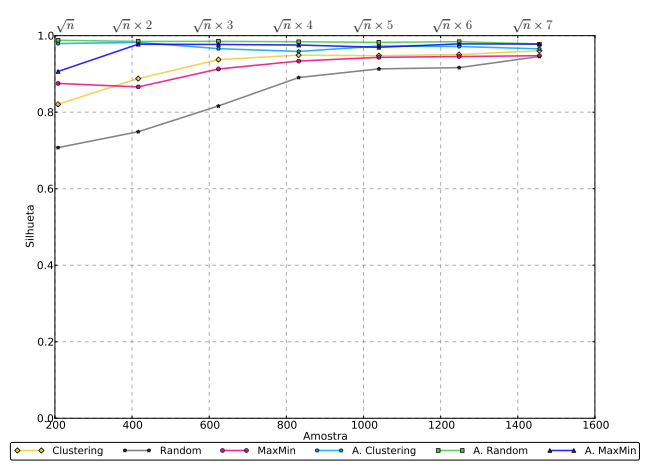

(h) shuttle

Figura 4.6: Análises comparativas das amostragens. Usando-se essa análise é possível definir que a amostragem por agrupamento define melhores resultados, em termos de coeficiente de silhueta, e que conforme a amostra cresce, o resultado também melhora. 


\section{Aplicações}

\subsection{Considerações Iniciais}

sta seção tem o objetivo de descrever algumas aplicações da abordagem proposta nessa projeto de mestrado, fornecendo evidências da sua aplicabilidade. Dados diversos fatores como o acelerado crescimento da Internet e os avanços nas tecnologias associadas a dispositivos para obtenção e armazenamento de informação visual, o número de imagens em formato digital tem aumentado exponencialmente, gerando grandes coleções de imagens. Estas coleções precisam de alguma forma ser organizadas e administradas para que possam ser adequadamente usadas. Assim, aproveitando a capacidade de melhoramento de agrupamentos da abordagem proposta neste trabalho, foi elaborado um aplicativo para auxiliar os usuários a organizar coleções de imagens.

Para testar o sistema proposto, diferentes conjuntos de imagens foram utilizados extraídos de dois domínios: imagens médicas e imagens diversas. A seguir esses conjuntos são detalhados bem como os métodos usados para extrair as características desses conjuntos.

- Corel 1000 (Li e Wang, 2003): Contém 1.000 imagens coloridas, categorizadas em 10 classes com 100 imagens cada. As classes existentes são: Africa, beach, buildings, buses, dinosaurs, elephants, flowers, horses, mountains e food. As características foram extraídas com os descritores SIFT (Lowe, 2004) produzindo 150 dimensões. A Figura 5.1 apresenta exemplos desta base.

- Caltech (Fergus et al., 2003): contém 4 classes e um total de 3.100 imagens. As classes são: airplanes (1074 imagens), houses(750 imagens), faces (450 imagens) e motorcycles(826 

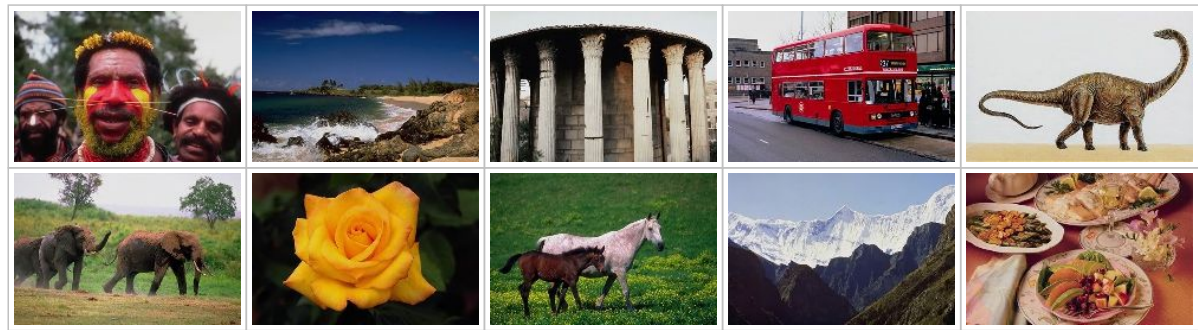

Figura 5.1: Amostras da base de imagens Corel 1000.

imagens). Para essa base as características foram extraídas usando a abordagem bag-ofvisual features-(BoVF) (Yang et al., 2007b) e como resultado foram obtidas 150 dimensões. Uma imagem de cada classe é apresentada na Figura 5.2.
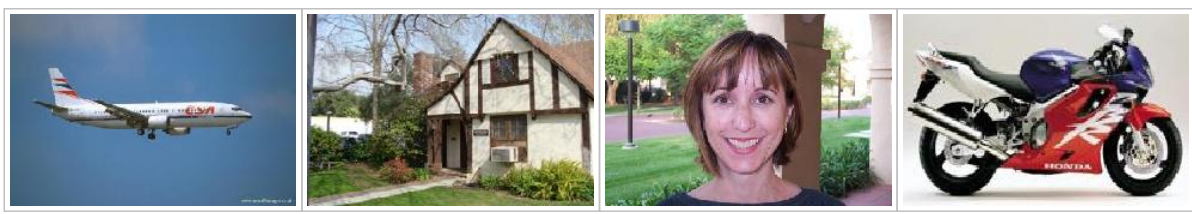

Figura 5.2: Amostras da base de imagens Caltech.

- ImageCLEF-2009¹: conjunto de imagens de raio-X de várias partes do corpo humano. Foi considerada uma amostragem de 4.590 imagens correspondentes às classes: chest, cranium, leg e mamma com 1.500, 1.151, 1.600 e 339 imagens respetivamente. Na extração das características foram empregados os momentos de Zernike (Kim e Kim, 2000) resultando em 256 dimensões. Um exemplo de cada classe pode ser visto na Figura 5.3.
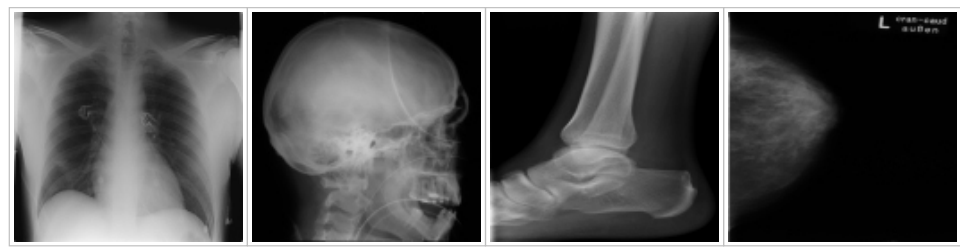

Figura 5.3: Amostras da base de imagens ImageCLEF-2009.

A seguir o funcionamento do sistema para organização de imagens é detalhado e resultados de sua aplicação são apresentados.

\subsection{Aplicação em Coleções de Imagens}

Para a organização de uma coleção de imagens, o sistema proposto define os seguintes passos:

\footnotetext{
${ }^{1}$ http://www.imageclef .org/2009/medical/
} 
a) Um subconjunto de imagens é selecionado da coleção de imagens e projetado no espaço visual. O usuário pode reorganizar o layout movendo as imagens a fim de formar grupos de imagens semelhantes segundo seu ponto de vista.

b) Os grupos definidos pelo usuário são selecionados e um rótulo (ou nome) é atribuído a cada grupo.

c) O layout manipulado pelo usuário é usado para definir as transformações que irão modificar o conjunto de dados de acordo com as novas relações de similaridade. Após a transformação cada imagem no conjunto de dados é classificada como pertencente a um dos grupos criados pelo usuário.

Uma imagem é atribuída a um determinado grupo criado pelo usuário se esse for o grupo mais próximo da imagem no espaço transformado. A distância de uma imagem para um grupo é definida como a distância média da imagem às amostras representativas daquele grupo.

Se a representação multidimensional das amostras após a interação do usuário estiverem armazenadas (após a aplicação do N-IFS), qualquer nova imagem adicionada ao conjunto de dados pode ser adequadamente transformada pela sua transformação afim associada. Portanto, uma nova imagem pode ser automaticamente classificada como pertencente a uma classe sem intervenção do usuário. De fato, o armazenamento das características transformadas somente para as amostras é suficiente para redefinir os grupos, bem como classificar as novas instâncias adicionadas ao conjunto de dados segundo os grupos predefinidos pelo usuário. Assim, a ferramenta pode ser usada de forma incremental se os grupos inicialmente definidos pelo usuário forem representativos o suficiente.

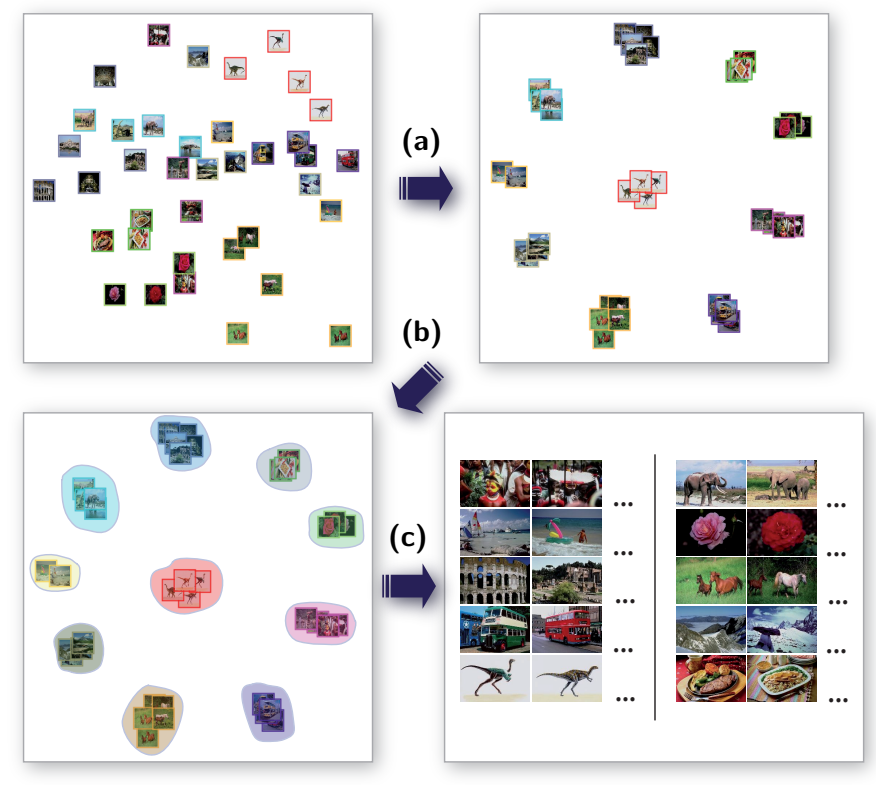

Figura 5.4: Visão geral do sistema de organização de coleções de imagens sobre a base Corel 1000 
A Figura 5.4 apresenta uma esquematização do sistema proposto usando como exemplo a base Corel 1000. Inicialmente um subconjunto de imagens é selecionado da coleção de imagens e projetado ao espaço visual. O usuário reorganiza o layout manipulando as imagens com o fim de formar grupos de imagens semelhantes (passo (a)). Os grupos definidos pelo usuário são selecionados e um rótulo é atribuído a cada grupo (passo (b)). Com base ao layout manipulado pelo usuário são definidas as transformações que irão modificar o conjunto de dados. Após a transformação, cada imagem no conjunto de dados é classificada como pertencente a um dos grupos estabelecidos pelo usuário (passo (c)).

Por razões de comparação, o mecanismo de classificação descrito acima é executado usando o espaço original e o espaço transformado de características. Como resultado, usando o espaço original as imagens corretamente classificadas representam 30.4\% (número de imagens corretamente classificadas dividido pelo número total de imagens da coleção). Empregando-se o espaço transformado pela abordagem proposta, a acurácia aumenta consideravelmente alcançando $82.5 \%$. Observe que a interação do usuário criou o mesmo número de grupos que as classes existentes no conjunto de dados.

A Tabela 5.1 exibe os resultados (matriz de confusão) das classificações antes e depois da transformação sobre a base Corel 1000. Cada linha mostra quantas instâncias de uma determinada classe são classificadas como pertencente a uma determinada classe, e erroneamente classificadas como membro de outras classes. A Tabela 5.1(a) corresponde à classificação no espaço de característica original e a Tabela 5.1(b) corresponde à classificação no espaço transformado. Pode-se observar que os resultados de classificação são muito melhores após de transformar o espaço de características (números nas células diagonais, que correspondem a imagens corretamente classificadas são muito maiores que as fora da diagonal da matriz).

A Figura 5.5 compara as projeções (realizada pela técnica LAMP) dos conjuntos de dados completos, antes e após a transformação. Cada imagem é representada por um ponto e as cores identificam as classes dessas imagens. A separação de classes após a transformação é evidente, comprovando assim a eficácia da abordagem proposta para transformação do espaço de características quando coleções de imagens são transformadas.

O mesmo processo de classificação é aplicado sobre a base de imagens Caltech. O resultado é apresentado na Figura 5.6. O resultado da acurácia foi de $24.90 \%$ usando o espaço original de características. Considerando o espaço transformado a acurácia subiu para 86.22\%. As matrizes de confusão das classificações antes e depois da transformação são apresentadas na Tabela 5.2. A Tabela 5.3(a) corresponde à classificação feita no espaço característica original. Pode-se observar que usando as características originais nenhuma imagem da classe avião foi classificada corretamente. Os resultados são muito melhores após a transformação, como é mostrado na Tabela 5.3(b).

A Figura 5.7 compara as projeções (realizadas pela técnica LAMP) dos conjuntos de dados completos, antes e depois da transformação. Cada imagem é representada por um ponto e as cores identificam as classes dessas imagens. Observe que novamente na projeção do conjunto 


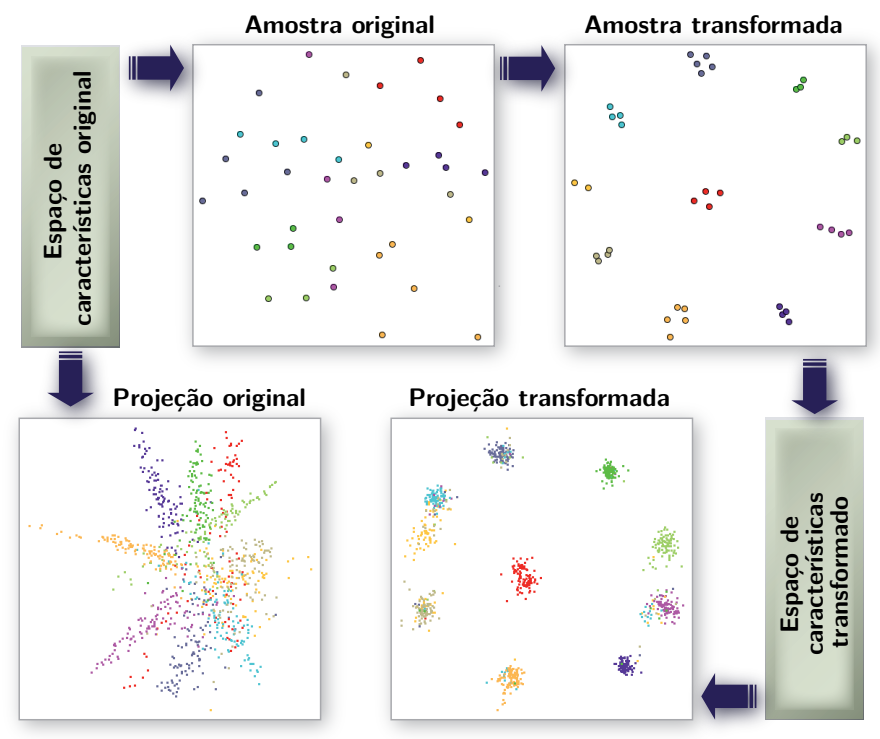

Figura 5.5: Projeções do conjunto de dados Corel 1000 considerando o espaço de características original e transformado.

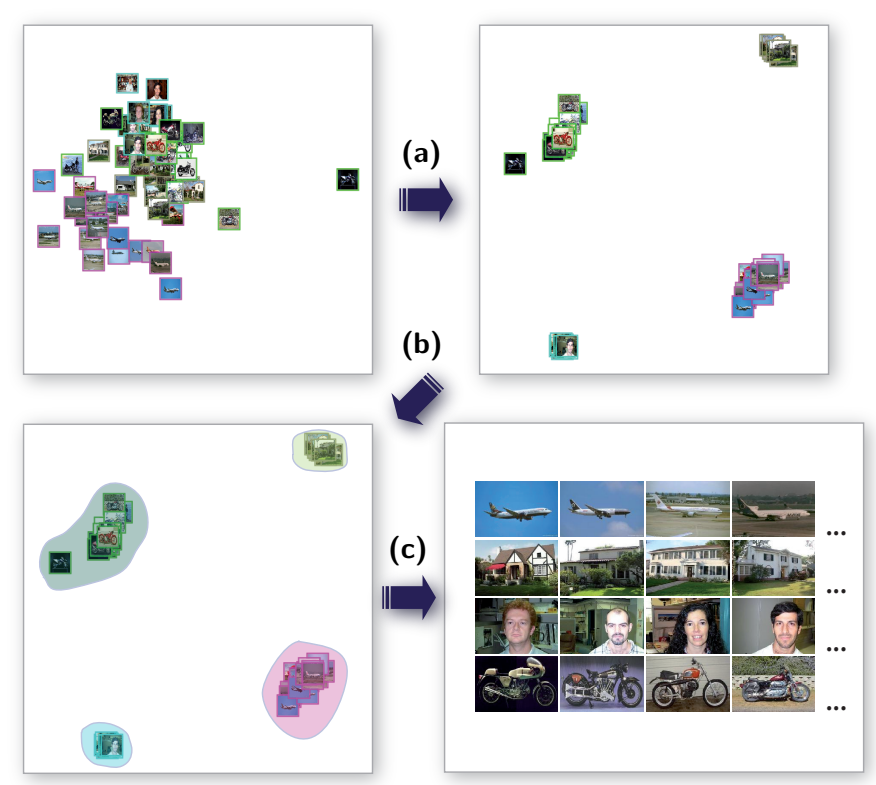

Figura 5.6: Visão geral do sistema de organização de coleções de imagens com a base Caltech 
Tabela 5.1: Matriz de confusão gerada a partir da classificação do conjunto Corel 1000.

(a) Espaço de características Original.

\begin{tabular}{|c|c|c|c|c|c|c|c|c|c|c|c|}
\hline & \multicolumn{10}{|c|}{ Predito } \\
\hline & & Africa & beach & buildings & buses & dinosaurs & elephants & flowers & horses & mountains & food \\
\hline \multirow{10}{*}{ 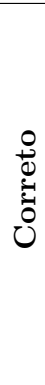 } & Africa & 17 & 82 & 0 & 0 & 0 & 0 & 0 & 0 & 0 & 1 \\
\hline & beach & 0 & 100 & 0 & 0 & 0 & 0 & 0 & 0 & 0 & 0 \\
\hline & buildings & 0 & 100 & 0 & 0 & 0 & 0 & 0 & 0 & 0 & 0 \\
\hline & buses & 0 & 65 & 0 & 35 & 0 & 0 & 0 & 0 & 0 & 0 \\
\hline & dinosaurs & 0 & 100 & 0 & 0 & 0 & 0 & 0 & 0 & 0 & 0 \\
\hline & elephants & 0 & 97 & 0 & 0 & 0 & 0 & 0 & 0 & 0 & 3 \\
\hline & flowers & 0 & 38 & 0 & 0 & 0 & 0 & 61 & 0 & 0 & 1 \\
\hline & horses & 0 & 100 & 0 & 0 & 0 & 0 & 0 & 0 & 0 & 0 \\
\hline & mountains & 0 & 100 & 0 & 0 & 0 & 0 & 0 & 0 & 0 & 0 \\
\hline & food & 0 & 9 & 0 & 0 & 0 & 0 & 0 & 0 & 0 & 91 \\
\hline
\end{tabular}

(b) Espaço de características Transformado.

\begin{tabular}{|c|c|c|c|c|c|c|c|c|c|c|c|}
\hline & \multicolumn{10}{|c|}{ Predito } \\
\hline & & Africa & beach & buildings & buses & dinosaurs & elephants & flowers & horses & mountains & food \\
\hline \multirow{10}{*}{ 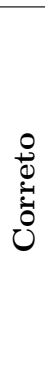 } & Africa & 88 & 0 & 1 & 0 & 0 & 9 & 0 & 1 & 0 & 1 \\
\hline & beach & 8 & 56 & 2 & 2 & 0 & 14 & 1 & 1 & 16 & 0 \\
\hline & buildings & 2 & 2 & 86 & 2 & 0 & 2 & 0 & 0 & 5 & 1 \\
\hline & buses & 0 & 0 & 0 & 99 & 0 & 0 & 0 & 0 & 1 & 0 \\
\hline & dinosaurs & 0 & 4 & 0 & 0 & 95 & 0 & 0 & 0 & 0 & 1 \\
\hline & elephants & 12 & 1 & 6 & 0 & 0 & 65 & 0 & 10 & 3 & 3 \\
\hline & flowers & 1 & 7 & 2 & 0 & 0 & 0 & 88 & 0 & 1 & 1 \\
\hline & horses & 1 & 1 & 0 & 0 & 0 & 0 & 0 & 98 & 0 & 0 \\
\hline & mountains & 4 & 22 & 9 & 1 & 0 & 4 & 0 & 2 & 58 & 0 \\
\hline & food & 4 & 0 & 0 & 1 & 0 & 0 & 0 & 1 & 2 & 92 \\
\hline
\end{tabular}

de dados modificado é possível distinguir a separação entre as classes, o que não é visível na projeção do espaço original.

Por fim, o mesmo teste é executado para a base ImageCLEF2009. O resultado das imagens corretamente classificadas, considerando o espaço de características original e transformado foram de $18.64 \%$ e $80.45 \%$, respectivamente. A Tabela 5.3 exibe as matrizes de confusão para os resultados das classificações desta base. A Figura 5.8 apresenta as projeções (produzidas pela técnica LAMP) dos conjuntos de dados completos, antes e depois da transformação. Novamente o bom resultado de separação pode ser observado para esse copnjunto de imagens após a transformação do espaço de características usando a abordagem proposta.

\subsection{Recuperação de Imagens baseada em Conteúdo}

Adicionalmente uma avaliação inicial da abordagem proposta no contexto de sistemas CBIR (Content-Based Image Retrieval) foi executada. Os sistemas CBIR frequentemente apresentam resultados imprecisos, devido ao espaço de características ser de baixo nível. Assim, transformando espaços de características com a incorporação dos interesses do usuário, espera-se alcançar uma elevada precisão nos resultados de consultas por similaridade no domínio de imagens. A fim 


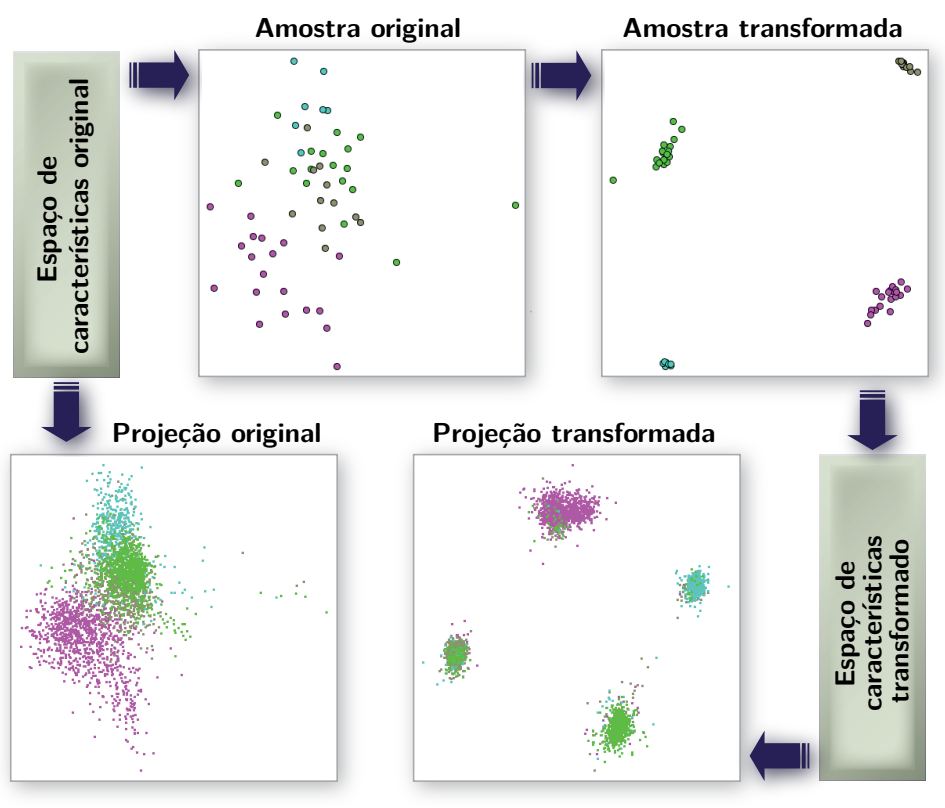

Figura 5.7: Projeções do conjunto de dados Caltech considerando o espaço de características original e transformado.

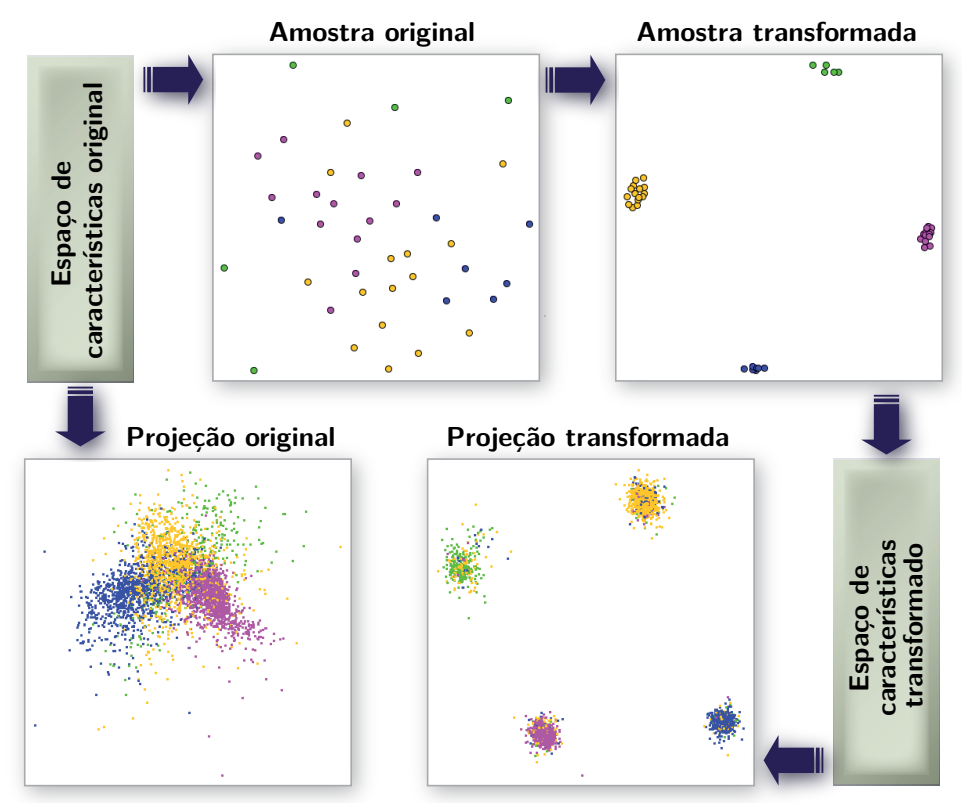

Figura 5.8: Projeções do conjunto de dados ImageCLEF2009 considerando o espaço de características original e transformado. 
Tabela 5.2: Matrizes de confusão gerada com a classificação da base Caltech.

(a) Espaço de características Original.

\begin{tabular}{|c|c|c|c|c|c|}
\hline & \multicolumn{4}{|c|}{ Predito } \\
\hline & & airplane & houses & faces & motorcycle \\
\hline \multirow{4}{*}{ 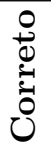 } & airplane & 0 & 10 & 1064 & 0 \\
\hline & houses & 0 & 312 & 438 & 0 \\
\hline & faces & 0 & 6 & 444 & 0 \\
\hline & motorcycle & 0 & 24 & 784 & 18 \\
\hline
\end{tabular}

(b) Espaço de características Transformado.

\begin{tabular}{|c|c|c|c|c|c|}
\hline & \multicolumn{4}{|c|}{ Predito } \\
\hline & & airplane & houses & faces & motorcycle \\
\hline \multirow{4}{*}{ 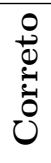 } & airplane & 998 & 43 & 6 & 27 \\
\hline & houses & 45 & 606 & 42 & 57 \\
\hline & faces & 4 & 36 & 372 & 38 \\
\hline & motorcycle & 26 & 83 & 20 & 697 \\
\hline
\end{tabular}

de avaliar a eficiência dos espaços de características nas tarefas de CBIR, empregamos os gráficos de Precisão e Revocação $P \& R$ (Baeza-Yates e Ribeiro-Neto, 1999), onde precisão e revocação são definidos como:

$$
\text { Precisão }=\frac{\left|R_{a}\right|}{|A|}, \quad \text { revocacão }=\frac{\left|R_{a}\right|}{|R|}
$$

onde $\left|R_{a}\right|$ é o número de imagens relevantes recuperadas. $|A|$ número de imagens recuperadas. $|R|$ o número de imagens relevantes no conjunto de dados.

Nos testes realizados, cada imagem foi usada para a consulta, retornando as $k$ imagens mais semelhantes utilizando consultas aos $k$ vizinhos mais próximos $(k N N)$ e a função de distância euclideana. Uma imagem é considerada relevante quando sua classe é a mesma da imagem de consulta.

A Figura 5.9 mostra as curvas de precisão e revocação médias obtidas da comparação entre o espaço de características original e o transformado do conjunto Corel 1000. Pode-se observar que o espaço de características transformado resultou em um aumento de precisão nas consultas por similaridade, em relação ao espaço de características original.

Uma comparação visual dos resultados de uma consulta por similaridade sobre o espaço de características original e transformado da base Corel 1000 é apresentada na Figura 5.10. A imagem com o quadro vermelho é usada como modelo de consulta. Na Figura (5.10(a)) são exibidas as imagens recuperadas usando o espaço de características original, onde pode se observar que 15 das imagens são não relevantes, enquanto todas as imagens são relevantes usando o espaço de características transformado (Figura (5.10(b))).

A Figura 5.11 apresenta o gráfico de $P \& R$ obtido para o conjunto Caltech. O espaço de características original inicialmente apresenta resultados melhores do que o espaço de características transformado, mas a precisão decai quando o valor de revocação aumenta, e é superado 
Tabela 5.3: Matrizes de confusão geradas com a classificação sobre o conjunto ImageCLEF2009.

(a) Espaço de características original.

\begin{tabular}{|c|c|c|c|c|c|}
\hline & \multicolumn{4}{|c|}{ Predito } \\
\hline & & chest & cranium & leg & mamma \\
\hline \multirow{4}{*}{ 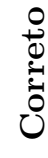 } & chest & 0 & 7 & 0 & 1493 \\
\hline & cranium & 0 & 517 & 0 & 634 \\
\hline & leg & 0 & 112 & 0 & 1488 \\
\hline & mamma & 0 & 0 & 0 & 339 \\
\hline
\end{tabular}

(b) Espaço de características transformado.

\begin{tabular}{|c|c|c|c|c|c|}
\hline & \multicolumn{4}{|c|}{ Predito } \\
\hline & & chest & cranium & leg & mamma \\
\hline \multirow{4}{*}{ 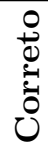 } & chest & 1411 & 9 & 70 & 10 \\
\hline & cranium & 99 & 812 & 222 & 18 \\
\hline & leg & 180 & 89 & 1221 & 110 \\
\hline & mamma & 25 & 33 & 32 & 249 \\
\hline
\end{tabular}

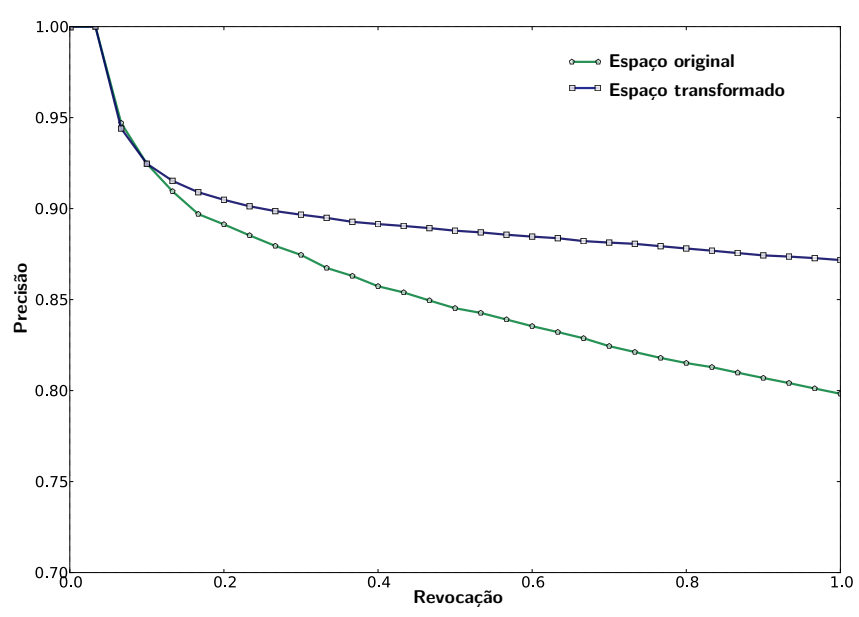

Figura 5.9: Curvas de precisão e revocação obtidas para o conjunto de imagens Corel 1000.

pelo espaço de características transformado. A Figura 5.12 exibe os resultados da consulta para a imagem com o quadro vermelho sobre o conjunto de imagens Caltech. Pode-se observar na Figura (5.12(a)) que 11 das imagens exibidas são não relevantes, e todas as imagens exibidas na Figura (5.12(b)) são relevantes.

\subsection{Considerações Finais}

Nesse capítulo foi apresentado um sistema para organização de coleções de imagens por conteúdo baseado na abordagem proposta. O sistema parte da projeção de uma amostra para permitir que um usuário modifique as relações de similaridade existentes no espaço de característica que descreve um conjunto de imagens. Com essa modificação o usuário pode compor grupos 


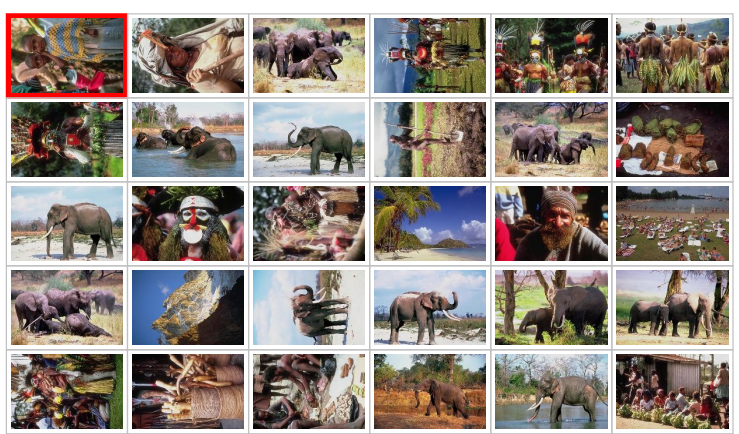

(a) Espaço de características original.

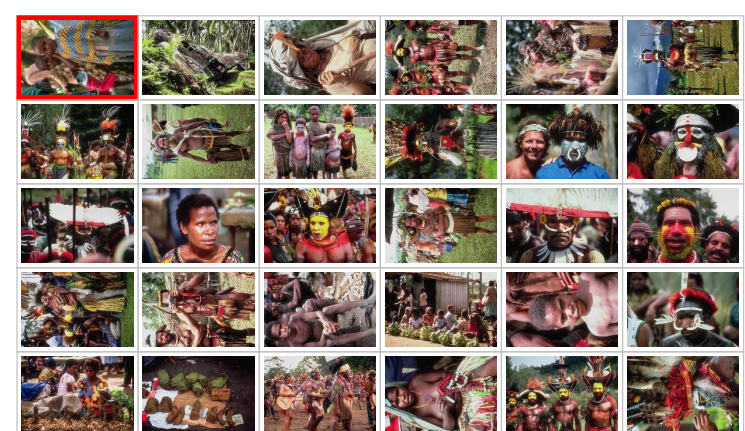

(b) Espaço de características transformado.

Figura 5.10: Imagens recuperadas do conjunto de dados Corel 1000.

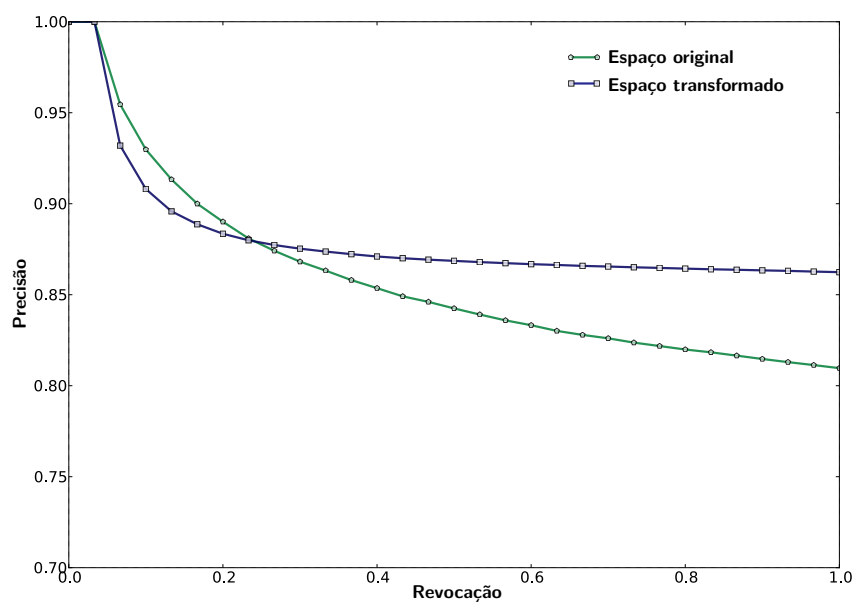

Figura 5.11: Curvas de precisão e revocação referentes ao conjunto de imagens Caltech.

de acordo com seu ponto de vista, moldando o espaço de características para atender suas necessidades.

Os resultados obtidos foram bastante encorajadores, melhorando bastante as relações de similaridade na formação dos grupos de imagens definidos pelo usuário. Além disso, testes para a recuperação de imagens baseada em conteúdo foram executados, melhorando índices de recuperação e revocação. Indicando que a abordagem proposta pode também ser usada com sucesso nesse nicho de aplicação. 


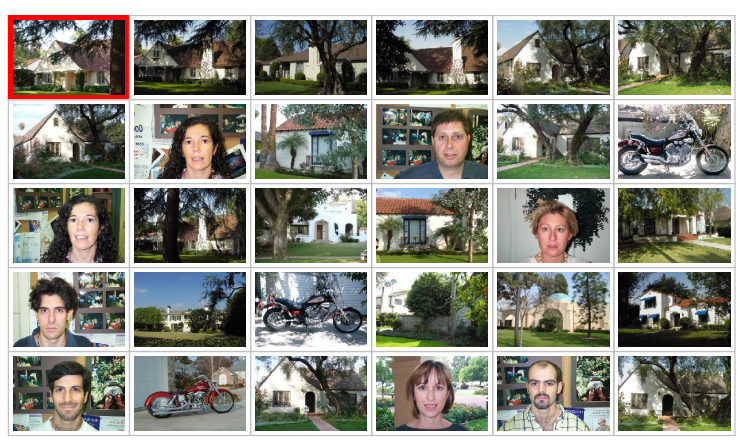

(a) Espaço de características original.

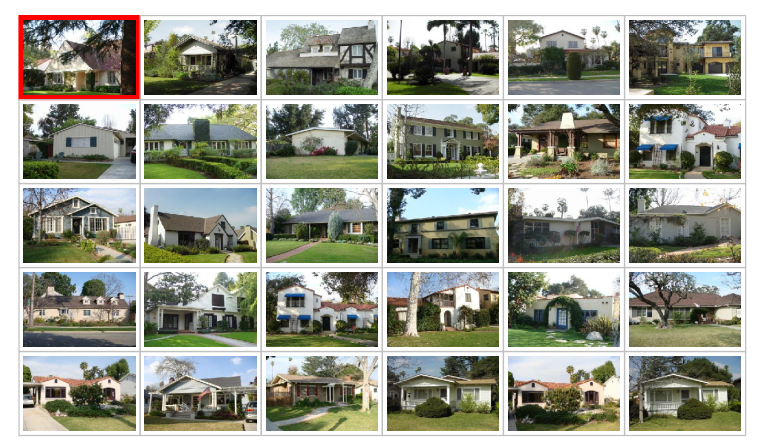

(b) Espaço de características transformado.

Figura 5.12: Imagens recuperadas do conjunto de dados Caltech. 



\section{Conclusões}

\subsection{Conclusões}

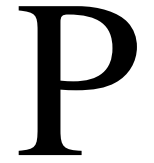

rojeções multidimensionais têm recebido uma atenção significativa devido à sua uti-

lidade para construir representações gráficas compactas que respeitam determinadas relações presentes na estrutura dos dados originais. Porém, nem sempre o layout produzido pela projeção condiz com o esperado pelo usuário. Diversas técnicas têm sido propostas para permitir que usuários possam interagir com uma projeção inicial a fim de conseguir uma projeção final de melhor qualidade, porém nenhuma abordagem na literatura atual de projeções multidimensionais é utilizada como um mecanismo para transformar conjuntos de dados multidimensionais.

Este trabalho apresenta uma nova abordagem para a transformação do espaço de caraterísticas envolvendo a manipulação do usuário sobre um subconjunto de amostras do conjunto de dados. Esse subconjunto de amostras é projetado ao espaço visual com a utilização de uma técnica de projeção multidimensional para ser manipulado afim de criar grupos de interesse. A partir dessa informação inicial, transformações locais são definidas para modificar o espaço de características conforme o ponto de vista do usuário. Interagir com um subconjunto de dados para dirigir uma transformação de todo o conjunto é uma funcionalidade muito útil que pode ser explorada em muitos problemas de visualização e mineração de dados, já que assim é possível embutir no processo conhecimento do usuário e seu ponto de vista.

Os resultados mostram que a abordagem proposta melhora a coesão e a separação entre grupos em conjuntos de dados multi-valorados, bem como resultados de aplicações em cenários de recuperação de informação baseada em conteúdo, evidenciando que projeções podem ser usadas como uma guia para a melhoria de conjuntos de dados multidimensionais. 


\subsection{Limitações}

Embora os resultados apresentados neste trabalho sejam promissores, existem algumas limitações em relação a utilização da técnica proposta. A primeira limitação refere-se ao processamento de conjuntos de dados com um grande número de grupos e poucas amostras representativas por grupo, ou amostras representativas ruins. Nesse caso a transformação pode piorar a identificação dos grupos existentes. Por exemplo, quando o conjunto de dados Letter Image Recognition (Asuncion e Newman, 2007) é processado, o coeficiente de silhueta cai de 0,0098 para $-0,1502$. Esse conjunto contém 20,000 instâncias classificadas em 26 classes. Usando-se a heurística de empregar $\sqrt{n}=141$ amostras, a abordagem proposta falha por essas não conseguirem representar com sucesso a distribuição e os grupos presentes nos dados. A Figura 6.1 apresenta as projeções do conjunto original (Figura 6.1(a)), das amostras originais (Figura 6.1(b)), das amostras transformadas (Figura 6.1(c)) e do conjunto transformado (Figura 6.1(d)), onde fica evidente essa limitação.

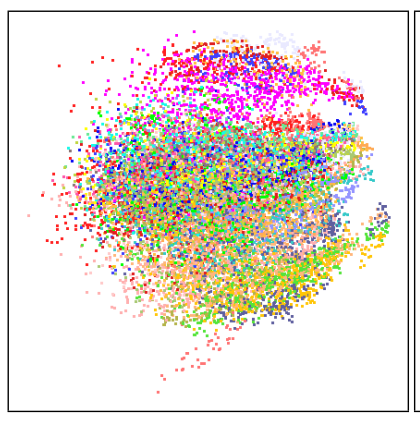

(a)

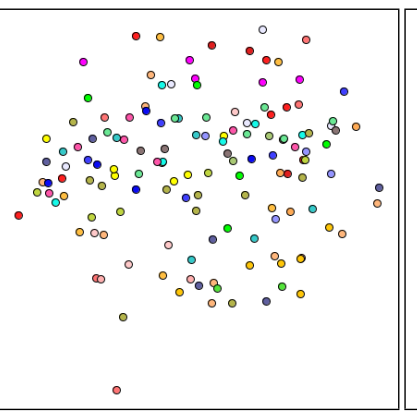

(b)

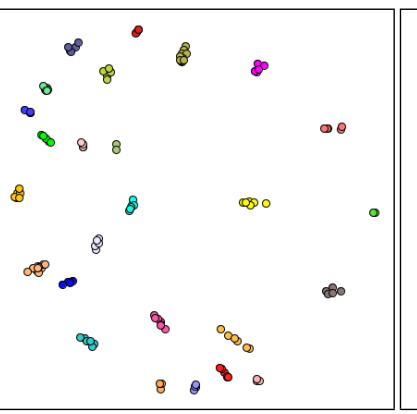

(c)

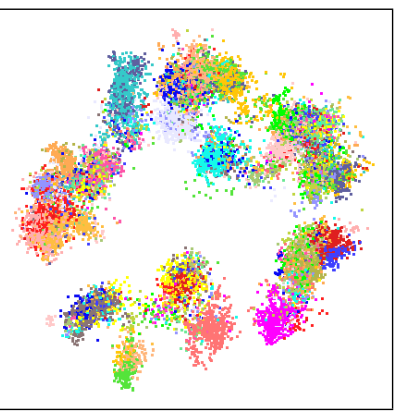

(d)

Figura 6.1: Resultado da aplicação da abordagem proposta sobre o conjunto de dados

\section{Letter Image Recognition.}

Outra limitação da proposta é ela não conseguir agrupar adequadamente instâncias que não são minimamente relacionadas entre si. De fato, a abordagem proposta é mais eficiente para melhorar grupos existentes do que criar novos grupos. Essa é uma limitação que precisa ser melhorar estudada e entendida.

\subsection{Trabalhos Futuros}

Considerando que a abordagem proposta depende muito da qualidade da amostra, um trabalho futuro poderá ser a investigação de como obter uma boa amostra representativa do conjunto de dados, assim como a ligação entre o número de amostras representativas a ser escolhida e o número de grupos presente.

Um aspecto interessante da abordagem proposta é que ela é inerentemente incremental, isso porque somente as coordenadas das amostras representativas no espaço transformado precisam 
ser conhecidas para a transformação de qualquer instâncias de dados, mesma as que originalmente não estão presentes no conjunto de dados. Uma problema a ser considerado neste cenário é o surgimento de novos grupos durante o processamento dos dados, uma vez que a transformação só irá funcionar se as amostras representarem todos os grupos existentes. A adaptação da abordagem proposta para descobrir novos grupos conforme dados são processados é um desafio a ser pesquisado. 



\section{Referências Bibliográficas}

Achlioptas, D. Database-friendly random projections: Johnson-lindenstrauss with binary coins. Journal of Computer and System Sciences, v. 66, n. 4, p. 671-687, 2003.

Andrews, D. F. Plots of High-Dimensional Data. Biometrics, v. 28, n. 1, 1972.

Asuncion, A.; Newman, D. UCI machine learning repository. 2007.

Disponível em: http://archive.ics.uci.edu/ml/

Baeza-Yates, R. A.; Ribeiro-Neto, B. Modern information retrieval. Boston, MA, USA: Addison-Wesley Longman Publishing Co., Inc., 1999.

Berger, W.; Piringer, H.; Filzmoser, P.; Gröller, E. Uncertainty-aware exploration of continuous parameter spaces using multivariate prediction. Computer Graphics Forum, v. 30, n. 3, p. 911-920, 2011.

Disponível em: http://dx.doi.org/10.1111/j.1467-8659.2011.01940.x

Bingham, E.; Mannila, H. Random projection in dimensionality reduction: Applications to imageand text data. In: in Knowledge Discovery and Data Mining, ACM Press, 2001, p. $245-250$.

CARD, S. K.; Mackinlay, J. D.; Shneiderman, B. Readings in information visualization: Using vision to think. London: Academic Press, 1999.

Chalmers, M. A linear iteration time layout algorithm for visualising high-dimensional data. In: IEEE Visualization, 1996., p. 127-132.

Chalmers, M. A linear iteration time layout algorithm for visualising high-dimensional data. In: IEEE Visualization, 1996, p. 127-ff.

Chen, W.; Ding, Z.; Zhang, S.; MacKay-Brandt, A.; Correia, S.; Qu, H.; Crow, J.; Tate, D.; Yan, Z.; Peng, Q. A novel interface for interactive exploration of dti fibers. Visualization and Computer Graphics, IEEE Transactions on, v. 15, n. 6, p. 1433 -1440, 2009. 
Chernoff, H. The use of faces to represent points in k-dimensional space graphically. Journal of the American Statistical Association, v. 68, n. 342, p. 361-368, 1973.

EAdEs, P. A heuristic for graph drawing. Congressus Numerantium, v. 42, p. 149-160, 1984.

Faloutsos, C.; Lin, K. Fastmap: A fast algorithm for indexing, datamining and visualizationof traditional and multimedia databases. In: ACM SIGMOD, 1995, p. 163-174.

Fayyad, U. M.; Piatetsky-Shapiro, G.; Smyth, P. Advances in knowledge discovery and data mining. cáp. From data mining to knowledge discovery: an overview, Menlo Park, CA, USA: American Association for Artificial Intelligence, p. 1-34, 1996.

Disponível em: http://portal . acm.org/citation. cfm?id=257938.257942

Fergus, R.; Perona, P.; Zisserman, A. Object class recognition by unsupervised scaleinvariant learning. In: In CVPR, 2003, p. 264-271.

Guo, D. Coordinating computational and visual approaches for interactive feature selection and multivariate clustering. Information Visualization, v. 2, n. 4, p. 232-246, 2003.

Disponível em: http://dx.doi.org/10.1057/palgrave.ivs.9500053

Hoffman, P.; Grinstein, G. G.; Pinkney, D. Dimensional anchors: A graphic primitive for multidimensional multivariate information visualizations. In: Workshop on New Paradigms in Information Visualization and Manipulation, ACM, 1999, p. 9-16.

Disponível em: http://dblp.uni-trier.de/db/conf/npiv/npivm1999.html\#HoffmanGP99

Ingram, S.; Munzner, T.; Irvine, V.; Tory, M.; Bergner, S.; Monndller, T. Dimstiller: Workflows for dimensional analysis and reduction. In: Visual Analytics Science and Technology (VAST), 2010 IEEE Symposium on, 2010, p. 3-10.

Ingram, S.; Munzner, T.; Olano, M. Glimmer: Multilevel mds on the gpu. IEEE Transactions on Visualization and Computer Graphics, v. 15, p. 249-261, 2009.

Disponível em: http://portal.acm.org/citation.cfm?id=1495798.1495997

Inselberg, A. Parallel coordinates: Visual multidimensional geometry and its applications. Secaucus, NJ, USA: Springer-Verlag New York, Inc., 2009.

Inselberg, A.; Dimsdale, B. Parallel coordinates: a tool for visualizing multi-dimensional geometry. VIS'90: Proceedings of the 1st Conference on Visualization, p. 361-378, 1990.

Jeong, D. H.; Ziemkiewicz, C.; Fisher, B.; Ribarsky, W.; Chang, R. ipca: An interactive system for pca-based visual analytics. Comput. Graph. Forum, v. 28, n. 3, p. 767$774,2009$.

Johansson, S.; Johansson, J. Interactive dimensionality reduction through user-defined combinations of quality metrics. IEEE Transactions on Visualization and Computer Graphics, v. 15, n. 6, p. 993-1000, 2009.

Disponível em: http://dx.doi.org/10.1109/TVCG.2009.153 
John, G. H.; Langley, P. Estimating continuous distributions in bayesian classifiers. In: Proceedings of the Eleventh conference on Uncertainty in artificial intelligence, UAI'95, San Francisco, CA, USA: Morgan Kaufmann Publishers Inc., 1995, p. 338-345 (UAI'95, ).

Disponível em: http://dl .acm.org/citation.cfm?id=2074158.2074196

Join, P.; Coimbra, D.; Cuminato, J. A.; Paulovich, F. V.; Nonato, L. G. Local affine multidimensional projection. IEEE Transactions on Visualization and Computer Graphics, v. 17, p. 2563-2571, 2011.

Disponível em: http://dx.doi.org/10.1109/TVCG.2011.220

Jolliffe, I. Principal component analysis. Springer, New York, NY, 1986.

Jourdan, F.; Melancon, G. Multiscale hybrid mds. In: Proceedings of the Information Visualisation, Eighth International Conference, IEEE Computer Society, 2004, p. 388-393.

Kaufman, L.; Rousseeuw, P. J. Finding groups in data: an introduction to cluster analysis. New York: John Wiley and Sons, 1990.

KeIm, D. A. Designing pixel-oriented visualization techniques: Theory and applications. IEEE Transactions on Visualization and Computer Graphics, v. 6, n. 1, p. 59-78, 2000.

Disponível em: http://dx.doi.org/10.1109/2945.841121

Keim, D. A.; Keim, D. A.; Kriegel, H.-P.; Kriegel, H. Visdb: Database exploration using multidimensional visualization. IEEE Computer Graphics and Applications, v. 14, p. 40-49, 1994.

Keim, D. A.; Kriegel, H.; Society, E. C. Visualization techniques for mining large databases: A comparison. IEEE Transactions on Knowledge and Data Engineering, v. 8, p. 923-938, 1996.

KIM, W.-Y.; KIM, Y.-S. A region-based shape descriptor using zernike moments. Sig. Proc.: Image Comm., v. 16, n. 1-2, p. 95-102, 2000.

KRUSKAL, J. Multidimensional scaling by optimizing goodness of fit to a nonmetric hypothesis. Psychometrika, v. 29, n. 1, p. 1-27, 1964.

LeEuw, J. Applications of convex analysis to multidimensional scaling. In: BARra, J.; BroDeau, F.; Romier, G.; Cutsem, B. V., eds. Recent Developments in Statistics, Amsterdam: North Holland Publishing Company, p. 133-146, 1977a.

LeEuw, J. Applications of convex analysis to multidimensional scaling. In: BARRA, J.; Brodeau, F.; Romier, G.; Custem, B. V., eds. Recent Developments in Statistics, North Holland Publishing Company, p. 133-146, 1977b.

Levina, E.; Bickel, P. J. Maximum likelihood estimation of intrinsic dimension. In: SAul, L. K.; Weiss, Y.; Bottou, L., eds. Advances in Neural Information Processing Systems 17, Cambridge, MA: MIT Press, p. 777-784, 2005. 
LI, J.; WAng, J. Z. Automatic linguistic indexing of pictures by a statistical modeling approach. IEEE Trans. Pattern Anal. Mach. Intell., v. 25, n. 9, p. 1075-1088, 2003.

Disponível em: http://dx.doi.org/10.1109/TPAMI.2003.1227984

Lowe, D. G. Distinctive image features from scale-invariant keypoints. Int. J. Comput. Vision, v. 60, n. 2, p. 91-110, 2004.

Disponível em: http://dx.doi.org/10.1023/B:VISI.0000029664.99615.94

Morrison, A.; Ross, G.; Chalmers, M. A hybrid layout algorithm for sub-quadratic multidimensional scaling. In: Information Visualization, 2002. INFOVIS 2002. IEEE Symposium on, 2002, p. $152-158$.

Morrison, A.; Ross, G.; Chalmers, M. Fast multidimensional scaling through sampling, springs and interpolation. IEEE Symposium on Information Visualization, p. 68-77, 2003.

Oliva, A.; Torralba, A. Modeling the shape of the scene: A holistic representation of the spatial envelope. Int. J. Comput. Vision, v. 42, n. 3, p. 145-175, 2001.

Disponível em: http://dx.doi.org/10.1023/A:1011139631724

Pal, N. R.; Bezdek, J. C. On cluster validity for the fuzzy c-means model. Trans. Fuz Sys., v. 3, n. 3, p. 370-379, 1995.

Disponível em: http://dx.doi.org/10.1109/91.413225

Paulovich, F.; Minghim, R. Hipp: A novel hierarchical point placement strategy and its application to the exploration of document collections. Visualization and Computer Graphics, IEEE Transactions on, v. 14, n. 6, p. $1229-1236,2008$.

Paulovich, F.; Pinho, R.; Botha, C.; Heiss, A.; Minghim, R. Pex-web: Contentbased visualization of web search results. In: Information Visualisation, 2008. IV '08. 12th International Conference, 2008a, p. $208-214$.

Paulovich, F. V.; Eler, D. M.; Botha, C. P.; R.Minghim; L.G.Nonato Piecewise laplacian-based projection for interactive data exploration and organization (submetido). IEEE VGTC Symposium on Visualization, v. 30, 2011a.

Paulovich, F. V.; Moraes, M. L.; Maki, R. M.; Ferreira, M.; Oliveira Jr., O. N.; OliveirA, M. C. F. Information visualization techniques for sensing and biosensing. Analyst, p. -, 2011b.

Paulovich, F. V.; Nonato, L. G.; Minghim, R.; Levkowitz, H. Least square projection: A fast high-precision multidimensional projection technique and its application to document mapping. IEEE Transactions on Visualization and Computer Graphics, v. 14, n. 3, p. 564$575,2008 \mathrm{~b}$.

Paulovich, F. V.; Silva, C. T.; Nonato, L. G. Two-phase mapping for projecting massive data sets. IEEE Transactions on Visualization and Computer Graphics, v. 16, p. 1281-1290, 2010 . 
Pekalska, E.; Ridder, D.; Duin, R. P. W.; Kraaijveld, M. A. A new method of generalizing sammon mapping with application to algorithm speed-up. In: BoAsson, M.; Kanndorp, J. A.; Tonino, J. F. M.; Vosselman, M. G., eds. Annual Conference of the Advanced School for Computing and Imaging, 1999, p. 221-228.

Pickett, R. M.; Grinstein, G. G. Iconographic displays for visualizing multidimensional data. In: Systems, Man, and Cybernetics, 1988. Proceedings of the 1988 IEEE International Conference on, 1988, p. 514-519.

Platt, J. C. Advances in kernel methods. cáp. Fast training of support vector machines using sequential minimal optimization, Cambridge, MA, USA: MIT Press, p. 185-208, 1999. Disponível em: http://dl.acm.org/citation. cfm?id=299094.299105

RAO, R.; CARD, S. K. The table lens: merging graphical and symbolic representations in an interactive focus+context visualization for tabular information. In: Conference companion on Human factors in computing systems, CHI '94, New York, NY, USA: ACM, 1994, p. 222( $\mathrm{CHI}$ '94, ).

Disponível em: http://doi.acm.org/10.1145/259963.260391

RoweIs, S. T.; Saul, L. K. Nonlinear dimensionality reduction by locally linear embedding. Science, v. 290, p. 2323-2326, 2000.

SAmmon, J. A nonlinear mapping for data structure analysis. IEEE Transactions on Computers, v. C-18, p. $401-409,1969$.

Seo, J.; Shneiderman, B. A rank-by-feature framework for interactive exploration of multidimensional data. Information Visualization, v. 4, n. 2, p. 96-113, 2005.

Disponível em: http://dx.doi.org/10.1057/palgrave.ivs. 9500091

Silva, C. T.; Paulovich, F. V.; Nonato, L. G. User-centered multidimensional projection techniques. Computing in Science Engineering, v. 14, n. 4, p. 74 -81, 2012.

Silva, V.; Tenenbaum, J. Sparse multidimensional scaling using landmark points. Relatório Técnico, Stanford, 2004.

Silva, V.; Tenenbaum, J. B. Global versus local methods in nonlinear dimensionality reduction. Advances in Neural Information Processing Systems 15, p. 721-728, 2003.

Silva, V. D.; Tenenbaum, J. B. Global versus local methods in nonlinear dimensionality reduction. In: Advances in Neural Information Processing Systems 15, MIT Press, p. 705$712,2002$.

Spence, R. Information visualization: Design for interaction (2nd edition). Upper Saddle River, NJ, USA: Prentice-Hall, Inc., 2007.

Steinbach, M.; Karypis, G.; Kumar, V. A comparison of document clustering techniques. In: In KDD Workshop on Text Mining, 2000. 
Swain, M.; Ballard, D. Color indexing. International Journal of Computer Vision, v. 7, p. 11-32, 1991.

Tan, P.; Steinbach, M.; Kumar, V. Introduction to data mining. Addison-Wesley, 2005.

Tejada, E.; Minghim, R.; Nonato, L. G. On improved projection techniques to support visual exploration of multidimensional data sets. Information Visualization, v. 2, n. 4, p. 218 231, 2003a.

Tejada, E.; Minghim, R.; Nonato, L. G. On improved projection techniques to support visual exploration of multidimensional data sets. Information Visualization, v. 2, n. 4, p. 218231, 2003b.

Tenenbaum, J. B.; Silva, V. D.; Langford, J. C. A global geometric framework for nonlinear dimensionality reduction. Science, v. 290, n. 5500, p. 2319-2323, 2000.

Torgerson, W. Multidimensional scaling of similarity. Psychometrika, v. 30, n. 4, p. 379393, 1965.

Torgeson, W. S. Multidimensional scaling of similarity. Psychometrika, v. 30, p. 379-393, 1965.

XIA, T.; TANG, N.-S.; WAng, X.-R. Consistency and asymptotic normality of the maximum likelihood estimates in reproductive dispersion linear models. Statistics and Probability Letters, v. 76, n. 11, p. 1137-1146, 2006.

Yang, J.; Hubball, D.; Ward, M. O.; Rundensteiner, E. A.; Ribarsky, W. Value and relation display: Interactive visual exploration of large data sets with hundreds of dimensions. IEEE Transactions on Visualization and Computer Graphics, v. 13, n. 3, p. 494-507, 2007a. Disponível em: http://dx.doi.org/10.1109/TVCG.2007.1010

YAng, J.; Jiang, Y.-G.; Hauptmann, A. G.; NGO, C.-W. Evaluating bag-of-visual-words representations in scene classification. In: Proceedings of the international workshop on Workshop on multimedia information retrieval, MIR '07, New York, NY, USA: ACM, 2007b, p. 197-206 (MIR '0\%, ).

Disponível em: http://doi.acm.org/10.1145/1290082.1290111

YAng, J.; Peng, W.; Ward, M. O.; Rundensteiner, E. A. Interactive hierarchical dimension ordering, spacing and filtering for exploration of high dimensional datasets. In: Proceedings of the Ninth annual IEEE conference on Information visualization, INFOVIS'03, Washington, DC, USA: IEEE Computer Society, 2003a, p. 105-112 (INFOVIS'03, ). Disponível em: http://dl .acm.org/citation.cfm?id=1947368.1947390

Yang, J.; Ward, M. O.; Rundensteiner, E. A.; Huang, S. Visual hierarchical dimension reduction for exploration of high dimensional datasets. In: Proceedings of the symposium on Data visualisation 2003, VISSYM '03, Aire-la-Ville, Switzerland, Switzerland: Eurographics 
Association, 2003b, p. 19-28 (VISSYM '03, ).

Disponível em: http://dl.acm.org/citation.cfm?id=769922.769924 